Prosodic Cues to Emotion: Perceptual and Acoustic Analyses

by

\title{
Erin DeBodt
}

B.A., Carleton University, 2008

A thesis submitted to the Faculty of Graduate Studies and Research in partial fulfillment of the requirements for the degree of

Master of Arts in Applied Language Studies

in

the School of Linguistics and Language Studies

Carleton University

Ottawa, Ontario

(C) 2010, Erin DeBodt 


$\begin{array}{ll}\begin{array}{l}\text { Library and Archives } \\ \text { Canada }\end{array} & \begin{array}{l}\text { Bibliothèque et } \\ \text { Archives Canada }\end{array} \\ \begin{array}{l}\text { Published Heritage } \\ \text { Branch }\end{array} & \begin{array}{l}\text { Direction du } \\ \text { Patrimoine de l'édition }\end{array} \\ \begin{array}{l}\text { 395 Wellington Street } \\ \text { Ottawa ON K1A ON4 } \\ \text { Canada }\end{array} & \begin{array}{l}395, \text { rue Wellington } \\ \text { Ottawa ON K1A ON4 } \\ \text { Canada }\end{array}\end{array}$

Your file Votre référence
ISBN: $978-0-494-79573-6$
Our file Notre référence
ISBN: $978-0-494-79573-6$

ISBN: $978-0-494-79573-6$

NOTICE:

AVIS:

The author has granted a nonexclusive license allowing Library and Archives Canada to reproduce, publish, archive, preserve, conserve, communicate to the public by telecommunication or on the internet, loan, distribute and sell theses worldwide, for commercial or noncommercial purposes, in microform, paper, electronic and/or any other formats.

The author retains copyright ownership and moral rights in this thesis. Neither the thesis nor substantial extracts from it may be printed or otherwise reproduced without the author's permission.

L'auteur a accordé une licence non exclusive permettant à la Bibliothèque et Archives Canada de reproduire, publier, archiver, sauvegarder, conserver, transmettre au public par télécommunication ou par l'Internet, prêter, distribuer et vendre des thèses partout dans le monde, à des fins commerciales ou autres, sur support microforme, papier, électronique et/ou autres formats.

L'auteur conserve la propriété du droit d'auteur et des droits moraux qui protège cette thèse. Ni la thèse ni des extraits substantiels de celle-ci ne doivent être imprimés ou autrement reproduits sans son autorisation.
In compliance with the Canadian Privacy Act some supporting forms may have been removed from this thesis.

While these forms may be included in the document page count, their removal does not represent any loss of content from the thesis.
Conformément à la loi canadienne sur la protection de la vie privée, quelques formulaires secondaires ont été enlevés de cette thèse.

Bien que ces formulaires aient inclus dans la pagination, il n'y aura aucun contenu manquant.

\section{Canadä}




\begin{abstract}
The present study examined the perceptual categorization of spoken sentences designed to convey five different emotions via semantic and prosodic cues. As well, the acoustic cues associated with the sentences that varied in emotional prosody were measured. Based on previous findings listeners were predicted to be able to recognize all emotions with a better than chance accuracy, and second, that the accurate perception of emotions would imply that there are emotion-specific patterns of voice cues (Johnstone \& Scherer, 2000). 45 English listeners were presented the sentences under two conditions: a) English sentences that varied in semantic affect but which had neutral prosodic affect (semantic condition), and b) French sentences that varied in prosodic affect but which had no semantic information for English listeners unfamiliar with French (prosodic condition). The listeners were asked to categorize the sentences they heard according to five categories: happy, sad, anger, fear, and neutral. Listeners were able to identify all affect categories at a level above chance for both conditions, exception for 'fear' and 'neutral' sentences. Seven acoustic cues (e.g., mean F0) were measured in the prosodic stimuli and were compared to the categorization data in order to determine if specific cues were linked to individual emotions. The results partially replicated findings in previous studies linking acoustic cues to emotions. Overall, the results extend knowledge of which acoustic cues are important for discriminating emotions and provide a baseline for emotion categorization performance that can be compared with populations that show deficits in perceiving affect in spoken language.
\end{abstract}




\section{Acknowledgements}

It is with immense gratitude that I acknowledge the support and help of my supervisor John Logan. Without his input, support and late nights, the body of this project would have never seen its conclusion.

Secondly, I'd like to thank the faculty of the School of Linguistics and Language Studies for always being willing to lend an ear and give advice. Throughout the course of my studies I've enjoyed working with and learning from all of you.

I would also like to express my sincerest thanks to Kanika Thakar whose input was always helpful and whose friendship has been invaluable.

Lastly, I would like to thank my family: mom, dad, Christian and Dylan who I'm sure all feel that they too have just written a thesis. Thank you all for your love and support and for staying positive when I wasn't. Your encouragement allowed me to reach the 'light at the end of the tunnel'. I love you all. 


\section{Table of Contents}

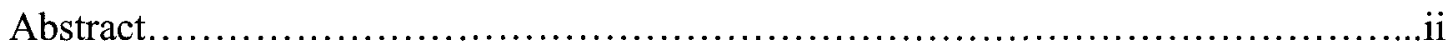

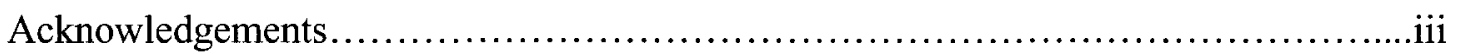

List of Figures..................................................................

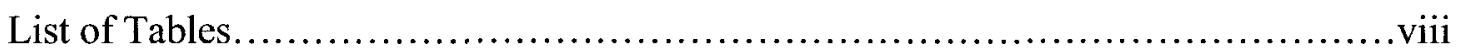

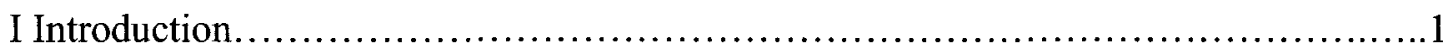

II Goals of the Present Study................................................

1 Emotion in Language.........................................................

1.1 Current Research Methods.........................................

1.1.1 Decoding studies......................................4

1.1.2 Encoding studies........................................11

1.2 Types of Acoustic Cues and Their Correlations With Emotion................17

1.3 Does Culture Make a Difference?.....................................21

1.3.1 The recognition of affective prosody in a foreign language........22

1.3.2 Accuracy of recognition in a second language...................23

1.4 Types of Disorders Affecting the Processing of Emotional Cues.............24

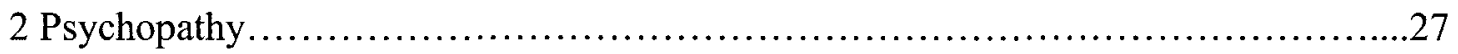

2.1 Emotional and Cognitive Impairments of the Psychopath.................27

2.1.1 Reduced fearfulness/anxiety .............................28

2.1.2 Impairments in emotional learning...........................29

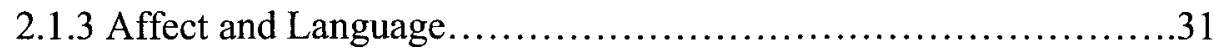

2.1.4 Prosodic information....................................... 32 
2.2 Attempts to Explain the Emotional Dysfunction. .33

2.2.1 Low-fear hypothesis....................................33

2.2.2 Violence inhibition mechanism model........................33

2.3 Measuring Psychopathy........................................... 34

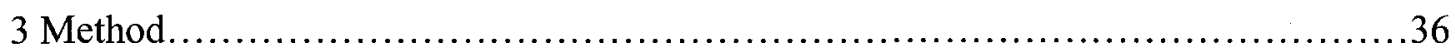

3.1 Perception Experiment...........................................37

3.1.1 Participants..............................................37

3.1.2 Verbal Material and Recording Procedure......................38

3.1.3 Design........................................................

3.1.4 Test Instruments........................................ 39

3.1.5 Procedure..................................................41

3.2 Production Experiment..........................................42

3.2.1 Procedure................................................42

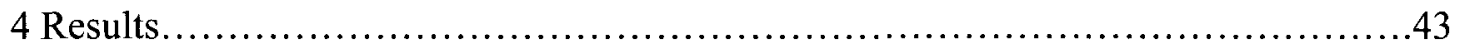

4.1 Perception Task ....................................................43

4.2 Production Task..................................................... 47

4.2.1 Acoustic cue measures......................................47

4.3.1 Correlations between acoustic cues and emotion categorization.....56

5 General Discussion..........................................................

5.1 Recognition by Listeners of Intended Emotions........................64

5.1.1 Listeners' poor recognition of 'fear' and 'neutral' .................64

5.2 Emotion-Specific Patterns of Acoustic Cues...........................69 
5.3 Comparison With Scherer's Descriptions. .71

5.4 Limitations and Considerations for Further Study.........................73

5.4 .1 Stimuli......................................................... 73

5.4.2 Acoustic Measures Included................................74

5.4.3 For Work Associated with Psychopathy......................75

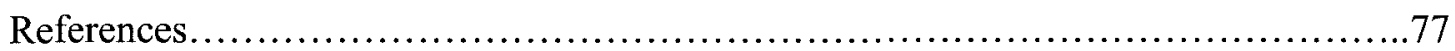

Appendix A Sentence Length Stimuli Used in the Present Study......................87

Appendix B SRP-III Questionnaire....................................... 92

Appendix C Language Experience Questionnaire................................. 96

Appendix D Explanation of Acoustic Measures................................ 102

Appendix E Descriptive Statistics of Individual Measures for Each Emotion Category103 


\section{List of Figures}

Figure 4.1 .............. Mean proportion of sentences correctly categorized from each emotion category in the semantic (English) and prosodic (French) conditions. Error bars represent \pm 1 standard error of the mean.

Figure 4.2............Mean categorization RTs (in seconds) for sentences from each emotion category in the semantic (English) and prosodic (French) conditions. Error bars represent \pm 1 standard error of the mean.

Figure 4.2.1........... Mean sentence duration (s) as a function of intended emotion and speaker gender.

Figure 4.2.2 .........F0 range (SD) as a function of intended emotion and speaker gender............................................... 50

Figure $4.2 .3 \ldots \ldots \ldots . . . F 0(\min )$ as a function of intended emotion and speaker gender....51

Figure 4.2.4 ..........F0 (max) as a function of intended emotion and speaker gender.

Figure 4.2.5 ..........Mean F0 values of the portrayals as a function of intended emotion and speaker

gender.

Figure 4.2 .6 . .Fo Contour Index (Rising[Hz]/Falling[Hz]) as a function of intended emotion and speaker gender.

Figure $4.2 .7 \ldots \ldots \ldots$..... speaker

gender.

Figure 4.2.8...........Mean voice intensity $(\mathrm{dB})$ as a function of intended emotion and speaker

gender. 


\section{List of Tables}

Table 1.1.1.............Percentage accuracy of facial and vocal emotion recognition in studies in Western and Non-Western countries (reproduced from Scherer, 2001)...........................................8

Table 1.2.1............. Overview of Major Voice Cues Relating to Fundamental Frequency........................................ 18

Table 2.2.2 ........... Overview of Major Voice Cues Not Related to Fundamental Frequency.

Table 3.1.4............. Norms for males and females for the Self-Report Psychopathy Scale (SRP-III) (Paulhus, D.L., Hemphill, J.D., \& Hare, R.D., in

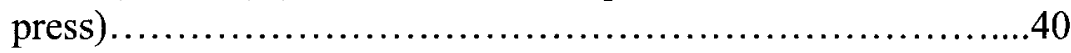

Table 3.2.1............ Voice Cues Analyzed in the Present Study.

Table 4.1.1.............Mean categorization RTs (in seconds) for sentences from each emotion category......................................47

Table 4.3.1 .............Correlations among variables for happy sentences..............57

Table 4.3.2............Correlations among variables for sad sentences...............68

Table $4.3 .3 . \ldots \ldots \ldots . . .$. Correlations among variables for angry sentences.............60

Table 4.3.4............Correlations among variables for fear sentences................61

Table 4.3.5.............Correlations among variables for neutral sentences.............63

Table 5.2.1 ............ Simplified summary of acoustic cues as a function of intended emotion and speaker gender..............................70

Table 5.2.2............Acoustic cues significantly correlated with emotion categories as a function of categorization accuracy and reaction times........71

Table 5.2.3............Acoustic cues found to be significant in the regression analysis as a function of categorization accuracy and reaction times........72 


\section{Introduction}

Expressing emotion in spoken language can be accomplished by either choosing what words you use or by how you say the words, or a combination of both. The "words you use" component refers to the semantic content of an utterance that incorporates the meaning of individual words plus their collective meaning derived from syntax. The "how you say" component refers to a system of non-segmental acoustic cues collectively known as prosody. Prosody is defined as the rhythm, stress, and intonation associated with connected fluent speech. The overarching goal of the present study was to investigate the role that semantic and prosodic cues play in determining the emotional categories perceived by listeners. Although this system of semantic and prosodic cues effectively conveys emotional information to most individuals, some individuals, such as psychopaths, display an impaired ability to perceive the affective states present in spoken language (e.g., Blair et al., 2002). It is this deficit in processing emotional information in speech by psychopaths that served as the impetus for the present study. In the first part of this thesis I describe some of the research methods currently being employed in studies involved with emotion categorization. I then provide a brief outline of the characteristics of psychopathy, followed by a detailed description of the deficits in processing semantic and prosodic information associated with psychopathy. In particular I focus on some recent studies that suggest that psychopaths have a reduced ability to perceive fear in spoken language. As a first step towards evaluating this hypothesis, in the present investigation I examined how well nonpsychopathic listeners could perceive emotion in spoken language. The rationale for doing so was two-fold. First, it is important to determine if some emotions, such as fear, are more difficult to perceive, not just by 
psychopaths but also by nonpsychopaths. Second, it is important to determine if potential differences in the perception of emotion in spoken language are associated with specific acoustic cues. To this end I describe some of the major acoustic features linked to the expression of emotion in spoken language. In this study, the term 'emotion' is taken to mean a state experienced by an individual in response to a stimulus in their environment (Scherer, 1986). The remainder of the thesis is a description of an experiment in which listeners were asked to classify spoken sentences produced by several speakers in which semantic and prosodic cues were varied to elicit five different emotional categories. In addition, the acoustic cues present in the sentences were analyzed to determine if the cues were consistent with what was observed in previous research. Finally, the relationship between the performance of listeners and the acoustic cues present in the sentences was evaluated.

\section{Goals of the Present Study}

Results from a pilot experiment indicated that a university sample of listeners were able to accurately categorize sentences that portrayed various emotions, except for sentences intended to convey 'fear'. From these findings, it was expected that the emotion portrayals would show certain characteristics. First, similar to previous research, listeners should be able to recognize all emotions with a better than chance accuracy and second, if listeners are able to perceive the emotions, this implies that there are emotionspecific patterns of voice cues (Johnstone \& Scherer, 2000). One goal of the production component of the present experiment was to identify patterns of cues that discriminate specific emotions. Secondly, as was mentioned, another goal of the study was to provide 
baseline information about how nonpsychopathic individuals recognize intended emotion categories.

\section{Emotion in Language}

A major influence on emotion research over the past 150 years has been the work of Charles Darwin. His research (1872/1965) placed equal importance on both the facial and vocal expression of emotion in humans and animals. However, since Darwin, work on the facial expression of emotion has dominated research, with only a limited amount of effort devoted to understanding the vocal expression of emotion (i.e., the prosodic characteristics of speech that denote different types of emotion). Methodological limitations were the primary reason for the relative lack of attention to the vocal expression of emotion (Scherer, 1986). Many of these limitations were associated with challenges developing methods for audio recording and acoustic analysis (e.g., spectrograms) that were not solved until as late as the 1940s. With the advent of these technological advances, research on vocal affect could begin in earnest. Chapter 1 will review some recent research on the vocal expression of emotion. First, I look at current research methods that require participants to decode and encode vocal affect. Second, I summarize the major acoustic correlates of emotion commonly included in encoding studies. Finally, I review some disorders which prevent typical processing of emotional cues.

\subsection{Current Research Methods}

Much of the current research in the area of vocal expression of emotion focuses on two major questions: (1) can listeners infer emotions from vocal cues? and (2) what 
are the specific vocal expression patterns for specific emotions? (Banse \& Scherer, 1996). Question 1 refers to a communicative process, often referred to as decoding, and question 2 refers to a related process, often termed encoding. This section will focus mainly on listeners' ability to decode emotion in speech, while the following section will review studies looking at the encoding process.

\subsubsection{Decoding studies.}

Decoding studies examine the ability and/or inability of listeners to infer actual or portrayed emotions from a spoken utterance. To achieve this goal, a speaker (e.g., an actor) is asked to read material aloud while simultaneously portraying a particular emotion. The material is recorded and then played aurally for participants who are instructed to give a response indicating the emotion they feel is being portrayed. Their responses are analyzed to determine whether the listeners are able to decode the intended emotion. The verbal material used in these studies may consist of numbers (e.g., Pfaff, 1958), letters of the alphabet (e.g., Davitz \& Davitz, 1959), pseudo words or utterances (e.g., Wurm et al., 2001), vowels (e.g. Kaiser, 1962), or common speech materials such as words or sentences (e.g., Cosmides, 1983; Banse \& Scherer 1996; Juslin \& Laukka, 2001). Although the material may differ depending on the study, the same material is always used within a study for portrayals of different emotions, hence it is known as the standard content paradigm. The underlying assumption is that because the verbal material remains the same in the different portrayals, any differences in the listener's judgements must be the result of vocal cues produced by the speaker.

Most studies using this paradigm have actors or untrained participants record the emotion portrayals as opposed to using naturally occurring speech samples. This 
distinction has spurred debate among researchers as to which approach should be used (see Bachorowski \& Owren, 1995; Kappas \& Hess, 1995; Johnstone \& Scherer, 2000). While it seems intuitive that natural speech samples should be used in order to produce representative results, one can foresee a number of complications with regards to experimental design. First, a number of ethical issues prohibit the experimental induction of 'real' emotions with naive participants. Second, even if one were to successfully navigate around ethical guidelines and elicit some type of natural response, it is likely that the intensity of these responses would be low and unlikely to yield representative vocal expressions. Furthermore, 'real' emotions may result in a blend of several affective states rather than a relatively 'pure' emotion (Banse \& Scherer, 1996). Considering the difficulties associated with obtaining good, natural samples, the issue facing researchers is that although portrayals may not be 'natural' enough, natural samples may not be 'emotional' enough or 'clear' enough.

Given that portrayals are used much more often than natural samples, it is evident that researchers are subscribing to the belief that emotion portrayals are similar - if not identical to, and, in fact, based on, natural expressions. This belief is not unreasonable, as there is evidence that suggests portrayals and natural expressions are quite similar. In a study by Williams and Stevens (1972), portrayals of fear and natural expressions of fear were compared. Both speech samples involved increases in $\mathrm{F} 0(M)$ and range (R), as well as 'irregular' bumps' or 'tremors' in the F0 contour. The only difference reported was that the effects were slightly larger in the portrayal.

Banse and Scherer (1996) proposed an interesting approach to this debate. They asked "How natural are real-life emotional expressions? (p. 618). They argue that this 
question has been addressed by Janney and his colleague (Arndt \& Janney, 1991; Caffi \& Janney, 1994) who distinguished between emotional and emotive communication. According to previous work (Marty, 1908), emotional communication is a type of spontaneous and unintentional burst of emotion in speech. Emotive communication is non-automatic, and has no necessary relation to 'real' inner affective states. It is seen rather as a means of signaling affective information in speaking to interaction partners. Banse and Scherer claim that, "...Because actors should be perfectly able to convincingly produce emotive vocal messages one can claim reasonable ecological validity for using the actor portrayal paradigm in studying vocal expression" (p. 618). They even go so far as to suggest that studying emotive messages might really be an indirect way to study 'real' emotional communication.

Studies that use this paradigm focus on emotions related to the "basic emotions" proposed by Paul Ekman (Ekman, 1972, 1992). Ekman argues that there are only a small number of basic emotions and that all others have evolved from this group. He calls all other emotions "non-basic emotions" and describes them as a blend or a mix of emotional states. In 1972 Ekman proposed the following list as the basic emotions:
Anger
Disgust
Fear
Happiness
Sadness
Surprise

In the 1990's, however, Ekman further expanded his list of basic emotions to include the following:

Amusement

Contempt

Contentment 


\section{Embarrassment \\ Excitement \\ Guilt \\ Pride in achievement \\ Relief \\ Satisfaction \\ Sensory pleasure \\ Shame}

Despite Ekman's expanded list of emotions, most of the emotion literature has continued to focus on his original taxonomy of basic emotions.

Reviewing 60 years of research on this paradigm, several authors (van Bezooijen, 1984; Frick, 1985; Scherer, 1979, 1986; Standke, 1992) have shown that listeners are actually quite good at making judgements about the affective state or attitude of a speaker from vocal expression. A review of about 30 studies revealed an accuracy percentage of about $60 \%$ which is four to five times the rate expected by chance (Scherer, 1982). Although the majority of emotions are identified accurately, some emotions are recognized poorly on the basis of vocal cues alone, in particular shame, disgust, and fear (fear will be revisited in later chapters). This may not necessarily be due to limitations of the human perceptual/cognitive system, but instead may be due to the validity of assuming that the same type of speech (i.e., a sentence-length utterance) is appropriate in all emotion situations. The standard sentence paradigm may not be appropriate for emotions such as disgust and shame for which people either vocalize rarely, or use other forms of vocalization, such as short interjections (Banse \& Scherer, 1996).

Why are some emotions difficult to perceive when vocalized? One answer may come from comparing confusion frequencies between vocal and facial emotion expression. Table 1.1.1, reproduced from Scherer (2001), compares recognition accuracy 
for both vocal and facial portrayal. The data were compiled from studies that examined a comparable range of emotions in both modalities (see Scherer 1999b; Ekman, 1994; Scherer et al., 2001a).

Table 1.1.1

Percentage accuracy of facial and vocal emotion recognition in studies in Western and Non-Western countries (reproduced from Scherer, 2001)

\begin{tabular}{lcccccccc}
\hline & Neutral & Anger & Fear & Joy & Sadness & Disgust & Surprise & Mean \\
\hline $\begin{array}{l}\text { Facial/ } \\
\text { Western/20 }\end{array}$ & & 78 & 77 & 95 & 79 & 80 & 88 & 78 \\
$\begin{array}{l}\text { Vocal/ } \\
\text { Recent }\end{array}$ & & & & & & & & \\
Western/11 & 74 & 77 & 61 & 57 & 71 & 31 & & 62 \\
$\begin{array}{l}\text { Facial/Non- } \\
\text { Western/11 }\end{array}$ & 59 & 62 & 88 & 74 & 67 & 77 & 65 \\
$\begin{array}{l}\text { Vocal/Non- } \\
\text { Western/1 }\end{array}$ & 70 & 64 & 38 & 28 & 58 & & & 52
\end{tabular}

Note: Empty cells indicate that the respective emotions have not been studied in these regions. Numbers following the slash in column 1 indicate the number of countries studied.

As Scherer points out, recognition of emotion is more accurate for facial expression than vocal expression. He posits several reasons to account for this difference. First, whereas vocal expressions tend to be dynamic and less likely to produce stable patterns, facial expressions denoting emotions depend on basic muscle configurations (Ekman, 1972; 1994) that are often reinforced by static stimuli such as photographs. Also, emotions from similar families are more distinctive from one another in vocal expression than in facial expression. An emotion family (e.g., Ekman, 1992) is a concept that acknowledges that there are many kinds of anger, joy, fear, etc. For example, the important vocal differences between the expression of exuberance and quiet happiness could explain some of the lack 
of replication for results in studies concerned with the expression of joy since researchers tend not to distinguish which kind of joy has been used (Scherer, 1986).

Although many studies have looked at how accurately emotions are identified, it is also advantageous to explore the confusion frequencies of different emotions. A study by Banse and Scherer (1996) found that each emotion has a specific confusion pattern, with the exception of disgust, which was generally confused with all other negative emotions. They suggest that rather than consider confusions as errors, they should be taken as indicators of similarities between emotion categories. After undertaking a qualitative analysis of the confusion patterns, Banse and Scherer surmised that there were three dimensions of similarity of errors: quality, intensity, and valence. They describe the 'quality' dimension as being the most obvious. Emotion pairs such as hot anger and cold anger, anxiety, and fear panic are similar in quality but were found to differ mainly in intensity. Furthermore, confusions between emotion pairs were symmetric. These results indicate that confusion between emotions that are related in quality could be attributed to a lack of a well-defined cut-off between the intense and the mild form of the respective emotions. For example, elation was often confused with despair and hot anger and panic fear, all of which differ greatly in quality but which are similar in intensity. The existence of a third dimension, valence, was supported by the finding that positive emotions were found to be more easily confused with other positive emotions than negative emotions. For example, pride is confused more often with the positive emotions elation, happiness, and interest (39\%) than with all negative emotions taken together (19\%) (Banse \& Scherer, 1996, p. 632). In his 2003 review, Scherer states that it is imperative for future studies to report on confusion matrices. He cites Scherer et al. 
(2001a,b) as further support for this argument. They used the fact that confusion matrices were similar across culture as basis for the existence of universal inference rules. He argues that this would not be possible using only comparable accuracy coefficients because judges might have arrived at the converging judgements in different ways.

In addition to the prosodic cues to emotion (discussed in detail in the following section), cues to emotion also are conveyed by the semantic content of utterances. Wambacq and Jerger (2004) evaluated the relative contribution of semantic and prosodic sources of information about emotion in speech using an Event Related Potential (ERP) methodology. More specifically, they investigated whether affective prosody is processed when a consistent relationship is apparent between prosody and semantics. Wambacq and Jerger found that negative words combined with a negative tone of voice evoked a stronger orienting response than stimuli that were presented using either negative semantics or negative prosody individually. This finding suggests that in normal situations individuals involuntarily process emotional prosody and emotional semantics concurrently. 


\subsubsection{Encoding studies.}

Decoding studies recently have begun to include acoustic analyses of their stimuli to determine that the emotion portrayals are valid. Voice cues that researchers have traditionally examined can be broadly divided into the following categories: fundamental frequency, voice intensity, voice quality, and temporal aspects of speech (Juslin \& Laukka, 2001). The fundamental frequency (F0) is the frequency at which the vocal folds open and close across the glottis during phonation and is reflected as the pitch of the voice. Voice intensity (VoInt) is heard as the loudness of the voice and is determined by both respiratory and phonatory action. It reflects the effort required to produce the speech. Voice quality is subjectively heard as the timbre of the voice and is determined by such aspects as phonation type, phonation register, and articulatory settings. This can be reflected by characteristics of speech such as slurring or a breathy voice. Lastly, temporal aspects of speech concern the temporal sequence of the production of sounds and silence. This is realized by characteristics such as speech rate and pausing.

As noted earlier in Chapter 1 , listener-judges can reliably recognize different emotions based only on vocal cues. Researchers have taken this to mean that the vocal expression of emotions is differentially patterned. A century of research in behavioural biology, psychology, and the speech and communication sciences suggests that a large number of different emotional and motivational states are indeed indexed and communicated by specific acoustic characteristics of the concurrent vocalizations (Banse \& Scherer, 1996). However, the precise nature of the vocal cues used by encoders to communicate emotions remains remarkably elusive. The inconsistency of findings in this area is its most consistent and defining feature (Frick, 1985; Murray \& Arnott, 1993). In 
fact, an apparent paradox in the research has been revealed: whereas judges seem to be reliably accurate at recognizing emotions from voice cues, scientists have been relatively unsuccessful in identifying a set of cues that can reliably discriminate among emotions (Scherer, 1986). Therefore, some researchers believe that cues only reflect the activity dimension of emotions (Davitz, 1964), or a combination of arousal and valence (Bachorowski, 1999). In any case, the question still remains as to why the evidence linking acoustic cues to specific emotions is inconclusive. Banse and Scherer (1996) suggest three possible reasons. First, in most encoding studies, a very restricted set of emotions is used. Banse and Scherer argue that because of this restriction it is impossible to distinguish between acoustical characteristics that exclusively index non-specific activation or arousal and those that reflect the valence or quality aspects of emotional states. Second, researchers have traditionally examined only F0 and energy parameters, which are likely to reflect mostly non-specific physiological arousal (Scherer, 1979, 1986). Therefore, the limited inclusions of acoustic measures may account for the lack of consistent findings in terms of emotion-specific acoustic profiles. Third, much of the rationale for these studies has been atheoretical in nature which has prevented any real systematic evaluation of the empirical findings or the development of testable hypotheses.

One of the first attempts to provide a testable hypothesis linking acoustic cues and vocal affect was Scherer's component process theory (Scherer, 1984, 1986).

Component process theory conceptualizes emotion as an episode of temporary synchronization of all major subsystems of organismic functioning represented by five components (cognition, physiological regulation, motivation, motor expression, and 
monitoring-feeling) in response to the evaluation or appraisal of an external or internal stimulus event as relevant to central concerns of the organism. (Banse \& Scherer, 1996, p. 616)

Component process theory is based on the idea that although the different components typically work independently of one another, during an emotion episode they are recruited to work in unison. Scherer states that emotion has to be seen as a process and not a steady state of the organism.

To further elaborate, Scherer (1986) proposes that each organism's information processing subsystem continuously scans external and internal stimuli and performs stimulus evaluation checks (SECs) using functionally defined criteria. This theory specifies the following SECs that are predicted to always occur in the same sequential order. The first is a novelty check that evaluates whether there is a change in the pattern of external or internal stimulation. Second is an intrinsic pleasantness check. This evaluates whether a stimulus event is pleasant or unpleasant and induces approach or avoidance tendencies respectively which are based on innate feature detectors or on learned associations. Third is a goal/need significance check. This check evaluates whether a stimulus event is relevant to important goals or needs of the organism, whether it is conducive or obstructive to obtaining goals or satisfying needs, and how urgently a behavioural response is required. Fourth is a coping potential check that evaluates the underlying cause of a stimulus event, the coping potential available to the organism, the relative power of the organism to change or avoid the outcome through fight or flight, and the potential of adjustment to the final outcome via internal restructuring. Lastly, the norm/self compatibility check evaluates whether the event, particularly an action conforms to social norms, cultural conventions or expectations of significant others, and 
whether it is consistent with internalized standards and conformities as part of the selfconcept or ideal self (Scherer, 1986). According to the theory, the organism, while in the process of sequentially evaluating a stimulus event according to each SEC, will experience changes in the components of an emotional state according to the outcome of each subsequent SEC modifying the effects of the outcome of the preceding SEC. Therefore, each consecutive SEC will add to the meaning of the emotional event for the organism and at each step changes in the different subsystems are instigated that may affect the states resulting from earlier SEC outcomes.

How does Scherer's model make predictions about vocal expression? Vocalization is produced by the action of the striated musculature. Scherer assumes that each outcome of an SEC will have an effect on the somatic nervous system (SNS), which will have a distinctive effect on muscle tension or local muscle action. Additionally, changes in other organismic subsystems such as the autonomic nervous system (ANS) will affect the muscle units used for voice production. In other words, the characteristics of the vocal expression at a particular time are the net result of the effects of the outcomes of following SECs in the information processing subsystem and of the total effect of the changes of other subsystems impinging on the SNS. Scherer provides a nice example to help illustrate the model:

...After appraisal of a stimulus as dangerous and requiring action (obstructive to important goal of survival; coping ability not guaranteed), fundamental frequency of the voice (F0) will increase because of the functional response of the SNS (increased muscle tension); at the same time, salivation will decrease because of the changes in the ANS (sympathetic dominance). Both effects will tend to make the voice more high-pitched (changes in vocal fold vibration 
and vocal tract resonance). If, a split second later, the event is reevaluated as a hoax, the state of the fast-responding SNS will change again, lowering pitch because of a decrease in muscle tone. The ANS is slower and it is likely that the effect of reduced salivation on vocal tract resonance will persist for some time. (Scherer, 1986, p. 148)

On the basis of this theoretical framework, Scherer was able to make detailed predictions about the acoustic characteristics of the speech signal by first specifying specific outcomes of the SECs (prototypical profiles of appraisal results) for all of the major modal emotions. As an example, the effect of appraising an object as intrinsically umpleasant is assumed by Scherer to result in faucal and pharyngeal constriction and a tensing of the vocal tract walls. These physiological effects should be realized acoustically as having more high-frequency energy, rising of the F1 (first formant), falling of the F2 (second formant) and F3 (third formant), and narrow F1 bandwidth. (Formants are regions of energy displayed in spectrograms that are based on the resonant frequency of the vocal tract; formant patterns changes as a function of changes in vocal tract shape.) The pattern of predictions for each modal emotion is obtained by a cumulation of the effects of the postulated profile of SEC outcomes for that emotion. Banse and Scherer (1986) tested the predictions of specific profiles of acoustic parameters for a set of major modal emotions both to check the theoretical framework, and to encourage a more theory-driven approach to studying the vocal expression of emotion. Many of Scherer's hypotheses were indeed supported, although some required revision on the basis of the empirical evidence. Banse and Scherer called for more information about acoustic cues to be included in future studies. 
Other researchers have also incorporated physiological effects into their hypotheses about acoustic patterning for emotions. Juslin and Laukka (2001) were largely interested in the effect of intended intensity on the judgments of vocal expression. However, they also compared their results to Scherer's 1986 theoretical predictions. They found that a number of Scherer's predictions were supported by their data but also that several predictions were not supported. By using a strict criterion that prediction and result should match exactly where both the sign and the direction should be the same (see Banse \& Scherer, 1986 for an explanation of signs), 33\% of the predictions matched the results. A more generous criterion, that only the direction of each effect should be the same, yielded a $57 \%$ match of predictions to results. Juslin and Laukka noted also that the correspondence between result and prediction differed noticeably depending on the emotion. The smallest percentage of matches between result and prediction occurred for fear portrayals with weak emotion intensity $(0 \%)$, and for sadness portrayals with strong emotion intensity $(0 \%)$. When these emotions were left aside, the mean percentage of matches for the remaining emotions grew to $70 \%$, with the largest number of matches occurring for anger portrayals with strong emotion intensity (88\%). Interestingly, the predictions were more accurate for some acoustic cues, such as voice intensity (VoInt) and standard deviation $(S D)$, than for others, such as F1 mean $(M)$. In light of the subsequent data, it is conceivable that Scherer's model needs to be revised. For example, Juslin and Laukka's study, as well as several others (Banse \& Scherer, 1996; Fonagy \& Magdics, 1963; Scherer et al., 1991) failed to support the prediction that fear portrayals with weak emotion intensity are associated with increases in F0 $(S D)$ and high-frequency energy. 


\subsection{Types of Acoustic Cues and Their Correlations With Emotion}

As noted above, researchers have not yet arrived at a consensus about which acoustic cues are associated with the vocal expression of emotion. Although measures relating to fundamental frequency are often included that permit broad predictions about emotion recognition, little to no consistency exists concerning the types of acoustic cues studied. In the following section a list of acoustic measures used in several studies is presented, along with an explanation of how they are realized in different types of vocal affect. In addition, the perceptual correlate of the acoustic cues is indicated.

Tables 1.2.1 and 1.2.2 are compiled from several sources (Scherer, 1986; Murray \& Arnott, 1993; Juslin \& Laukka, 2001, Burkhardt et. al, 2006). Table 2.2.1 shows some acoustic cues and their perceptual attributes associated with fundamental frequency (F0). Table 1.2.1 shows various other acoustic cues that are frequently measured in studies. 
Table 1.2.1

Overview of Major Voice Cues Relating to Fundamental Frequency

\begin{tabular}{|c|c|c|}
\hline Voice Cue & Description & Perceptual Attribute \\
\hline $\begin{array}{l}\text { Fundamental } \\
\text { Frequency }(M)\end{array}$ & $\begin{array}{l}\text { Vibration rate of vocal folds as averaged } \\
\text { over a speech utterance }\end{array}$ & Pitch \\
\hline $\begin{array}{l}\text { Fundamental } \\
\text { Frequency }(S D)\end{array}$ & Measure of dispersion & Pitch variability \\
\hline $\begin{array}{l}\text { Fundamental } \\
\text { Frequency (max) }\end{array}$ & $\begin{array}{l}\text { Highest measure of frequency in an } \\
\text { utterance }\end{array}$ & Pitch maximum \\
\hline $\begin{array}{l}\text { Fundamental } \\
\text { Frequency (floor) }\end{array}$ & $\begin{array}{l}\text { Lowest measure of frequency in an } \\
\text { utterance }\end{array}$ & Pitch base level \\
\hline $\begin{array}{l}\text { Fundamental } \\
\text { Frequency } \\
\text { perturbations } \\
\text { (Jitter) }\end{array}$ & $\begin{array}{l}\text { Slight variations in the duration of glottal } \\
\text { cycles }\end{array}$ & $\begin{array}{l}\text { Pitch perturbations (often } \\
\text { reminiscent of a shaky or } \\
\text { crying voice) }\end{array}$ \\
\hline $\begin{array}{l}\text { Fundamental } \\
\text { Frequency contour }\end{array}$ & $\begin{array}{l}\text { Fundamental frequency values plotted } \\
\text { over time }\end{array}$ & Intonation \\
\hline
\end{tabular}


Table 2.2.2

Overview of Major Voice Cues Not Related to Fundamental Frequency

\begin{tabular}{|c|c|c|}
\hline Voice Cue & Description & Perceptual Attribute \\
\hline $\begin{array}{l}\text { Voice Intensity } \\
(M)\end{array}$ & $\begin{array}{l}\text { Energy values for a speech sound wave } \\
\text { averaged over an utterance }\end{array}$ & Loudness \\
\hline $\begin{array}{l}\text { Voice Intensity } \\
(S D)\end{array}$ & $\begin{array}{l}\text { Difference between highest and lowest } \\
\text { intensity }\end{array}$ & Loudness variability \\
\hline $\begin{array}{l}\text { Formant } 1,2,3 \\
\text { (M) }\end{array}$ & $\begin{array}{l}\text { Frequency of the first (lowest), second, or } \\
\text { third formant (significant energy } \\
\text { concentration in the spectrum) averaged } \\
\text { over an utterance }\end{array}$ & Voice quality \\
\hline $\begin{array}{l}\text { Formant } \\
\text { Bandwidth }\end{array}$ & $\begin{array}{l}\text { Width of the spectral band containing } \\
\text { significant formant energy }\end{array}$ & Voice quality \\
\hline Formant Precision & $\begin{array}{l}\text { Degree to which formant frequencies } \\
\text { attain values prescribed by the } \\
\text { phonological system of a language }\end{array}$ & Voice quality \\
\hline $\begin{array}{l}\text { High-frequency } \\
\text { Energy }\end{array}$ & $\begin{array}{l}\text { Relative proportion of energy in the upper } \\
\text { frequency region (e.g., }>1 \mathrm{kHz})\end{array}$ & Voice quality \\
\hline Speech Rate & Number of speech segments per time unit & Velocity of speech \\
\hline Pause Proportion & $\begin{array}{l}\text { Number of breaks in frequency per time } \\
\text { unit }\end{array}$ & $\begin{array}{l}\text { Amount of pauses in } \\
\text { speech }\end{array}$ \\
\hline
\end{tabular}

Despite a lack of consistency in testing these acoustic cues, sets of descriptions for commonly studied emotions are beginning to emerge. The following is a set of repeatedly studied emotions summarized by Pittam and Scherer (1993, p. 188-189):

Anger: Anger generally seems to be characterized by an increase in mean F0 and mean energy. Some studies, which may have been measuring "hot" anger (most studies do not explicitly define whether they studied hot [aggressive or explosive anger] or cold [passive and quiet] anger), also show increases in F0 variability and in the range of F0 across the utterances encoded. Studies in which these characteristics were not found may 
have been measuring cold anger. Further anger effects include increases in highfrequency energy and downward-directed F0 contours. The rate of articulation usually increases.

Fear: There is considerable agreement on the acoustic cues associated with fear. High arousal levels would be expected with this emotion, and this is supported by evidence showing increases in mean $\mathrm{F} 0$, in $\mathrm{F} 0$ range, and high frequency energy. Rate of articulation is reported to be speeded up. An increase in mean F0 has also been found for milder forms of the emotion such as worry or anxiety.

Sadness: As with fear, findings converge across studies. A decrease in mean F0, F0 range, and mean energy is usually found, as are downward-directed F0 contours. There is evidence that high-frequency energy and rate of articulation decrease. Most studies have investigated the quieter, subdued forms of this emotion rather than the more highly aroused forms, such as desperation. The latter variant might be characterized by an increase of $\mathrm{F} 0$ and energy.

Joy: This is one of the few positive emotions studied, most often in the form of elation rather than more subdued forms such as enjoyment or happiness. Consistent with the high arousal level that one might expect, findings converge to describe increases in mean F0, F0 range, F0 variability, and mean energy. Some evidence exists for an increase in high-frequency energy and rate of articulation.

Disgust: As Scherer (1989) noted, the results for disgust tend to be inconsistent across studies. The few that have included this emotion vary in their encoding procedures from measuring disgust (or possibly displeasure) at unpleasant films to actor simulation of the emotion. The studies that have used the former found an increase in mean F0, 
whereas those that have used the latter found the reverse - a lowering of mean F0. This inconsistency is echoed in the decoding literature.

Although these findings may seem quite robust, evidence is still not conclusive due in part mostly to the methodological issues (as described in previous sections) surrounding the study of emotion.

\subsection{Does Culture Make a Difference?}

As noted, visual cues to emotion have been shown to be both integral to the processing of emotion, as well as being fairly recognizable cross-culturally. Given that prosodic cues also seem to have an important role in the decoding of affective information, it follows that they also may be universally recognizable. Burkhardt, Audibert, Malatesta, Türk, Arslan, and Auberge (2006) compared the effects of prosodic cues on emotional speech across four cultures. Sentences with identical semantic content were translated into each of the four target languages and systematically manipulated on the basis of the following: pitch range, duration model, and jitter simulation. Participants were asked to rate on a scale from one to seven how appropriate the manner of speaking was for the meaning of the sentence they heard. No effect of language was found. That is not to say however, that there were not some differences on a more feature-based level. The results from the different countries did show some differences on the basis of pitch, duration, and jitter simulation (a synthesized effect used to emulate a shaky, or tearful voice). For example, in terms of the effect of pitch range for a 'frightening' message, French and German listeners preferred a small pitch-range, while German and Turkish did not make a distinction. In contrast to all the other countries, the French preferred a 
broad pitch-range for the neutral sentences, and the Turkish seemed to find a small pitch range acceptable for a friendly expression.

The results from this study indicate that, for the most part, listeners, irrespective of their language, were able to make use of the affective information as a whole to interpret the sentences as intended.

Similarly, Pell, Paulmann, Dara, Alasseri and Kotz (2009) looked at how language influences the vocal communication of emotion. They looked at emotion recognition as well as acoustic cues in four language contexts (English, German, Hindi and Arabic). Affective material was produced by four speakers and consisted of pseudoutterances that were meant to resemble their native language. Emotion recognition and acoustic patterns were analyzed within and across the languages. Although recognition rates did vary by language, all emotions could be recognized strictly from vocal cues in each language at levels above chance. They describe their results as emphasizing that vocal expressions of 'basic' emotion in speech exhibit modal tendencies in their acoustic and perceptual attributes that are largely unaffected by language or linguistic similarity. While this study did not include French (which our study is concerned with) it further suggests that acoustic attributes are similar across languages and that language-specific characteristics alone do not affect in a substantial way the ability of listeners to categorize basic emotions.

\subsubsection{The recognition of affective prosody in a foreign language.}

Whereas Burkhardt et al. (2006) demonstrated that listeners seem to be fairly accurate at decoding the acoustic cues to emotion in another language, Pell and Skorup 
(2008) examined whether vocal cues to emotion are implicitly processed in a foreign language (more specifically, a language to which the participants would have had limited or no exposure), and whether exposure duration to prosody affects perception of emotion. Pell and Skorup presented English participants with Arabic pseudo-utterances in a happy, sad or neutral prosody that acted as primes for happy, sad, or false face targets. Individuals were asked to judge whether the face matched the emotion being represented in the speech stream. Prosody duration was independently manipulated at either $600 \mathrm{~ms}$ or $1000 \mathrm{~ms}$. Pell and Skorup found that English listeners did indeed demonstrate sensitivity to the emotional content of the Arabic utterances, despite the fact that the prosodic cues were implanted within a language that was very typologically distinct from their native language. It should be noted however, that when exposed to the Arabic speech, listeners were most accurate with the emotion congruency between the prosody and the face on after at least $1000 \mathrm{~ms}$ of the prosodic information was available. This indicates that extra exposure to the prosodic information of the foreign language may be required compared to stimuli presented in the native language.

\subsubsection{Accuracy of recognition in a second language.}

Pell and Skorup's (2008) work provided evidence that individuals are able to correctly identify the appropriate emotion in the presence of affective prosodic cues in a foreign language that is completely unknown to them. Moreover, they are able to do so more accurately after being exposed to its prosodic information for a specific amount of time. If this is the case, then there must be some implications for the accuracy of an individual in a second or foreign language that they have acquired. 
In 2005, Dromey, Silveira and Sandor compared the accuracy of identifying the intended emotion of a sentence between three different language groups. The groups were constructed based on whether the participants were English mother tongue (EMT) polyglots, other mother tongue (OMT) listeners, or EMT monoglots. They were asked to listen to single English words, and to check off from a list of emotions which one the speaker seemed to be communicating for that word. The results showed that the EMT polyglot listeners were more accurate than the OMT listeners in their identification of the intended emotion in spoken English words. The OMT listeners did perform at a level above chance, however, indicating that individuals who did not acquire English as a first language are still capable of detecting affective prosody at the single word level. Interestingly, the EMT polyglots performed somewhat more accurately than the EMT monoglots. This finding could indicate that there is an advantage in recognizing prosody for individuals who grew up with the native language of the speaker, and have also learned a foreign language. Perhaps the experience of learning a second language can help to develop additional sensitivity to prosodic features in the speech stream. For this hypothesis to be true, it would also have to be true that it is a necessary part of the language acquisition process to, on some level, discriminate between the prosody of the L1 and the L2, thus indicating that there are salient differences across languages.

\subsection{Types of Disorders Affecting the Processing of Emotional Cues}

The amygdalar complex is a medial temporal lobe structure in the brain that has been shown to perform a primary role in the processing and memory of emotional reactions. When the amygdala is damaged, social perception is impaired, with defective recognition of facial expressions of emotion (Adolphs, Tranel, Damasio, \& Damasio, 
1994; Young, Hellawell, van de Wal, \& Johnstone, 1996). Of the major emotions, the processing of anger and fear have been shown repeatedly to be disrupted by amygdala damage (Adolphs et al., 1994; Adolphs, Tranel, Damasio \& Damasio, 1995; Calder et al., 1996). Evidence also suggests that the amygdala's role in the recognition of certain emotions is not limited to vision (Scott et al., 1997). Scott and colleagues reported on a woman in her early fifties who, following a series of sterotaxic operations targeted at the left and right amygdala had impaired perception of the intonation patterns essential to the perception of vocal affect. Following the surgery, the woman's ability to recognize familiar and unfamiliar faces was tested and no general impairment of face recognition was found. Conversely, she showed poor processing of social signals from the face. In terms of facial expressions, recognition of fear was severely affected and there was also evidence of impaired recognition of anger. In Scott's study, they assessed the woman's ability to perform a number of auditory and voice perception tasks. Her performance indicated that her interpretation of paralinguistic signals involved in the communication of emotion was impaired. Interestingly, her recognition of emotions was impaired across the same basic emotions of fear and anger for voices and faces. Scott et al. felt that this was consistent with impairment of a mechanism geared to interpreting emotional signals regardless of their source rather than a mechanism responsive to only faces (which was earlier believed to be the case). Displays of anger and fear by other people are most often signals of danger or immediate threat in the environment. The deficit in recognition of fear and anger after amygdala damage could reflect the involvement of the amygdala in the appraisal of danger and the emotion of fear. Since this study, others have found similar results from studies including more participants, all indicating that patients, 
particularly with bilateral over unilateral damage to the amygdala, show an impairment recognizing fear and anger in both facial and vocal modalities (Adolphs, 2003; Bierly, 2004).

Impairments such as that as described in Scott et al.'s (1997) study are also present in other disorders. Impaired emotion identification has been repeatedly demonstrated in patients with schizophrenia (Dougherty et al., 1974; Kerr \& Neale, 1993; Borod, 2000; Edwards et al., 2001; Silver et al., 2002). Katcharska-Pietrua et al. (2005) tested emotion recognition by patients with schizophrenia and found that their accuracy was impaired in both visual and vocal modalities. Furthermore, this impairment increased with the duration of the disease. Several studies also demonstrated emotion recognition deficits in patients with Parkinson's Disease (e.g., Ariatti, Benuzzi, \& Nichelli, 2008; Beatty, Goodkin, Weir, \& Staton, 1989; Blonder, Gur, \& Gur, 1989), as well as in adults with Attention Deficit Hyperactivity Disorder (ADHD) (Miller, Hanford, Fassbender, Duke, \& Schweitzer, 2010). Interestingly, patients with ADHD made more fearful emotion errors than a control group.

Psychopathy is another disorder which is associated with a deficit in processing emotion cues. The emotion processing impairment observed in those with psychopathy underlies the research presented in this thesis. In Chapter 2 I describe the characteristics of psychopathy and various theoretical accounts of the mechanisms responsible for the behaviour of psychopaths. In addition, I review several studies that focus on the impaired ability of psychopaths to process emotion cues. 


\section{Psychopathy}

Akin to patients with amygdala damage and ADHD, psychopaths show a reduced sensitivity to vocal affect (Bagley, Abramowitz \& Kosson, 2009), and in particular sad and fearful affect (Blair et al., 2002). This chapter will first describe the cognitive and emotional impairments associated with psychopathy, followed by the two current models that attempt to explain why psychopathic individuals show emotional dysfunction and poor socialization. Lastly, it will cover the current methods of measuring psychopathy.

\subsection{Emotional and Cognitive Impairments of the Psychopath}

One of the first attempts to describe psychopathy was by Hervey M. Cleckley in 1941. Cleckley worked as a clinical psychiatrist and documented what he considered to be cases of psychopathy in his book, The Mask of Sanity. In this book, he laid out 16 fundamental criteria for psychopathy: superficial charm; lack of anxiety; lack of guilt; undependability and egocentricity; failure to form lasting intimate relationships; failure to learn from punishment; poverty of emotion; lack of insight into the impact of one's behaviour on others and failure to plan ahead. The current view of psychopathy is derived from Cleckley's work; it is described as a disorder that manifests itself in interpersonal, behavioural and emotional dimensions (Blair, 2005). The disorder is typically associated with a series of impairments primarily affecting emotional processing. According to Blair (2005), psychopathic individuals present with reduced responses to threatening stimuli, reduced emotional learning and relearning, reduced empathic responding, difficulties with aspects of moral reasoning and difficulties with affective language. Much work has been done to understand and describe the cognitive and emotional impairments that accompany psychopathy. However, the ultimate cause is still unknown. 


\subsubsection{Reduced fearfulness/anxiety.}

One of the earliest theorists to associate reduced anxiety with psychopathy was David Lykken. In 1957 he suggested that the psychopathic individual "has an attenuated experience, not of all emotional states, but specifically anxiety or fear" (Lykken, 1995, p.118). His argument was that reduced fearfulness or anxiety interferes with socialization and contributes to the development of psychopathy. In his 1957 study, Lykken demonstrated low fearfulness in individuals with psychopathy using two different tasks. The first examined the ability of psychopathic individuals to show aversive conditioning that involved learning that an unpleasant event (e.g., an electric shock or a loud noise) was associated with a real world event. In Lykken's study the unpleasant event, referred to as the 'aversive unconditioned stimulus' (US), was a harmless but painful electric shock. This shock caused the participants to sweat - an automatic unconditioned response to the electric shock. The amount of sweating can be measured by the ease with which the skin can carry an electrical current (the degree of electrodermal activity). In Lykken's study participants heard a buzzer for 5 seconds that served as the conditioned stimulus (CS). Immediately after the buzzer, the participants received the US (shock). Ultimately, the participant learned a conditioned response (CR) to the CS. Lykken discovered that participants with psychopathy showed a reduced electrodermal CR to the buzzer compared to the control group, which supported the idea that individuals with psychopathy show impaired aversive conditioning. Similar results have been found by Flor, Birbaumer, Hermann, Ziegler, and Patrick (2002) and Hare and Quinn, (1971).

Related work has also shown that psychopaths fail to generate, or generate to a lesser extent, emotional autonomic responses to other fear-inducing stimuli, such as being 
asked to imagine unpleasant or fearful experiences (Patrick, Cuthbert, \& Lang, 1994). They also show reduced emotional responding to threatening stimuli in startle reflex paradigms. For example, psychopaths have an attenuated startle reflex (the response of mind and body to a sudden unexpected stimuli) following negative visual primes, such as an assault scene, compared to a control group (Levenston, Patrick, Bradley \& Lang, 2000; Patrick, 1994).

\subsubsection{Impairments in emotional learning.}

Instrumental learning. While research has made it clear that psychopaths show reduced responding to threatening stimuli, their emotional impairments are far more complex than simply having inappropriate or atypical responses to negative stimuli. Individuals with psychopathy also display deficits in emotional learning, particularly when instrumental learning is indexed through passive avoidance paradigms and response reversal (Blair, 2005). Instrumental learning is the ability to learn to commit specific behaviors through reward or punishment. One type of instrumental learning is passive avoidance in which individuals learn how to react toward positive stimuli while avoiding negative stimuli that can lead to punishment. In other words, passive avoidance helps individuals to avoid or approach stimuli appropriately. Lykken (1957) was the first to show that psychopaths were impaired in passive avoidance learning. Many researchers have replicated Lykken's findings and showed that relative to comparison groups, individuals with psychopathy make more passive avoidance errors regardless of the negative reinforcer (e.g. money, cigarettes, confectionery) (Newman \& Kosson, 1986; Newman \& Schmitt, 1998; Newman, Widom \& Nathan, 1985; Thornquist \& Zuckerman, 1995). Another type of impairment observed in psychopaths that falls under the umbrella 
of instrumental learning is their performance in extinction or response reversal tasks. These are the names given to variants of tasks in which a participant must learn to either withhold or change a behavioural response once they learn that their original response to a stimulus is no longer rewarded. For example, one extinction task that is often used is a card playing task that was originally developed by Newman and colleagues (Newman, Patterson, \& Kosson, 1987). The task requires participants to decide whether or not to play a card. In the beginning, each time the participant plays a card, they are rewarded. As time passes, however, the probability of reward decreases. The participant should stop playing cards when more cards are associated with punishment rather than reward. Both children and adults with psychopathic tendencies have great difficulty learning to stop playing cards once the punishment becomes more frequent than the reward. Often, they may end up losing all the points that they had gained (Fisher \& Blair, 1998; Newman et al., 1987; O’Brien \& Frick, 1996).

Empathic response. The emotional/empathic response is the ability to feel the emotion that another person is experiencing. Appropriate empathic responding to victims has long been linked to the suppression of antisocial behaviour (Eisenberg et al., 1996; Perry \& Perry, 1974). Failure to learn that the display of negative emotion, such as fear or anger, is aversive can lead an individual to stray from societal norms. There are several different paradigms which can be used to determine one's empathic responsiveness. One paradigm type involves the direct measurement of an individual's autonomic responses to the distress of others. Participants are shown images on a screen and at the same time, their skin conductance is measured. Using this methodology, both children with psychopathic tendencies and adult psychopaths were found to have reduced autonomic 
responsiveness to the distress of others relative to a comparison group (Blair, 1999b; Blair, Jones, Clark, \& Smith, 1997).

\subsubsection{Affect and Language}

Semantic information. Research has made it clear that psychopathic individuals have an impaired ability to process emotion. Considering that one of the most outward and intentional expressions of emotion is via language, it follows that their processing of affective (emotional) language likely would be impaired. One way to measure the impact of affective input on linguistic processing is by using a lexical decision task. In this type of task, an individual is presented with a string of letters and is asked to decide as quickly and as accurately whether or not they form a word. The letters form either neutral or emotional words or pronounceable pseudo-words (Graves, Landis, \& Goodglass, 1981; Strauss, 1983; Williamson, Harpur, \& Hare, 1991). Non psychopathic criminals were found to respond faster to emotional words than to neutral ones, in addition to showing larger event-related potentials (ERPs - a type of brain activity measured at the scalp) to emotional words over central and parietal sites. In contrast, psychopathic criminals did not show a notable difference in reaction times or ERPs between the emotional words versus the neutral words (Kiehl, Hare, McDonald \& Brink,1999a; Lorenz \& Newman, 2002; Williamson et al., 1991).

In another study Hare (1996) examined how participants grouped spoken words that varied in emotion content. From a list of three words they were asked to determine which two were most closely related, for example, "warm, loving, wise" or "foolish, shallow, sleep". Responses were scored by the following three types of word groupings: antonym, domain (related to human), polarity (negative/positive), domain and polarity 
(positively/negatively toned and pertaining to humans). When psychopathic individuals were compared to non-psychopaths, the pairings made by the psychopaths appeared to be based more on learnt associations rather than on their emotional significance. Several studies (e.g. Hare, Williamson, \& Harpur, 1988b; Kiehl et al., 1999a; Lorenz \& Newman, 2002; Newman, Schmitt, \& Voss, 1997) using different paradigms have investigated the ability of psychopaths to make inferences about affective semantic information and have found that they present with notably reduced ability to perceive the emotional content of linguistic information. More specifically, psychopaths show reduced conceptual knowledge concerning moral emotions, reduced influence of affect information during lexical decision, and a notable absence of appropriate affect input on specific tasks investigating semantic knowledge (Blair et al., 2005).

\subsubsection{Prosodic information.}

The ability of psychopaths to discriminate emotion based on affective prosody has received relatively little attention until recently. Blair et al. (2002) were the first to investigate the ability of psychopathic individuals to process emotional information from vocal intonation. They tested both psychopathic and non-psychopathic individuals by presenting semantically neutral, isolated words (e.g., "carpet") with intonations conveying happiness, disgust, anger, sadness, and fear, and asking the participants to identify the emotion of the speaker based on prosody. Their study observed that psychopathic individuals were severely impaired in their recognition of the fearful vocal affect relative to the comparison group. There was also an association between impaired recognition of sad affect and higher PCL-R scores (a measure of psychopathy which will be discussed in following sections). A follow up study in 2005 by Blair et al. showed that 
boys with psychopathic tendencies also showed impairment for the recognition of fearful vocal affect.

\subsection{Attempts to Explain the Emotional Dysfunction}

The following sections outline two models designed to account for why psychopathic individuals show emotional dysfunction and poor socialization.

\subsubsection{Low-fear hypothesis.}

The low-fear model (e.g. Patrick, 1994) suggests that failed socialization in psychopathic individuals is the result of a reduced ability to experience fear, and therefore a failure to adjust behaviour in response to negative consequences this behaviour may have led them to in the past. The low-fear model works on the assumption that moral socialization is achieved through punishment. The healthy individual is frightened by punishment and associates this fear with the action that led to the consequence. Therefore, in theory, that individual should be less likely to engage in that action in the future. According to this model, psychopaths are less aversively aroused by punishment and form weaker associations to the event that caused the punishment. They are therefore more likely to engage in the punished action in the future than healthy individuals. Empirical support for this position is drawn from experiments that demonstrate psychopathic individuals have impaired fear conditioning (Lykken, 1957) and impaired startle reflex potentiation (Levenston et al., 2000).

\subsubsection{Violence inhibition mechanism model.}

The second model that attempts to explain the emotional dysfunction and poor socialization of psychopaths is the violence inhibition mechanism (VIM) model (Blair, 2005). According to this model, for moral socialization to occur an individual needs to 
learn to pair distress cues with the acts that caused the distress. For example, when a healthy child views pain in another individual, he or she finds it aversive. More specifically, the VIM model suggests the existence of a mechanism that preferentially responds to sad and fearful displays of emotion. The healthy individual learns to avoid initiating behaviours that result in the sadness or fear of others because this is aversive to the observer. One of the important predictions of the VIM is that individuals with psychopathy should show significant difficulty when processing fearful or sad expressions. A study by Blair et al. (2002) was one of the first to provide evidence that, indeed, psychopaths not only present with difficulties in recognizing and generating autonomic responses to facial expressions of sadness and fear but they also show difficulty with sad and fearful vocal affect. The same impairment has been shown in several additional studies (Blair, Richell, Mitchell, Leonard, Morton, \& Blair, 2006; Verona, Patrick, Curtin, Bradley, \& Lang, 2004), and has also been shown to exist in boys with psychopathic tendencies (Blair, Budhani, Colledge, \& Scott, 2005).

\subsection{Measuring Psychopathy}

Many current measures of psychopathy can trace their origins to Cleckley's (1941) original characterization of psychopathy. One measure that was heavily influenced by Cleckley's work is the Psychopathy Checklist (PCL) developed by Robert Hare and colleagues. The PCL (Hare, 1980) and its derivatives, such as the Psychopathy Checklist-Revised (PCL-R) (Hare, 2003) are currently the most widely used measures of psychopathy in forensic settings. The PCL-R lists features that have been found to be characteristic of psychopaths and is used to assess adult populations. Following the development of the adult PCL-R, assessment tools which measure psychopathy in 
childhood and adolescence have also been developed. These include the Antisocial Process Screening Device (APSD) (Frick \& Hare, 2001a) and the Psychopathy Checklist: Youth Version (Forth et al., 2003, Kosson et al., 2002a).

The PCL-R is scored based on 20 items that characterize psychopathy, including unreliability; impulsivity; lack of remorse; lack of empathy, plus emotional traits such as callousness, lack of anxiety, lack of guilt, undependability, dishonesty, a diminished capacity for remorse, superficial charm, and poor behavioural control (Hare, 1991). The PCL-R assessment consists of both an extensive file review and a semi-structured interview. The 20 behavioural items are scored using a 0-1-2 scale, so an individual can obtain a score ranging from $0-40$. Adults scoring 30 or above are generally considered psychopathic, while those who score 20 or below are considered non-psychopathic.

The PCL-R was developed using data from forensic samples. For this reason, researchers do not conduct studies using the PCL-R when evaluating psychopathy in nonforensic groups. Specific reasons for not using the PCL-R in non-forensic samples involve the limited amount of normative PCL-R data from non-forensic samples, items from the PCL-R being rarely applicable to non-forensic samples, and the extensive training required to adequately administer the PCL-R. As a consequence, other measures of psychopathy in non-forensic samples have been developed. These include the Psychopathy Personality Inventory (PPI; Lilienfeld \& Andrews, 1996), Self-Report Psychopathy (SRP-II) scale (Williams \& Paulhus, 2004), and the Levenson Self-Report Psychopathy (LSRP) scale (Levenson, Kiehl, \& Fitzpatrick, 1995). In the current study the Self-Report Psychopathy (SRP-II) scale was used to assess psychopathy. The SRP-II was developed using a non-forensic population and consists of 60 items, with an abridged 
version containing 31 items (Paulhus \& Williams, 2002; Salekin et al., 2001). According to Paulhus and Williams the SRP-II is a good predictor of misbehaviors and discriminates sub clinical psychopaths from other personalities like narcissists and machiavellians.

To summarize, it is clear that individuals with psychopathy display reduced sensitivity to affective information contained in language, regardless of paradigm. However, more research is needed to further clarify the nature of the language impairment. It is not clear whether their impairment is due to their ability to extract semantic information, prosodic information, or both. In previous studies (Blair et al., 2002; Blair et al., 2005) that have investigated the ability of psychopaths to recognize affective prosody, the stimuli used consisted only of isolated words. To further investigate the affective language impairment, the use of isolated words would not be sufficient as they do not incorporate semantic information about affect (where "semantic" incorporates the meaning of individual words plus their collective meaning derived from syntax). In addition, the amount of prosodic information present in isolated words is severely limited. Taking into account this situation, one goal of the present study was to investigate the role of semantic and prosodic information in determining how listeners assign sentence length stimuli to different emotion categories. As a first step, before investigating semantic and prosodic cues to emotion in psychopathic individuals, the present study explored the role of semantic and acoustic cues in categorizing sentences in nonpsychopathic individuals.

\section{Method}

The present study consisted of two separate components, a perceptual task and a production task. The goal of the perceptual task was to a) examine how well 
nonpsychopathic listeners could perceive emotion in spoken language and b) how ratings of quality of emotions correlate with accuracy of emotion recognition. (Results from the rating data were not included in this thesis.) The goal of the production task was to a) determine that acoustic cues present in the sentences used for the production experiment were consistent with what was observed in previous research and b) to evaluate the relationship between the performance of listeners and the acoustic cues present in the stimuli. The rationale for these two components is two-fold. First, it is important to determine if some emotions, such as fear, are more difficult to perceive not only by psychopaths but also by nonpsychopaths. Second, it is important to determine if potential differences in the perception of emotion in spoken language are associated with specific acoustic cues and how the stimuli use in the present study compared with stimuli used in previous work.

\subsection{Perception Experiment}

\subsubsection{Participants.}

Forty-five participants took part in this study (26 females and 19 males), the majority of whom were Carleton University students. Their ages ranged from 18-35 ( $M=$ 20.02, $S D=2.69$ ). Participants were recruited online through the undergraduate psychology pool at Carleton University, or by word of mouth from the experimenter. All participants were native English speakers or had native-like proficiency of English and had little or no experience with French both in comprehension and production. Of all the participants, $8 \%$ spoke a second language that was not French. The remaining $92 \%$ were monolingual English speakers. Language proficiency of participants was determined by self-rating using a language experience questionnaire (see below for details). 


\subsubsection{Verbal Material and Recording Procedure}

The verbal material consisted of 93 spoken sentences which varied by affect and language. Five affect categories were used: happy (e.g., All my wishes came true that day.), sad (e.g., The house seemed empty without her), anger (e.g., My boss screamed at me in front of the customer), fear (e.g., I heard someone's footsteps behind me), and neutral (e.g., I made a list and went off to the store). See Appendix A for a complete listing of sentences for each affect category. The sentences were recorded by two male and two female speakers who were fluent bilingual speakers of English and French. Within each group of speakers (i.e. within each gender group) one speaker was a native speaker of English while the other speaker was a native speaker of French. The speakers recorded each of the 93 sentences in both English and French (written scripts in both languages were provided to the speakers). When recording the English sentences, they were asked to produce the sentences with a neutral prosody (neutral tone of voice) and when recording the French sentences they were asked to maintain a natural prosody (natural tone of voice) consistent with the intended affect category. Recording the sentences in this way resulted in two conditions for English listeners who had little or no French comprehension ability. The English sentences represented a semantic condition where cues to the intended affective category were available only via the semantic content of the sentences (i.e. the affective prosodic information was absent/minimal). The French sentences represented a prosodic condition in which only prosodic cues to affect category were available (i.e., the semantic cues were not available to the listener). 
Sentences were recorded in a sound-attenuated booth using a headset microphone. Praat software (Boersma \& Weenick, 2008) was used for recording and editing the individual sentences. The sentences were digitized at a sampling rate of $44 \mathrm{kHz}$.

\subsubsection{Design.}

A $5 \times 4 \times 2$ repeated-measures design was used, with five levels of the affect variable (happy, sad, angry, neutral and fear), four levels of the speaker variable (which speaker was presented first), and two levels of the native language of the speaker (French or English). Each participant heard sentences from all affect categories produced in both languages by all four speakers. Specifically, participants were presented with four counterbalanced lists (counterbalanced by speaker and affect category). Each list contained all 93 sentences which were presented in random order. There were two lists for French sentences and two lists for English sentences. The four lists were counterbalanced across participants and in total, participants heard 372 portrayals.

\subsubsection{Test Instruments.}

Self-Report Psychopathy Scale. The SRP-III (Williams, Paulhus \& Hare, 2007) was administered via computer before the test sentences were presented to measure the degree of psychopathy present in each participant. Participants classified as having psychopathic characteristics beyond that found in a normative sample were excluded from further analysis. The SRP-III is a 64 item experimental self-report measure of psychopathy that has been shown to have moderate predictive validity with respect to recidivism (e.g., Boccaccini et al., 2007; Lilienfeld \& Fowler, 2006). The SRP-III Scale is a significant predictor of a variety of unethical and antisocial behaviours in college students (Nathanson, Paulhus, \& Williams, 2006; Williams et al., 2007). It consists of 
four factors: Interpersonal Manipulation, Callous Affect, Erratic Life Style and Criminal Tendencies. Individuals are scored on each of the four factors, and an overall score is given. The following table are the norms for both males and females based on mean and standard deviation.

Table 3.1.4

Norms for males and females for the Self-Report Psychopathy Scale (SRP-III) (Paulhus, D.L., Hemphill, J.D., \& Hare, R.D., in press).

\begin{tabular}{lrrrc}
\hline \multicolumn{1}{c}{ Factors } & \multicolumn{3}{c}{ Males } & \multicolumn{2}{c}{ Females } \\
\hline & Mean & SD & Mean & SD \\
Interpersonal Manipulation (IPM) & 47.2 & 9.5 & 41 & 8.9 \\
Callous Affect (CA) & 44.5 & 7.2 & 34.3 & 8 \\
Erratic Life Style (ELS) & 46.5 & 9 & 41.4 & 8.2 \\
Criminal Tendancies (CT) & 26.9 & 8.9 & 22.8 & 8.3 \\
Overall Score & 165.2 & 27.4 & 139.6 & 25.4
\end{tabular}

Based on the SRP scores of the participants, only the data from one of the 45 participants in the present study had to be removed. After the removal of this data, the overall mean of SRP scores was 143.95 , with $\mathrm{SD}=24.03$. For more information regarding SRP scores, please refer to section 4.1 of Chapter 4 .

Language Experience Questionnaire. An electronic language questionnaire was used to assess participant's experience and level of proficiency in French. Participants were asked to rate their French language history or their knowledge of French on a scale of 1 (no current knowledge of French) to 5 (strongly confident in French knowledge). Open answer questions were also asked to gain insight into their current use of the language such as how often the participant spoke French, whether they watched French 
television, and the highest level the participant attained in French language instruction. Responses to the questionnaire were used to determine if the participants had little or no knowledge of French. Based on responses to the language experience questionnaire, all participants were deemed to have negligible knowledge of French.

\subsubsection{Procedure.}

In the first phase of the experiment participants provided written informed consent and then completed the language experience questionnaire followed by the SRPIII on a laptop in the testing room. In the second phase, participants moved into a soundattenuated booth and were presented with the spoken sentences from the different affect categories. Sentences were presented over headphones in a randomized order. A practice round of 10 trials (sentences) was provided, and participants were instructed to adjust volume during this time so that volume remained constant throughout the duration of the testing period. Practice sentences did not overlap with the sentences presented in the categorization task. Participants were presented the first half of the trials either entirely in French or entirely in English followed by a 5 minute break. Depending on whether the participant first heard French or English sentences, the second half of the trials would be presented entirely in the language which they had not yet heard (e.g. first set: English, second set: French) allowing them to hear both the semantic condition (English sentences) and the prosodic condition (French sentences).

For each trial, participants were asked to categorize the sentence they heard using one of five category labels: happy, sad, fear, anger and neutral. After categorizing the sentence, participants were then asked to rate the quality of the affect (how well they felt the sentence portrayed the affect category they had chosen) using a 7-point rating scale (1 
= low quality, $4=$ moderate quality; $7=$ high quality). (The data from the rating task were not included in the analyses completed for this thesis.) Psyscope software (Cohen, MacWhinney, Flatt, \& Provost, 1993) was used to display the categorization and rating scales, as well as to collect responses and reaction times of the participants.

\subsection{Production Experiment}

A major goal of the present study was to analyze the acoustic characteristics of the spoken sentences used in the perception experiment.

\subsubsection{Procedure.}

The 93 sentences that were recorded in French and used in the perception experiment were subjected to detailed acoustic analyses of seven acoustic cues (Table 3.2.1). The English sentences were not included because they were meant to lack relevant affective prosodic information. For a description of how the sentences were generated, see section 3.1.2. For details concerning the acoustic analyses, see Appendix D.

Table 3.2.1

Voice Cues Analyzed in the Present Study

\begin{tabular}{lll} 
Voice Cue & Abbreviation & Perceptual Attribute \\
\hline Fundamental frequency $(M)$ & F0 $(M)$ & Pitch \\
Fundamental frequency $(\max )$ & F0 (max) & Pitch maximum \\
Fundamental frequency $(\min )$ & F0 (min) & Pitch minimum \\
Fundamental frequency $(S D)$ & F0 $(S D)$ & Pitch variability \\
Fundamental frequency contour & F0 contour & Pitch contours (up/down) \\
Fundamental frequency perturbations & Jitter & Pitch perturbations \\
Voice Intensity $(M)$ & Volnt $(M)$ & Loudness
\end{tabular}




\section{Results}

\subsection{Perception Task}

Before analyzing the performance of participants in the perception task, the SelfReport Psychopathy scale scores were analyzed to ensure that any individuals with high levels of psychopathic characteristcs were excluded from the analyses. The mean of SRP scores for all 45 participants was 145.53 , with a standard deviation $(S D)=26.01$; this is comparable to the normed mean of 152.4 for students at the University of British Columbia where the scale was developed. A criterion of two standard deviations from the mean was applied to exclude participants. This meant that any participant scoring more than 197 was removed from further analysis. (The criterion of two standard deviations for removal was based on the fact that scores within two SD units of the mean encompass approximately $95 \%$ of scores, with scores either above or below this criterion being the $\sim 2.5 \%$ most extreme scores.) Using this criterion, data from one participant were removed (participant 15; SRP score $=215$ ). With the data from this participant removed, the mean for the remaining 44 participants was 143.95 , with $S D=24.03$. The remaining SRP scores ranged from 98 to 194 . (The range of possible values for the total SRP score is 64 to 320 .)

Figure 4.1 shows the mean proportion of sentences correctly categorized by participants as a function of the five emotions and the two languages included in this study. 
Figure 4.1

Mean proportion of sentences correctly categorized from each emotion category in the semantic (English) and prosodic (French) conditions Error bars represent \pm 1 standard error of the mean.

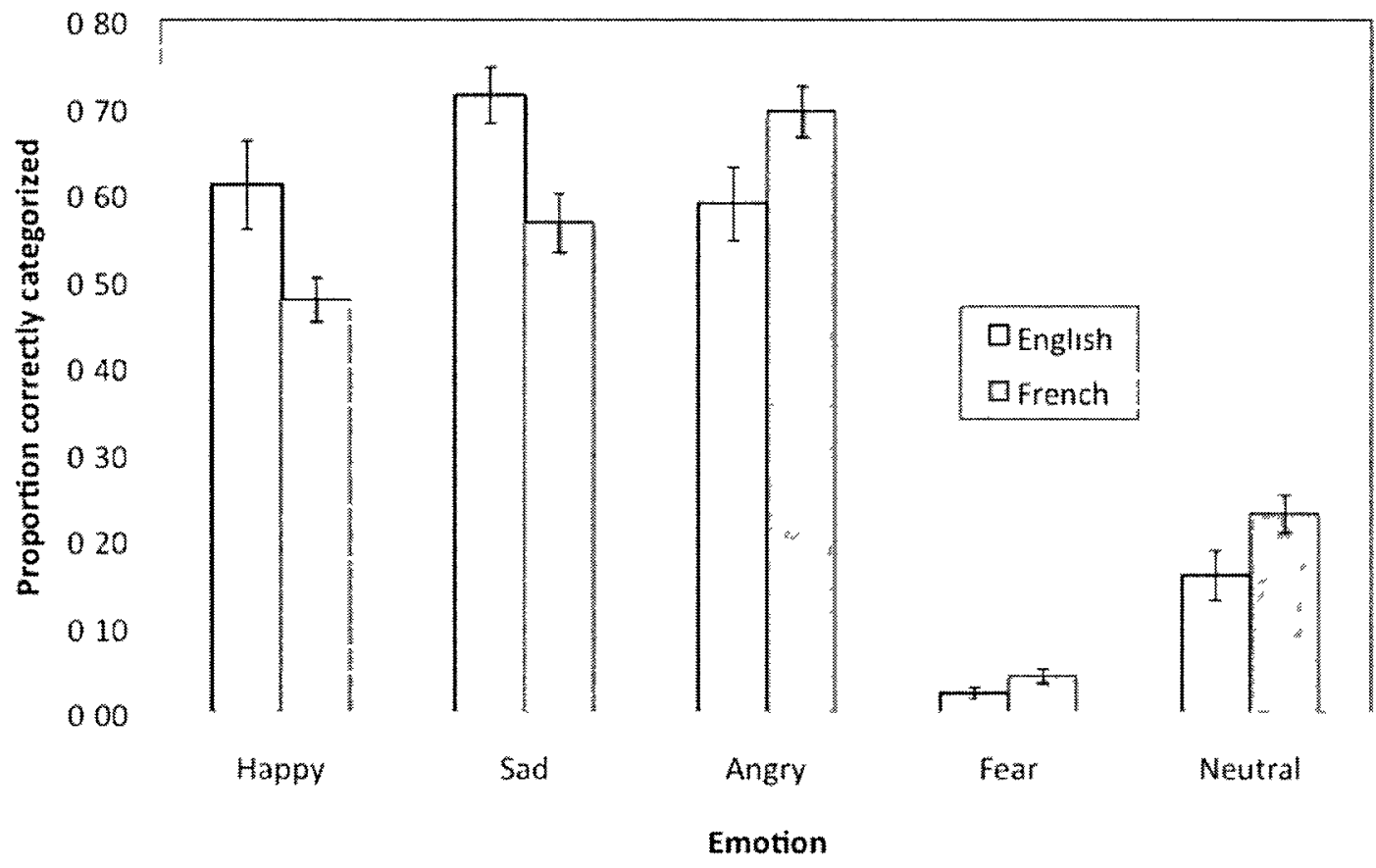

As is evident from Figure 4.1, participants accurately categorized three out of the five emotions, with 'sad' and 'angry' most accurately categorized. In contrast, participants were very poor at categorizing sentences that were meant to be fearful and neutral in both the semantic (English) and prosodic (French) conditions. This pattern of results is somewhat at odds with the current research. While it is sometimes common for groups to be less accurate at recognizing 'fear' in comparison to other emotions, it is still most often recognized at a level above chance (e.g. Juslin \& Laukka, 2001). (Chance in the present categorization task would be $1 / 5$, or $20 \%$, based on the five alternatives available to participants.) Possible explanations for this difference will be discussed in the next chapter. Also, for 'happy' and 'sad' sentences, participants were more accurate when presented with the semantic (English) condition than when they heard the prosodic 
condition (French). For 'anger', 'fear' and 'neutral' however, they were more accurate when they heard the prosodic condition than the semantic condition.

A 5 (emotion category) X 2 (English versus French) repeated measures analysis of variance (ANOVA) was used to evaluate the statistical significance of the pattern of results observed in Figure 4.1. Statistical significance in the analyses of categorization accuracy (and in the following analyses of RT data) was set at $p=.05$. A significant effect of emotion was obtained, $F(4,176)=150.94$, as well as a significant interaction between emotion and language, $F(4,174)=9.47$. Post-hoc tests (Bonferroni-corrected $t-$ tests) indicated significant differences in categorization accuracy between all emotion categories except for between 'anger' and 'sad' sentences. The lack of a main effect for language but an interaction between emotion category and language is due to the roughly $10 \%$ advantage for the categorization accuracy of English over French sentences for the 'happy' and 'sad' sentences compared to the opposite pattern for 'anger', 'fear', and 'neutral' sentences. Post-hoc tests indicated a significant difference between English and French sentences except for 'fear' sentences. 
Figure 4.2

Mean categorization RTs (in seconds) for sentences from each emotion category in the semantic (English) and prosodic (French) conditions. Error bars represent \pm 1 standard error of the mean.

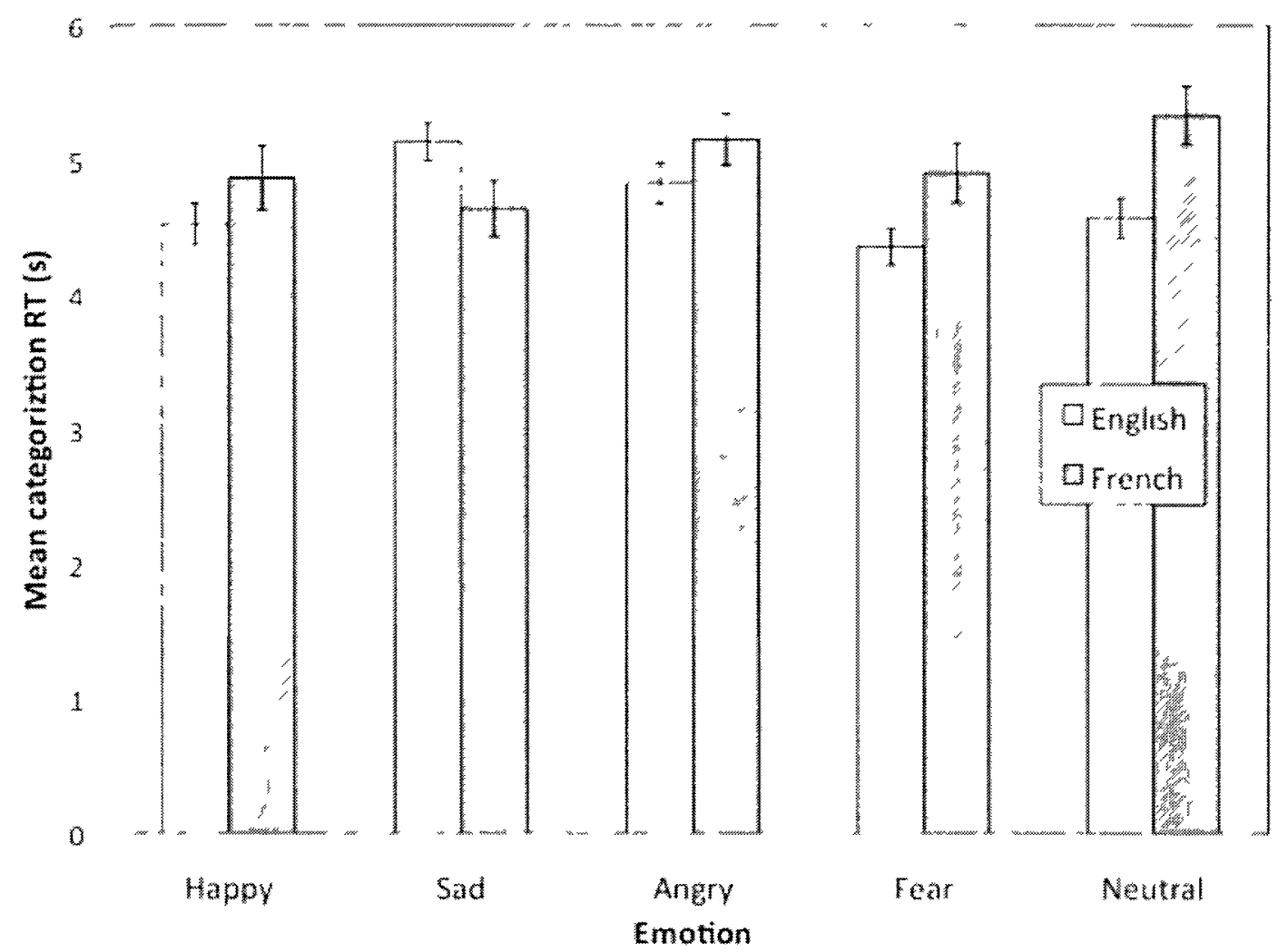

Figure 4.2 shows the mean categorization RTs as a function of the five emotions and the two languages included in the study. RTs of approximately $5 \mathrm{~s}$ were required by participants to categorize all emotions. Sentences from the prosodic (French) condition were categorized more slowly than sentences from the semantic (English) condition, except for 'sad' sentences. Paralleling the ANOVA done for the accuracy data, an identical ANOVA was used to evaluate the RT data. A significant effect of emotion was obtained, $F(4,176)=7.70$, as well as a significant interaction between emotion and language, $F(4,174)=13.58$. No main effect for language was observed. Table 4.1 
provides the mean categorization RTs for each emotion. Post-hoc tests (Bonferronicorrected t-tests) indicated significant differences in mean categorization RTs for the following emotion comparisons: 'happy' vs. 'anger' and 'neutral'; 'sad' vs. 'fear'; 'anger' vs. 'fear'; 'fear' vs. 'sad', 'anger', and 'neutral'; and 'neutral' vs. 'happy' and 'fear'. Significant differences in RT were observed between languages for each emotion category. Overall, the categorization RT data do not fit a coherent pattern that can be compared to the categorization accuracy data. In some cases, it appears that longer RTs are correlated with higher accuracy rates. For example, 'sad' and 'anger' had two of the slowest mean RTs, and were the two most accurately categorized. However, 'neutral' also had a very slow reaction time, but was very poorly categorized.

Table 4.1.1

Mean categorization RTs (in seconds) for sentences from each emotion category.

\begin{tabular}{|l|l|l|}
\hline Emotion & Mean (s) & $\begin{array}{l}\text { Standard } \\
\text { Error }\end{array}$ \\
\hline Happy & 4.99 & .132 \\
\hline Sad & 4.63 & .148 \\
\hline Anger & 4.69 & .152 \\
\hline Fear & 4.95 & .139 \\
\hline Neutral & 4.89 & .137 \\
\hline
\end{tabular}

\subsection{Production Task}

\subsubsection{Acoustic cue measures.}

The following figures show the mean values of the eight acoustic variables which were measured across the French sentences in this study. They are presented in terms of intended emotion and gender of the speaker. For a more detailed explanation of each 
acoustic variable see section 2.2 or Appendix D. Figure 4.2.1 presents the mean duration of the sentences as a function of intended emotion and gender. Figures 4.2.2 - 4.2.8 present the mean values for several measures associated with $\mathrm{F} 0$ and voice quality as a function of intended emotion and gender.

Figure 421

Mean sentence duration (s) as a function of intended emotion and speaker gender

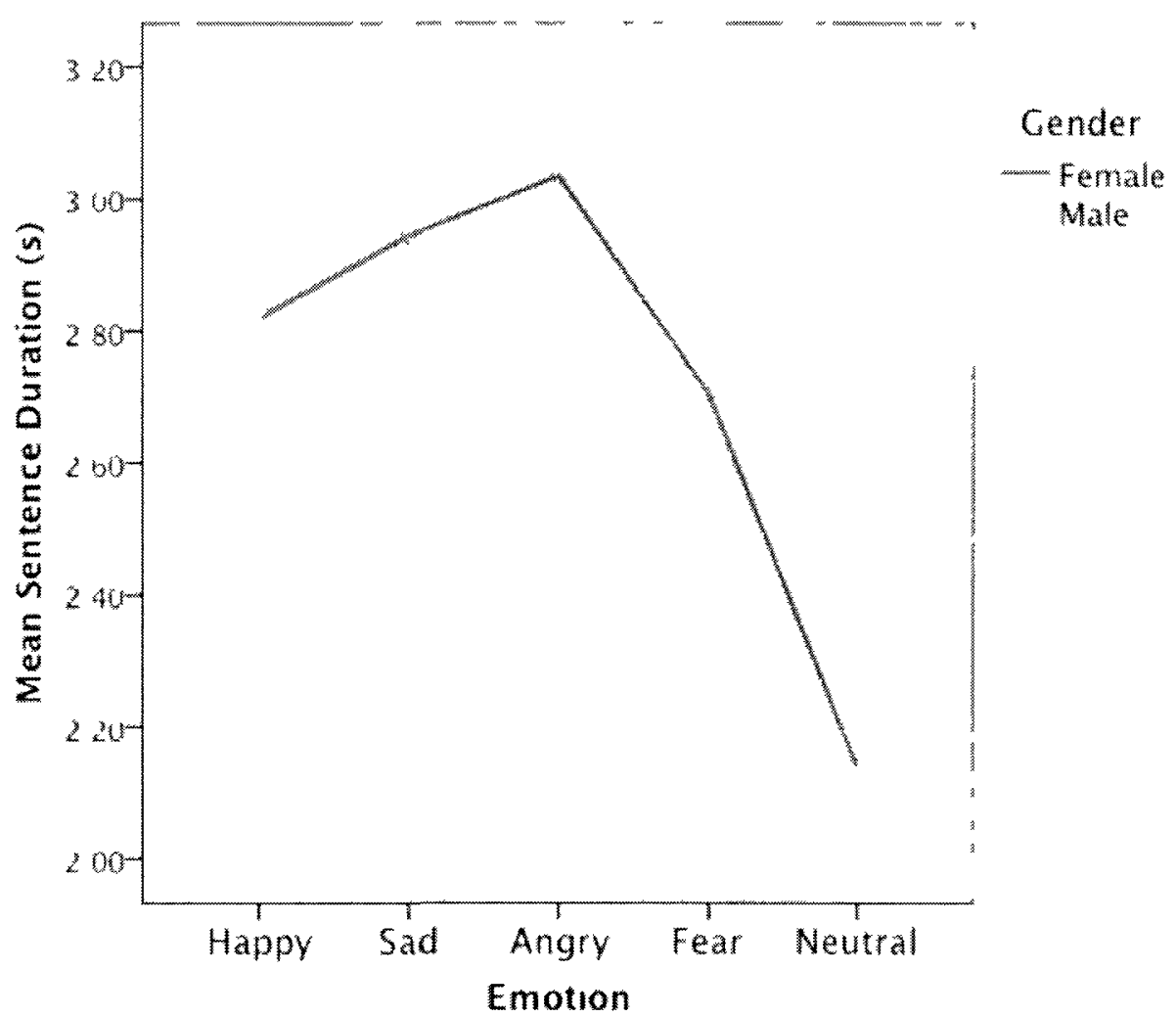

Duration. Overall, the female speakers appeared to have a slightly faster rate of speech for all emotions compared to the male speakers, except for 'happy'. In terms of the emotional categories, sentences which were intended to be 'fearful', 'angry', 'sad' and 'happy' had mean durations which ranged between 2.7 to 3.2 seconds, while the neutral sentences tended to be shorter (between 2.2 - 2.4 seconds). 
F0. The results for the most commonly reported measure of fundamental frequency, F0 $(M)$ varied considerably, which was to be expected (e.g. Scherer, 1989). For the female speakers, 'happy', 'angry' and 'fearful' portrayals yielded high values of F0 $(M)$, while 'sad' and 'neutral' portrayals yielded lower F0 $(M)$ values. The male speakers produced a similar pattern of results, although fearful portrayals yielded more moderate than high values of F0 $(M)$. In terms of F0 standard deviation $(S D)$ (represented as pitch range), the results were varied. For females, 'happy', 'sad', and 'neutral' had the highest F0 (SD), while males had highest values for 'happy', 'angry', and 'fear'. Interestingly, 'fear' for females had a drastically low value compared with all other emotions. Despite the high variability for F0 $(S D)$, the results for F0 ( $\min$ ) and (max) were almost identical for males and females. 'Happy', 'anger' and 'sad' had the highest values for $\mathrm{F} 0$ min and $\mathrm{F} 0$ max.

The results of the F0 contour index indicated that for both genders, 'happy', 'anger', and 'sad' portrayals had more downward F0 contours than 'fear' and 'neutral' portrayals. For the male speakers, 'neutral' portrayals did not show much difference between upward and downward F0 contours, while 'fear' was the only emotion that was produced with more upward than downward F0 contours. For female speakers, there were more upward than downward F0 contours for both 'neutral' and 'fear' portrayals. 
Figure 4.2.2

F0 range (SD) as a function of intended emotion and speaker gender

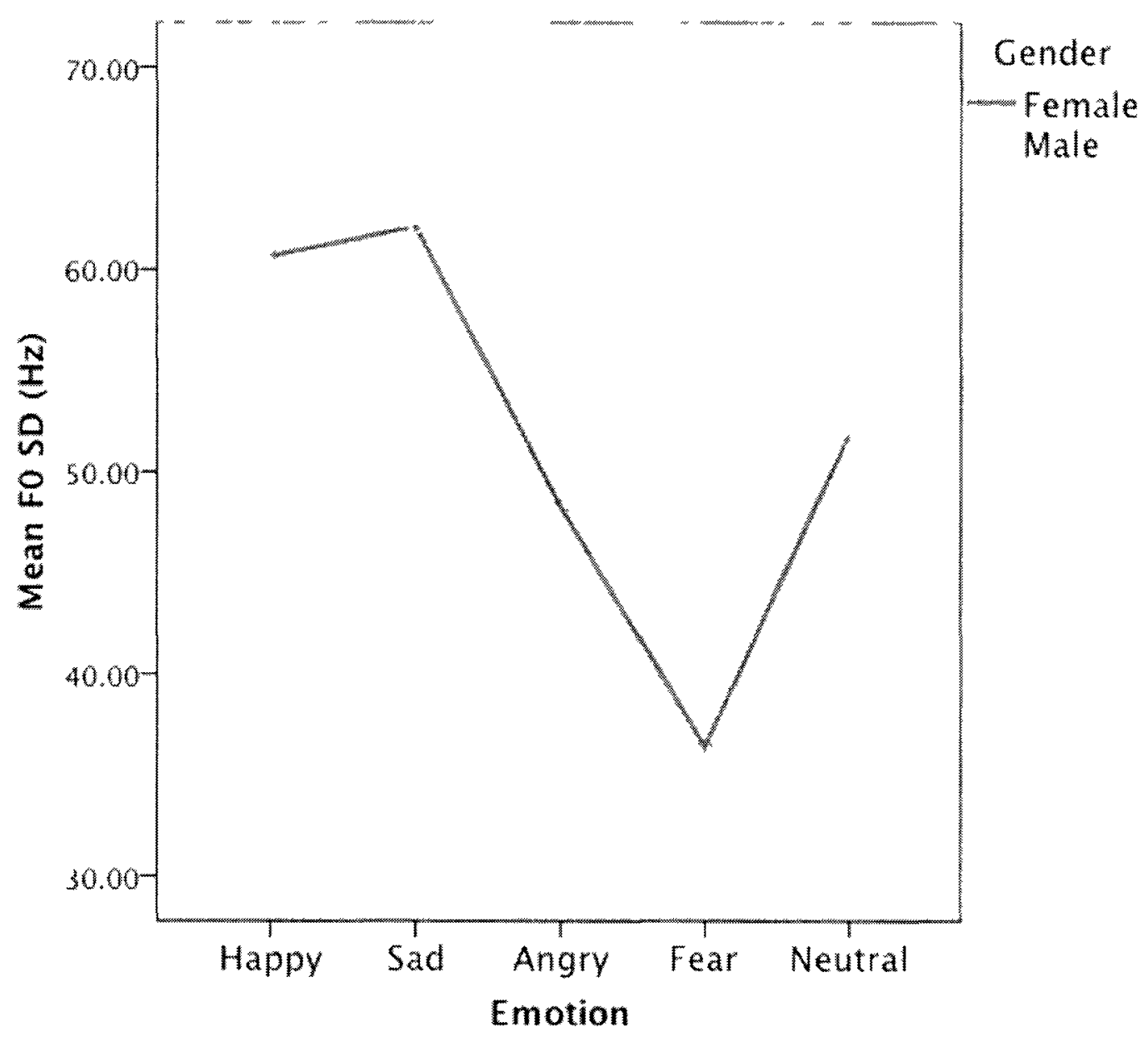


Figure 4.2.3

FO(min) as a function of intended emotion and speaker gender

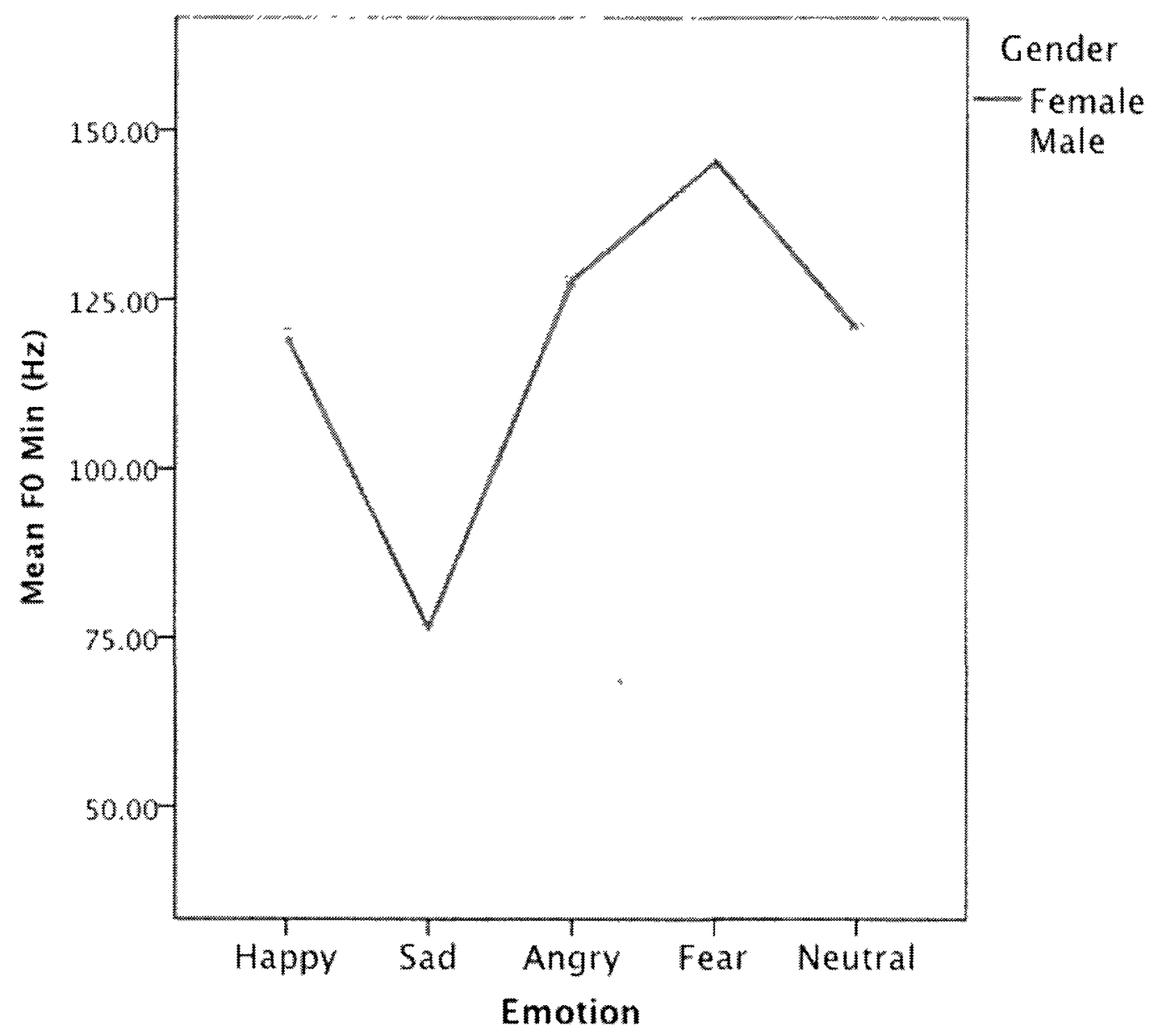


Figure 4.2.4

FO (max) as a function of intended emotion and speaker gender.

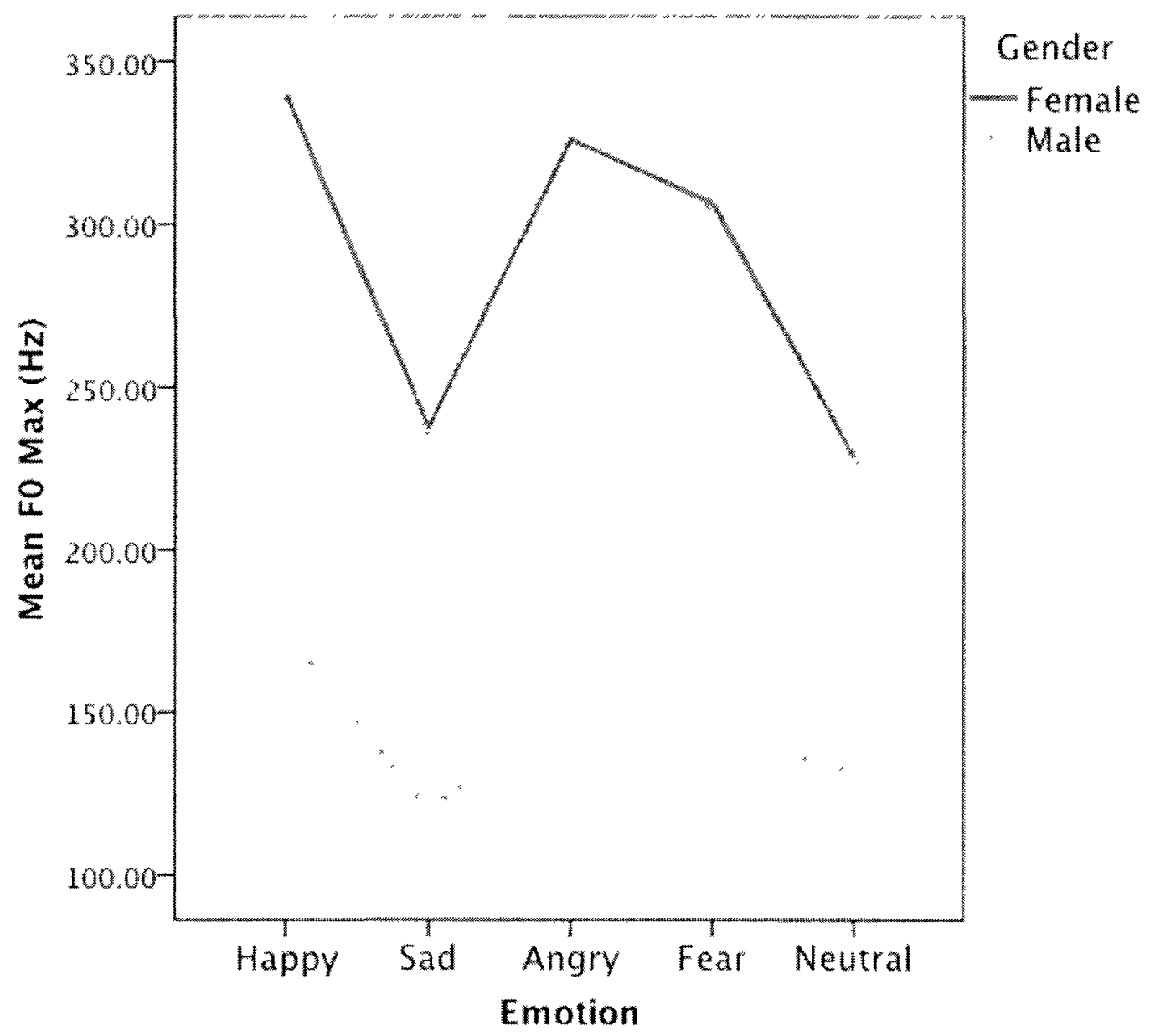


Figure 4.2.5

Mean F0 values of the portrayals as a function of intended emotion and speaker gender.

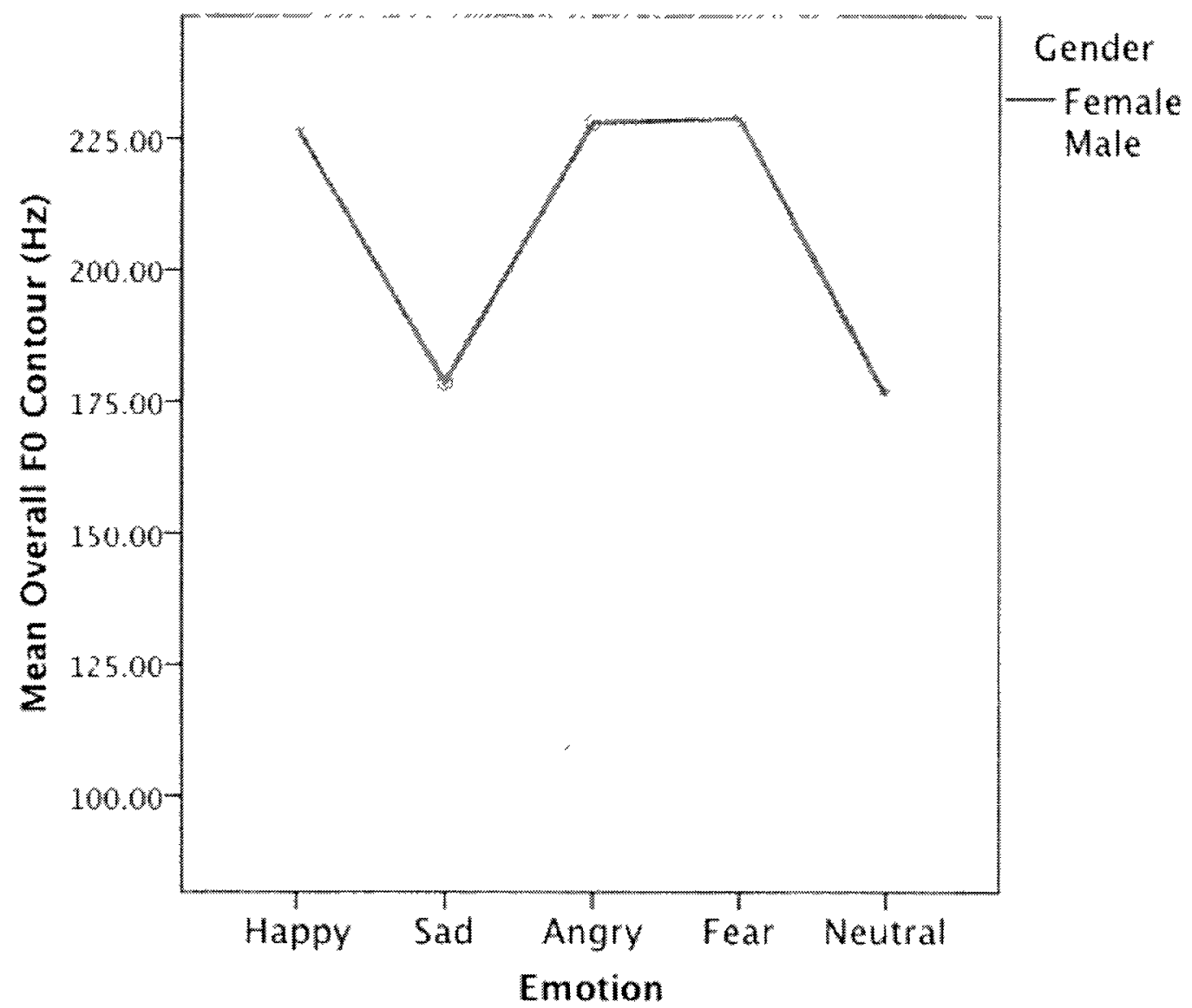


Figure 4.2.6

Fo Contour Index (Rising[Hz]/Falling[Hz]) as a function of intended emotion and speaker gender

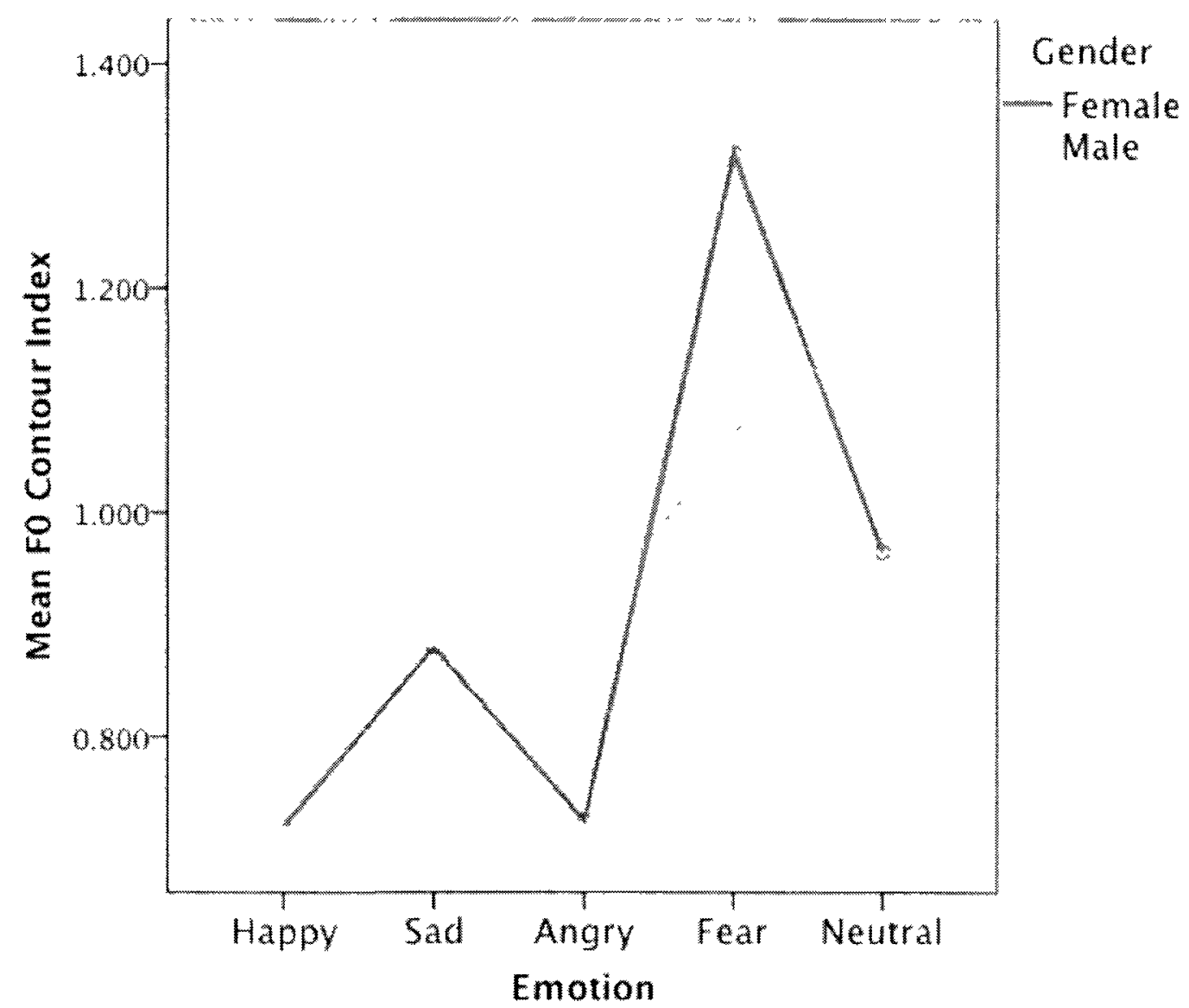

Voice Quality. The results for jitter $(M)$ varied greatly depending on speaker gender. Male speakers showed little variance among all five emotions and had much higher values (between 3-3.4\%) across the emotions than female speakers (between 22.6\%). For female speakers, there was more variance across emotions; 'sad' and 'neutral' portrayals had higher values than 'happy', 'angry' and 'fear' portrayals. Given that jitter is often said to be representative of a shaky or crying voice, it is not surprising that the values should be higher for the 'sad' portrayals. 
Voice intensity. Voice intensity showed high values for 'happy' and 'anger' for both genders. 'Sad' had the lowest values for intensity, while 'fear' differed for female and male speakers. Interestingly, male speakers produced 'fear' with a moderate intensity (although still lower than 'neutral'). Female speakers produced 'fear' with the second highest intensity values of all five emotions.

\section{Figure 4.2.7}

Mean percentage of Jitter as a function of intended emotion and speaker gender

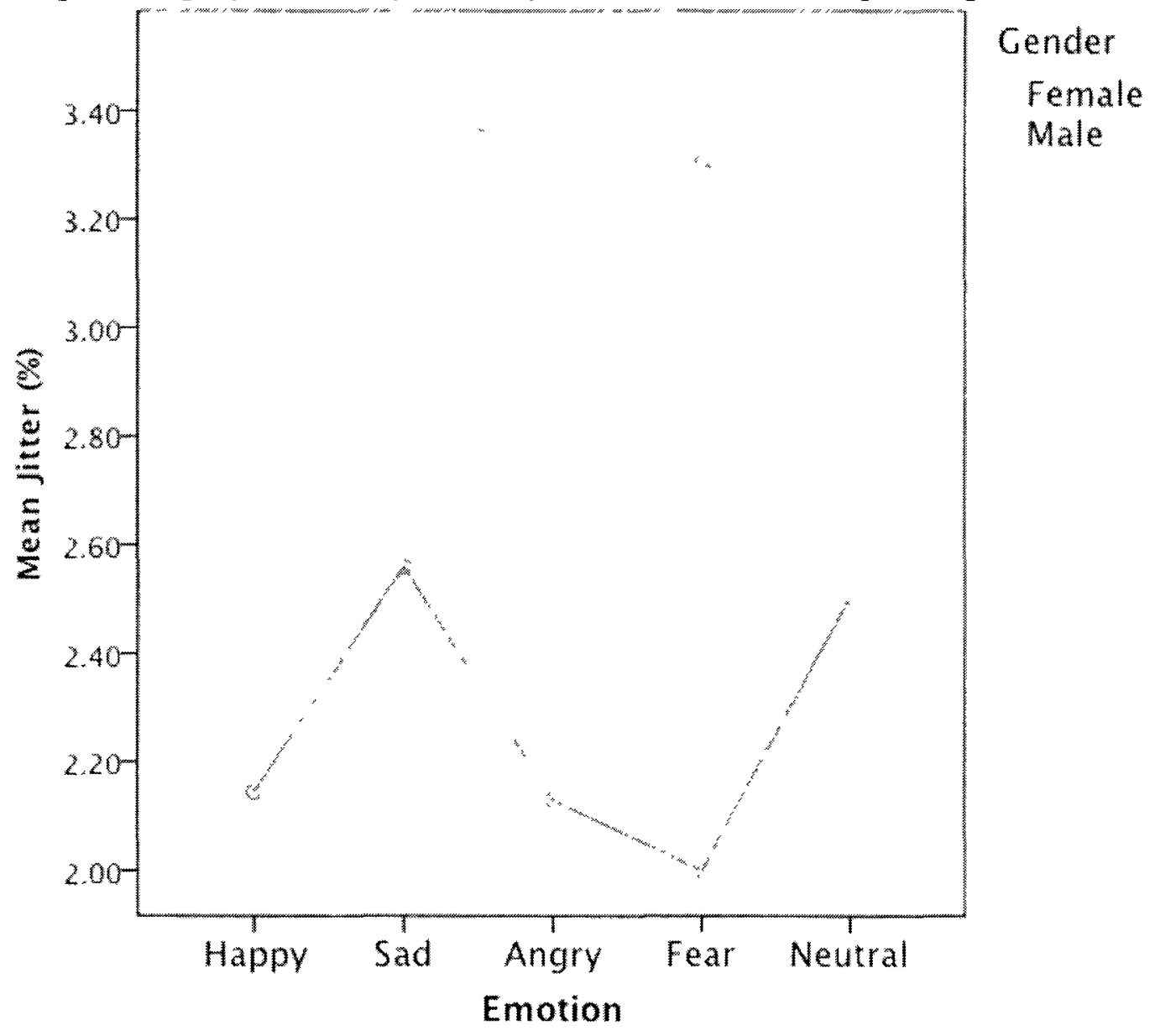


Figure 4.2.8

Mean voice intensity $(\mathrm{dB})$ as a function of intended emotion and speaker gender

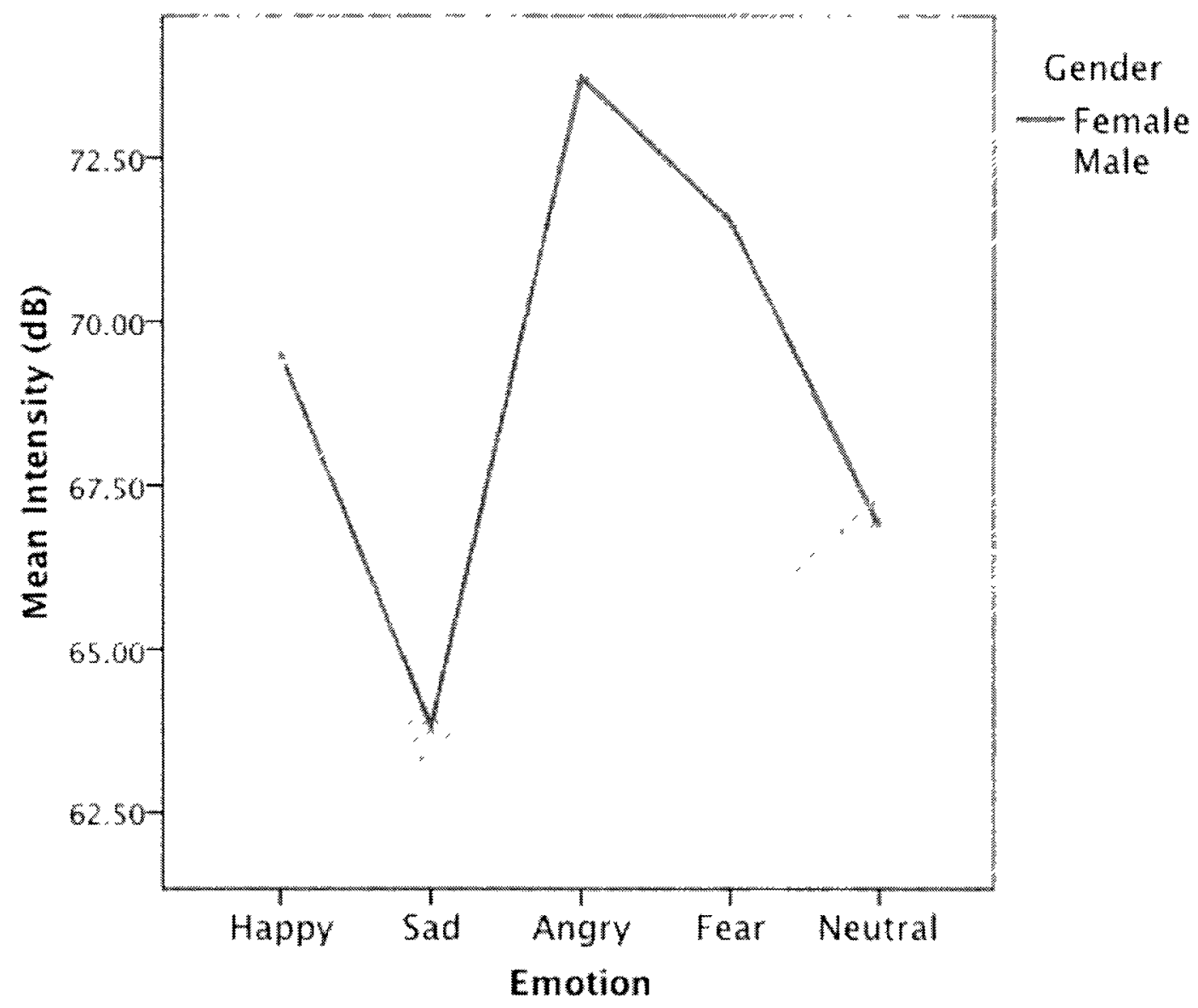

\subsubsection{Correlations between acoustic cues and emotion categorization.}

Five sets of multiple regression analyses were completed, one for each emotion category (happiness, sad, angry, fear, and neutral). For each set of analyses the dependent variables were 1) categorization accuracy and 2) response time (RT). The predictor variables were the seven acoustic cues associated with each emotion described in Tables 2.2.1 and 2.2.2: $\mathrm{F} 0(M), \mathrm{F} 0(\max ), \mathrm{F} 0(\mathrm{~min}), \mathrm{F} 0(S D), \mathrm{F} 0$ contour, Jitter, VoInt $(M)$. The goal of the regression analyses was to determine which acoustic cues predicted categorization accuracy and RT for each emotion. 
For each emotion the correlations among the predictor and dependent variables are provided, followed by the regression analyses for categorization accuracy and for RT. It is important to note that in evaluating these correlations among acoustic parameters that are derived from measures of speech, some significant intercorrelations are to be expected because a majority of the measures are derived from F0 characteristics. In the regression analyses, the nominal $\mathrm{p}$-value for significance is .05 , although values of $\mathrm{p}<$ .10 also will be discussed.

Table 4.3.1

Correlations among variables for happy sentences

\begin{tabular}{|l|l|l|l|l|l|l|l|l|l|}
\hline & F0 $(M)$ & F0 SD & F0 Min & F0 Max & Jitter & VoInt & F0 Cont & P(cor) & RT \\
\hline F0 $(M)$ & 1 & -.102 & $.786^{* *}$ & $.234^{*}$ & $-.740^{* *}$ & -.033 & -.094 & .149 & .150 \\
\hline F0 SD & -.102 & 1 & -.089 & -.062 & .173 & -.073 & -.028 & -.038 & .102 \\
\hline F0 Min & $.786^{* *}$ & -.089 & 1 & .226 & $-.706^{* *}$ & .108 & -.128 & .106 & .060 \\
\hline F0 Max & $.234^{*}$ & -.062 & .226 & 1 & -.209 & .024 & -.076 & -.105 & -.007 \\
\hline Jitter & $-.740^{* *}$ & .173 & $-.706^{* *}$ & -.209 & 1 & $-.246^{*}$ & -.032 & .063 & -.107 \\
\hline VoInt & -.033 & -.073 & .108 & .024 & $-.246^{*}$ & 1 & .186 & -.071 & $-.267^{*}$ \\
\hline F0 Cont & -.094 & -.028 & -.128 & -.076 & -.032 & .186 & 1 & -.074 & -.072 \\
\hline P(cor) & .149 & -.038 & .106 & -.105 & .063 & -.071 & -.074 & 1 & -.184 \\
\hline RT & .150 & .102 & .060 & -.007 & -.107 & $-.267^{*}$ & -.072 & -.184 & 1 \\
\hline
\end{tabular}

${ }^{* *}$ Correlation is significant at the 0.01 level (2-tailed).

*Correlation is significant at the 0.05 level (2-tailed).

'Happy' sentences. Both dependent variables, P(cor) and RT, were not significantly correlated with any of the acoustic measures associated with happiness, with one exception: VOInt and RT $(r=-.267)$. Several variables were significantly correlated with F0 $(M)$, including F0 Min $(r=.786)$, F0 Max $(r=.234)$, and Jitter $(r=-.740)$. F0 
was significantly correlated with Jitter $(r=-.706)$. Jitter was significantly correlated with VoInt $(r=-.246)$.

The overall $\mathrm{R}$ value in the regression for categorization accuracy was not significantly different from zero, $F(7,64)=1.2, p=.316$, with an $R^{2}=.116$. Only two acoustic variables made a contribution to categorization accuracy for happiness: Jitter $(\mathrm{beta}=.434, p=.034)$ and $\mathrm{F} 0(M)(\mathrm{beta}=.410, p=.071)$. For the regression analysis of RT, the overall $R$ value was not significantly different from zero, $\mathrm{F}(7,64)=1.283, \mathrm{p}=$ .273 , with an $\mathrm{R}^{2}=.123$. Only one acoustic variable made a contribution to $\mathrm{RT}$ : Volnt $($ beta $=-.295)$.

Table 4.3.2

Correlations among variables for sad sentences

\begin{tabular}{|l|l|l|l|l|l|l|l|l|l|}
\hline & F0 (M) & F0 SD & F0 Min & F0 Max & Jitter & Volnt & F0 Cont & P(cor) & RT \\
\hline F0 (M) & 1 & $-.418^{* *}$ & $.546^{* *}$ & $.924^{* *}$ & $-.708^{* *}$ & $.622^{* *}$ & -.051 & .137 & .126 \\
\hline F0 SD & $-.418^{* *}$ & 1 & $-.301^{* *}$ & $-.406^{* *}$ & $.598^{* *}$ & $-.665^{* *}$ & $-.311^{* *}$ & -.150 & -.046 \\
\hline F0 Min & $.546^{* *}$ & $-.301^{* *}$ & 1 & $.513^{* *}$ & $-.359^{* *}$ & $.329^{* *}$ & -.046 & .044 & .198 \\
\hline F0 Max & $.924^{* *}$ & $-.406^{* *}$ & $.513^{* *}$ & 1 & $-.690^{* *}$ & $.620^{* *}$ & -.013 & .090 & $.317^{* *}$ \\
\hline Jitter & $-.708^{* *}$ & $.598^{* *}$ & $-.359^{* *}$ & $-.690^{* *}$ & 1 & $-.736^{* *}$ & -.170 & -.206 & -.093 \\
\hline VoInt & $.622^{* *}$ & $-.665^{* *}$ & $.329^{* *}$ & $.620^{* *}$ & $-.736^{* *}$ & 1 & .177 & .203 & .002 \\
\hline F0 Cont & -.051 & $-.311^{* *}$ & -.046 & -.013 & -.170 & .177 & 1 & -.026 & -.012 \\
\hline P(cor) & .137 & -.150 & .044 & .090 & -.206 & .203 & -.026 & 1 & -.178 \\
\hline RT & .126 & -.046 & .198 & $.317^{* *}$ & -.093 & .002 & -.012 & -.178 & 1 \\
\hline
\end{tabular}

**Correlation is significant at the 0.01 level (2-tailed).

${ }^{*}$ Correlation is significant at the 0.05 level (2-tailed).

'Sad' sentences. Both dependent variables, P(cor) and RT, were not significantly correlated with any of the acoustic measures associated with 'sad', with one exception: 
F0 Max and RT $(r=.317)$. In contrast to 'happy', the acoustic measures for 'sad' were highly intercorrelated. Rather than list all the significant correlations among the acoustic measures, I will note that the only acoustic measure that is not significantly correlated with any other measure is F0 Cont.

The overall $R$ value in the regression for 'sad' categorization accuracy was not significantly different from zero, $F(7,68)=.743, p=.636$, with an $R^{2}=.071$. No acoustic variables made a significant contribution to categorization accuracy for 'sad' when considered collectively in the regression analysis. In contrast to the regression analysis of categorization accuracy, the regression analysis of RT yielded an overall $R$ value was significantly different from zero, $F(7,68)=5.180, p=.000$, with an $R^{2}=.343$. Two acoustic variables made a significant contribution to RT: F0 $(M)$ (beta $=-1.176)$ and F0 Max (beta $=1.438)$, with VoInt making a marginally significant contribution (beta = .299). 
Table 4.3.3

Correlations among variables for angry sentences

\begin{tabular}{|l|l|l|l|l|l|l|l|l|l|}
\hline & F0 (M) & F0 SD & F0 Min & F0 Max & Jitter & Volnt & $\begin{array}{l}\text { F0 } \\
\text { Cont }\end{array}$ & P(cor) & RT \\
\hline F0 (M) & 1 & $-.306^{* *}$ & $.734^{* *}$ & $.962^{* *}$ & $-.666^{* *}$ & $.530^{* *}$ & -.126 & -.115 & -.020 \\
\hline F0 SD & $-.306^{* *}$ & 1 & $-.327^{* *}$ & $-.290^{* *}$ & $.499^{* *}$ & -.082 & .131 & -.084 & .112 \\
\hline F0 Min & $.734^{* *}$ & $-.327^{* *}$ & 1 & $.698^{* *}$ & $-.542^{* *}$ & $.558^{* *}$ & -.010 & -.078 & -.126 \\
\hline F0 Max & $.962^{* *}$ & $-.290^{* *}$ & $.698^{* *}$ & 1 & $-.640^{* *}$ & $.499^{* *}$ & -.147 & -.159 & .063 \\
\hline Jitter & $-.666^{* *}$ & $.499^{* *}$ & $-.542^{* *}$ & $-.640^{* *}$ & 1 & $-.555^{* *}$ & .072 & .119 & -.072 \\
\hline VoInt & $.530^{* *}$ & -.082 & $.558^{* *}$ & $.499^{* *}$ & $-.555^{* *}$ & 1 & -.004 & -.170 & -.044 \\
\hline $\begin{array}{l}\text { F0 } \\
\text { Cont }\end{array}$ & -.126 & .131 & -.010 & -.147 & .072 & -.004 & 1 & -.071 & -.081 \\
\hline P(cor) & -.115 & -.084 & -.078 & -.159 & .119 & -.170 & -.071 & 1 & - \\
\hline RT & -.020 & .112 & -.126 & .063 & -.072 & -.044 & -.081 & $-.382^{* *}$ & 1 \\
\hline
\end{tabular}

**Correlation is significant at the 0.01 level (2-tailed).

${ }^{*}$ Correlation is significant at the 0.05 level (2-tailed).

'Anger' sentences. Both dependent variables, P(cor) and RT, were not significantly correlated with any of the acoustic measures associated with 'anger'. However, P(cor) and RT were significantly correlated with each other $(r=-.382)$. The negative correlation is typical of many perception tasks in which as accuracy increases, RT decreases. Similar to the pattern of correlations observed for the acoustic measures for 'sad', the acoustic measures for 'anger' were highly intercorrelated. Again, as was the case with 'sad', the only acoustic measure for 'anger' that is not significantly correlated with any other acoustic measure is F0 Cont.

The overall $R$ value in the regression for 'anger' categorization accuracy was not 
significantly different from zero, $F(7,72)=.992, p=.444$, with an $R^{2}=.088$. No acoustic variables made a significant contribution to categorization accuracy for 'anger' when considered collectively in the regression analysis. In contrast to the regression analysis of categorization accuracy for 'anger', the regression analysis of RT yielded an overall $R$ value was marginally significantly different from zero, $F(7,72)=2.030, p=.063$, with an $R^{2}=.165$. Two acoustic variables made a significant contribution to RT: F0 $(M)$ (beta $=-1.014)$ and F0 Max (beta $=1.051)$, with Jitter making a marginally significant contribution (beta $=-.323$ )

Table 4.3.4

Correlations among variables for fear sentences

\begin{tabular}{|l|l|l|l|l|l|l|l|l|l|}
\hline & F0 (M) & F0 SD & F0 Min & F0 Max & Jitter & VoInt & $\begin{array}{l}\text { F0 } \\
\text { Cont }\end{array}$ & P(cor) & RT \\
\hline F0 (M) & 1 & $-.573^{* *}$ & $.724^{* *}$ & $.894^{* *}$ & $-.725^{* *}$ & $.798^{* *}$ & .209 & -.033 & .206 \\
\hline F0 SD & $-.573^{* *}$ & 1 & $-.431^{* *}$ & $-.565^{* *}$ & $.690^{* *}$ & $-.492^{* *}$ & -.048 & -.073 & -.026 \\
\hline F0 Min & $.724^{* *}$ & $-.431^{* *}$ & 1 & $.661^{* *}$ & $-.500^{* *}$ & $.582^{* *}$ & .229 & -.163 & .120 \\
\hline F0 Max & $.894^{* *}$ & $-.565^{* *}$ & $.661^{* *}$ & 1 & $-.619^{* *}$ & $.666^{* *}$ & .116 & -.063 & .175 \\
\hline Jitter & $-.725^{* *}$ & $.690^{* *}$ & $-.500^{* *}$ & $-.619^{* *}$ & 1 & $-.760^{* *}$ & $-.254^{*}$ & .076 & -.144 \\
\hline VoInt & $.798^{* *}$ & $-.492^{* *}$ & $.582^{* *}$ & $.666^{* *}$ & $-.760^{* *}$ & 1 & $.316^{* *}$ & -.174 & .133 \\
\hline $\begin{array}{l}\text { F0 } \\
\text { Cont }\end{array}$ & .209 & -.048 & .229 & .116 & $-.254^{*}$ & $.316^{* *}$ & 1 & -.131 & -.017 \\
\hline P(cor) & -.033 & -.073 & -.163 & -.063 & .076 & -.174 & -.131 & 1 & -.211 \\
\hline RT & .206 & -.026 & .120 & .175 & -.144 & .133 & -.017 & -.211 & 1 \\
\hline
\end{tabular}

${ }^{* *}$ Correlation is significant at the 0.01 level (2-tailed).

${ }^{*}$ Correlation is significant at the 0.05 level (2-tailed).

'Fear' sentences. Both dependent variables, $\mathrm{P}(\mathrm{cor})$ and $\mathrm{RT}$, were not significantly correlated with any of the acoustic measures associated with 'fear'. As was the case with 
'sad' and 'anger', a large number of significant intercorrelations are present between the acoustic measures for 'fear'. Noteworthy is the inclusion of two significant correlations involving F0 Cont: Jitter $(r=-.254)$ and Volnt $(r=.316)$. In the analyses of 'happy', 'sad', and 'angry', F0 Cont was notably absent from any correlations among the acoustic measures.

The overall $R$ value in the regression for 'fear' categorization accuracy was not significantly different from zero, $F(7,64)=1.516, p=.178$, with an $R^{2}=.142$. One acoustic variable made a significant contribution to categorization accuracy for 'fear' when considered collectively in the regression analysis: F0 $(M)$ (beta $=.741$ ). Two acoustic variables made a marginally significant contribution to categorization accuracy: F0 Min (beta $=-.288)$ and VoInt (beta $=-.391)$. Similarly, the regression analysis of RT yielded an overall $R$ value was not significantly different from zero, $F(7,64)=.687, p=$ .682 , with an $\mathrm{R}^{2}=.070$. No acoustic variables made a significant contribution to $\mathrm{RT}$ for 'fear'. 
Table 4.3.5

Correlations among variables for neutral sentences

\begin{tabular}{|l|l|l|l|l|l|l|l|l|l|}
\hline & F0 (M) & F0 SD & F0 Min & F0 Max & Jitter & VoInt & $\begin{array}{l}\text { F0 } \\
\text { Cont }\end{array}$ & P(cor) & RT \\
\hline F0 (M) & 1 & $-.381^{* *}$ & $.818^{* *}$ & $.807^{* *}$ & $-.666^{* *}$ & .218 & -.195 & .028 & .061 \\
\hline F0 SD & $-.381^{* *}$ & 1 & $-.389^{* *}$ & $-.293^{*}$ & $.651^{* *}$ & $-.347^{* *}$ & .108 & -.027 & -.145 \\
\hline F0 Min & $.818^{* *}$ & $-.389^{* *}$ & 1 & $.703^{* *}$ & $-.606^{* *}$ & .179 & -.116 & .064 & .117 \\
\hline F0 Max & $.807^{* *}$ & $-.293^{*}$ & $.703^{* *}$ & 1 & $-.568^{* *}$ & .161 & -.178 & -.005 & .037 \\
\hline Jitter & $-.666^{* *}$ & $.651^{* *}$ & $-.606^{* *}$ & $-.568^{* *}$ & 1 & $-.445^{* *}$ & .208 & -.033 & -.119 \\
\hline VoInt & .218 & $-.347^{* *}$ & .179 & .161 & $-.445^{* *}$ & 1 & -.154 & .010 & .142 \\
\hline $\begin{array}{l}\text { F0 } \\
\text { Cont }\end{array}$ & -.195 & .108 & -.116 & -.178 & .208 & -.154 & 1 & -.178 & -.160 \\
\hline P(cor) & .028 & -.027 & .064 & -.005 & -.033 & .010 & -.178 & 1 & $.301^{*}$ \\
\hline RT & .061 & -.145 & .117 & .037 & -.119 & .142 & -.160 & $.301^{*}$ & 1 \\
\hline
\end{tabular}

${ }^{* *}$ Correlation is significant at the 0.01 level (2-tailed).

${ }^{*}$ Correlation is significant at the 0.05 level (2-tailed).

'Neutral' sentences. Both dependent variables, P(cor) and RT, were not significantly correlated with any of the acoustic measures associated with 'neutral'. However, $\mathrm{P}($ cor) and RT were significantly correlated with each other $(r=.301)$. This positive correlation between $\mathrm{P}($ cor $)$ and $\mathrm{RT}$ is somewhat unusual, as it indicates a tendency for high levels of accuracy to be associated with slower RT, contrary to most perceptual tasks. It may be related to the relatively poor accuracy for categorizing 'neutral' sentences $(M=.232)$ compared to sentences from other emotion categories (e.g., $M=.428$ for 'happy', $M=.597$ for 'sad', $M=.705$; note that 'fear' categorization accuracy was even worse, $M=.072$ ). A relatively large number of intercorrelations exist between the acoustic measures, with the exception of F0 Cont. 
The overall $R$ value in the regression for 'neutral' categorization accuracy was not significantly different from zero, $F(7,64)=.417, p=.888$, with an $R^{2}=.044$. No acoustic variables made a significant contribution to categorization accuracy for 'neutral' when considered collectively in the regression analysis. Similarly, the regression analysis of RT yielded an overall $R$ value was not significantly different from zero, $F(7,64)=.623, p=$ .735 , with an $R^{2}=.064$. No acoustic variables made a significant contribution to RT for 'neutral'.

The results from the regression analyses will be considered in light of prior work in Chapter 5.

\section{General Discussion}

The following discussion will break down the results into several broad sections. It will consider the accuracy scores for emotion recognition by listeners, the patterns (if any) of acoustic cues for the different emotions, how they compare to patterns described in previous research and finally, what is implicated by the results for future investigations relating to emotional impairments in psychopathic individuals.

\subsection{Recognition by Listeners of Intended Emotions}

\subsubsection{Listeners' poor recognition of 'fear' and 'neutral'.}

One of the most intriguing findings of the present study was the poor ability of participants to identify 'fear' sentences. As noted in the literature review, it is not uncommon in emotion categorization studies for 'fear' to be among the more poorly recognized emotions (Scherer, 2001). However, in most cases, 'fear' is still recognized at 
a level above chance. So why, in this study, were 'fearful' sentences poorly perceived? Several reasons may account for this pattern of results: 1) the 'fear' sentences were not produced with sufficient and/or intense enough acoustic cues consistent with typical 'fear' utterances; 2) the 'fear' sentences were not produced as 'fear' per se but as another, perhaps similar emotion or mix of other emotions; 3) the acoustic cues associated with 'fear' in French are different in some way from the acoustic cues associated with 'fear' in English, 4) the use of sentence-length stimuli to convey emotion caused listeners to adopt a different strategy/strategies than when presented with word-length utterances that conveyed emotion; 5) a combination of these reasons or other unknown reasons. Each of these possibilities will be considered in turn.

The possibility that the 'fear' sentences used in the present were not produced with sufficient and/or intense enough acoustic cues consistent with typical 'fear' utterances cannot be ruled out. However, to the extent that the acoustic cues observed in 'fear' utterances used in the present experiment are similar to those observed in previous work would permit this possibility to be discounted. Similarly, the possibility that the 'fear' sentences were not produced as 'fear' per se but as another, perhaps similar emotion or mix of other emotions can be addressed by comparison of the acoustic cues present in the stimuli used in the present work with the acoustic cues observed in previous work (e.g., Scherer, 2001). However, the validity of this approach is mitigated to some degree by ongoing challenges in correlating emotions with specific acoustic cues.

The possibility that the acoustic cues associated with 'fear' in French are different in some way from the acoustic cues associated with 'fear' in English is unlikely given the 
universal quality of acoustic cues for emotion observed in previous work (Scherer, 2001). However, it is possible that the prosodic structure of French sentences, which is different from English sentences (i.e., whereas English is a stress-timed language, French is a syllable-timed language; Pike, 1947), interfered with the ability of English listeners to extract the relevant acoustic cues for 'fear'. This explanation is complicated by the fact that the other emotion categories were perceived relatively accurately compared to 'fear', although it doesn't rule out the possibility that an interaction between French prosody and the poor realization of acoustic cues for 'fear' led to an inability of participants to misidentify fear.

The possibility that the use of sentence-length stimuli to convey emotion caused listeners to adopt a different strategy/strategies than when presented with word-length utterances that conveyed emotion must be considered because it was one of the major differences between the present study and previous work. The rationale for using sentence-length stimuli was to provide listeners with a natural form of utterance, while also allowing for an adequate amount of prosodic information (compared to a single word utterances) to differentiate emotions. This rationale was based on the assumption that given a full length sentence, more prosodic and semantic information would be present than for single word stimuli. While sentence-length stimuli did not result in reduced accuracy for 'happy', 'sad', and 'anger' sentences compared to studies that did not use sentence length stimuli (e.g., Blair et al., 2002; 2005) it lends credence to the idea that it played some role in the poor categorization of 'fear' and 'neutral' sentences in the present study. According to Scherer's (1986) component process model, an individual experiencing 'emotion' is considered instead to be experiencing an 'emotion process', 
referring to a sequence of highly variable and quickly changing 'emotional states'. If this is the case, it could explain why 'fear' was so poorly recognized in the present study. Considering all of the emotions used in this study, 'fear' would theoretically be experienced the fastest. For example, a person, after winning the lottery (a stimulus) could experience a short feeling surprise, followed by a feeling of happiness or euphoria for a full day, or depending on the amount, for several days after. Similarly for sadness, the passing of a loved one (a stimulus) could evoke feelings of shock and surprise, but would most often be quickly followed by a long period of sadness. Fear however, is regularly triggered by a stimulus that is threatening, and therefore theoretically it would take place during the appraisal of a stimulus. In this case, it would be experienced far more briefly because mechanisms such as the 'fight or flight response' (Cannon, 1929) would take over. Because of the brevity of this emotion, it would be reasonable to assume that less vocalization would exist during the time it is experienced, and that those vocalizations would tend to be more abrupt than full length utterances.

In order to support this hypothesis about the possible effect of stimulus length, I will revisit the work of Scherer. In 1994, he proposed the existence of "affect bursts" which are short, emotional nonlinguistic units of sound, or as he described them, "very brief, discrete, nonverbal expressions of affect in both face and voice as triggered by clearly identifiable events" (p. 170). While this subject has been theoretically described in detail, it does not appear to have been tested experimentally, except for one study by Schröder (2003). He systematically explored the properties of affect bursts in German when presented in isolation (i.e, presented as brief auditory events). The emotion used in Schröder's study that was most closely related to 'fear' was 'threat'. In his study, 'threat' 
was among the most poorly recognized emotions. However, after looking at a confusion matrix, it was the only emotion category that was not recognized as the intended emotion. It was more often recognized as 'anger'. Interestingly, the affect burst they chose to represent 'threat' was a growl, which could easily be taken to represent 'anger'.

Additional research could evaluate the perceptual properties of affect bursts, specifically to test its effect on the accuracy of 'fear' recognition. Should affect bursts really be a better affective verbalization of 'fear', one would expect to see higher accuracy for categorization of bursts intended to be fearful than for sentences intended to be fearful.

The final possibility outlined above was that a combination of the above reasons and/or other unknown reasons conspired to reduce the accuracy of the 'fear' sentences. One possibility that could be explored in future work would be to examine the confusion matrix for the intended emotions to determine what emotion each intended emotion was most commonly confused with. This would also permit an examination of the relationship between acoustic cues associated with intended and perceived emotions.

The poor accuracy observe for 'neutral' sentences could simply be due to problems the speakers had in remaining prosodically unbiased while uttering semantically affective sentences. To further explore this possibility, it would be necessary to perform the same acoustic measures on the French sentences that were performed on the English (semantic condition) sentences that were intended to be prosodically 'neutral'. Alternatively, acoustic analysis of the 'neutral' stimuli from the present study 
could be compared with an acoustic analysis of random word strings of approximately the same length in order to completely isolate any effects of semantics.

Overall, while the poor categorization of 'fear' was not expected in light of previous research, it poses an intriguing research question and has important implications for the testing of emotional capabilities of populations who are suspected to have emotional impairments. For example, the fact that fear was so poorly recognized in both prosodic and semantic conditions, indicates that fear is inherently a difficult-to-perceive affect category even for nonpsychopathic individuals. It also suggests that sentencelength 'fear' stimuli may be a challenging emotion to produce in laboratory settings.

Noteworthy also was the finding that 'happy' and 'sad' were the only two emotion categories that were recognized more accurately when presented in the semantic (English) condition than in the prosodic (French condition). This could potentially also be explained by the hypothesis outlined above that different emotion processes require particular types of utterances (e.g. full length stimuli vs. affect bursts). This could also be true for the distinction between semantic and prosodic information. It is possible that the recognition of 'happy' and 'sad' rely more heavily on semantic than prosodic cues.

\subsection{Emotion-Specific Patterns of Acoustic Cues}

Table 5.2.1 is a qualitative summary of the pattern of acoustic cues from the present study as a function of intended emotion and speaker gender. 
Table 5.2.1 Simplified summary of acoustic cues as a function of intended emotion and speaker gender

\begin{tabular}{|c|c|c|c|c|c|c|c|c|c|c|}
\hline \multirow[b]{2}{*}{ Voice cue } & \multicolumn{2}{|c|}{ Happy } & \multicolumn{2}{|l|}{ Sad } & \multicolumn{2}{|c|}{ Angry } & \multicolumn{2}{|l|}{ Fear } & \multicolumn{2}{|c|}{ Neutral } \\
\hline & Male & Female & Male & Female & Male & Female & Male & Female & Male & Female \\
\hline $\mathrm{F} 0(M)$ & High & High & Low & Low & High & High & Mod & High & Mod & Low \\
\hline F0 (SD) & High & High & High & High & High & Mod & High & Low & Mod & Mod \\
\hline $\mathrm{F} 0(\mathrm{~min})$ & Mod & Mod & Low & Low & Mod & Mod & High & High & Low & Mod \\
\hline F0 (max) & High & High & Low & Low & Mod & High & Mod & Mod & Mod & Low \\
\hline F0 Contour & Low & Low & Mod & Mod & Low & Low & High & High & Low & High \\
\hline Jitter & High & Mod & High & High & High & Mod & High & Low & Mod & High \\
\hline VoInt $(M)$ & Mod & Mod & Low & Low & Mod & High & Low & High & Mod & Mod \\
\hline
\end{tabular}

Note: The qualifiers indicate the approximate cue values relative to the other emotions.

An examination of Table 5.2.1 indicates that many of the cue values were similar, if not identical, for the different emotions for both genders. However, when the acoustic cues were compared to the categorization accuracy of the listeners for the corresponding emotion categories (see the correlations in Chapter 4), very few cues were consistently correlated with categorization accuracy. Only $2 / 5$ emotions had acoustic variables that were significantly correlated with categorization accuracy while only $3 / 5$ emotions had acoustic variables that were significant in the regression analysis as a function of categorization accuracy. Moreover, there was little consistency about which cues were correlated. In contrast to categorization accuracy, a larger number of acoustic cues were correlated with response times (RTs). Table 5.2.2 provides a summary of the acoustic cues significantly correlated with categorization accuracy and RTs for each emotion category. Table 5.2.3 provides a summary of the significant acoustic cues from the regression analysis as a function of categorization accuracy and RTs. 
Table 5.2.2

Acoustic cues significantly correlated with emotion categories as a function of categorization accuracy and reaction times

\begin{tabular}{lll}
\hline Emotion & Categorization Accuracy & Reaction Times \\
\hline Happy & VoInt & VoInt \\
Sad & F0(max $)$ & F0(max $)$ \\
Angry & None & None \\
Fear & None & None \\
Neutral & None & None
\end{tabular}

Table 5.2.3

Acoustic cues found to be significant in the regression analysis as a function of categorization accuracy and reaction times

\begin{tabular}{lll}
\hline Emotion & Categorization Accuracy & Reaction Times \\
\hline Happy & F0 $(M)$, Jitter & VOInt \\
Sad & F0 (max $)$ & F0 $(M)$, FO (max) and VoInt \\
Angry & None & F0 $(M)$, F0 (max) and Jitter \\
Fear & FO $(M)$, F0 (min) and VoInt & None \\
Neutral & None & None
\end{tabular}

Examining Table 5.5.3, indicates that $\mathrm{F} 0(M), \mathrm{F} 0(\max )$ and VoInt could be predictors of reaction times. Interestingly, for categorization accuracy, $\mathrm{F} 0(M), \mathrm{F} 0(\max )$ and $\mathrm{VoInt}$ were also possible predictors.

\subsection{Comparison With Scherer's Descriptions}

In order to put the results for acoustic cues and categorization performance from this study into context, it is necessary to compare these results with previous work. In this section I compare the results of the present study to Scherer's description (Pittam \& 
Scherer, 1993) of acoustic cues correlated with the emotions (limiting my comparison to emotions evaluated in to the present study).

Happy/Joy. According to Pittam and Scherer, previous findings converged to link 'happy'/'joy' to increases in F0(M), F0 range (SD), F0 variability (jitter) and VoInt. In the present study, all cues (F0 (M), jitter, and VoInt), with the exception of F0 range (SD), were consistent with Pittam and Scherer's description.

Sadness. In Pittam and Scherer's description, F0 range (SD), VoInt, and F0 contour were linked to 'sad'. The results of the present study yielded a different pattern of acoustic cues, with the exception of VoInt.

Anger. Pittam and Scherer linked F0 $(M)$, jitter, and VoInt to 'anger'. In the present study the same cues were also linked to 'anger', with the exception of jitter. In addition, F0(max) was also linked to 'anger' in the present study.

Fear. According to Pittam and Scherer, considerable agreement exists that links $\mathrm{F} 0(M)$ and F0 range (SD) to 'fear'. In the present study, however, only F0 $(M)$ was linked to 'fear'. In addition, $\mathrm{F} 0(\mathrm{~min})$ and VoInt were linked to 'fear' in the present study. It is possible that the difference in acoustic cues linked to 'fear' observed in the present study versus previous work could be due to the poor categorization accuracy of the listeners in the present experiment. Also, as discussed above, it is possible that the speakers did not accurately portray 'fear' when they produced the 'fear' sentences.

Neutral. Neutral is considered a lack of emotion and therefore was not included in Scherer and Pittam's study. Consistent with the view that 'neutral' sentences, by definition, should not exhibit any links between acoustic cues and emotion 
categorization, no acoustic cues for neutral sentences were found to be significantly correlated to either categorization or reaction time performance in the present study.

Overall, the associations between acoustic cues and the emotions evaluated in the present study were similar to Pittam and Scherer's description of common acoustic cues associated with different emotions. These acoustic cues, however, tend to be generic and do little to define a true acoustic pattern that one could use to differentiate emotions based solely on their acoustic pattern. More work could be done to better define the acoustic cues used in the present study that were not found to be significant. For example, a better method for measuring the shape of the F0 contour could be developed than the contour index used in this study. It is possible that contour shape does have a significant effect on categorization accuracy, but that the current method for measuring contour did not capture this relation. Nonetheless, the present study indicates that measures of F0 including $(M)$, (max), and variability (jitter), as well as voice intensity (VoInt) do appear to have a bearing on emotion 'signatures'

\subsection{Limitations and Considerations for Further Study}

\subsubsection{Stimuli.}

One issue that commonly arises in the emotion literature is the appropriate method for generating stimuli. In the present study, an attempt was made to keep the stimuli as natural as possible by not placing limitations on aspects such as sentence length or initial phonemes. There is considerable disagreement in the literature about what type of stimuli best simulates the most natural outcomes, while at the same time allowing for control over variables. In the present study it was assumed that that using a more natural 
type of utterance would result in cues similar to the cues found in naturally occurring

utterances. However, the use of portrayals has recently been criticized (e.g. Bachorowski \& Owren, 1995; Kappas \& Hess, 1995). It has been argued that actors may create stereotypical portrayals and that certain voice cues such as jitter (F0 variability) may not be under voluntary control. However, if one were to induce emotion to create stimuli, there are a whole new set of complications such as ethical restrictions, and producing 'emotional-enough' stimuli. This debate has been considered and discussed more thoroughly in Chapter 2. In light of this debate, I argue that in order to make reliable assumptions about emotion research, much more work needs to be done in order to systematize methodologies. More focus needs to be placed on testing differences between studies which use different types of stimuli, and, more specifically, which types of stimuli produce replicable results. Furthermore, comparing results of studies such as the present study becomes much more difficult when many different methodologies are employed. A consensus among researchers must be reached if we are to further our knowledge of emotion.

\subsubsection{Acoustic Measures Included}

It would be advantageous to include more acoustic variables in an exploratory study such as this one. Specifically, more cues relating to voice quality could be incorporated in this type of investigation. Work by Scherer $(1996 ; 1986)$ has indicated that voice quality cues may be good predictors of specific emotions. It is clear that cues relating to F0 are central to specific emotions; however $\mathrm{F} 0$ is too broad a variable to be able to differentiate one emotion from another. Although time restraints dictated to a certain point how many cues could be analyzed in the present study, the measurement of 
more complex cues (i.e. voice quality), plus alternatives to some of the cues used in the present study (e.g., cues relating to contour, such as the contour index) could be expanded and more rigorously tested. Perhaps using more graphic representations of F0 contour rather than numerical representations may provide additional insight into how it is used by listeners and speakers.

\subsubsection{For Work Associated with Psychopathy}

It is important that before researchers begin making any assumptions about emotional impairments that reliable baselines for non clinical populations be established. Thus far, although researchers know individuals are capable of recognizing (most) intended emotions better than chance, relatively little is know about what underlies the accurate perception of emotions, and researchers still have yet to converge on accuracy findings for specific emotions (i.e. fear). In order to make assumptions about populations such as psychopaths, a more reliable and solid understanding of nonpsychopathic individuals is necessary. I would like to propose that one step towards achieving this goal is to continue Scherer (1994) and Schröder's (2003) work on affect bursts and how they relate to emotion recognition. Before describing emotion specific patterns of acoustic cues, it is first important to establish whether there are particular types of utterances that are most appropriate for facilitating specific emotion recognition.

In conclusion, the present study extends the range of knowledge about the perception of affect in spoken language and provides more directions for research in the area. It has moved beyond the one-word stimuli used in previous research (e.g. Blair et al., 2002; 2005) to more complex and perhaps more natural stimuli. A major finding of 
the study is that fear appears to be a particularly difficult affect category to perceive not only for psychopaths but also for nonpsychopaths; a finding that has implications for further research relating to psychopaths. As such, the results of the present study contribute to the establishment of a baseline for a typically functioning population. 


\section{References}

Adolphs, R., Tranel, D., Damasio, H., Damasio A. (1994). Impaired recognition of emotion in facial expressions following bilateral damage to the human amygdala. Nature, 372, 669-672.

Adolphs, R., Tranel, D., Hamann, S., Young, A., Calder, A., Phelps, E. et al. (1999). Recognition of facial emotion in nine individuals with bilateral amygdala damage. Neuropsychologia 37, 1111-1117.

Arndt, H., Janney, R.W. (1991). Verbal, prosodic, and kinesic emotive contrasts in speech. Journal of Pragmatics, 15, 521-549.

Ariatti, A. Benuzzi, F. \& Nichelli, P. (2008). Recognition of emotions from visual and prosodic cues in Parkinson's disease. Neurological Sciences, 29, 219-227.

Bachorowski, J. (1999). Vocal expression and perception of emotion. Current Directions in Psychological Science, 8, 53-57.

Bachorowski, J., Owren, M.J. (1995). Vocal expression of emotion: Acoustical properties of speech are associated with emotional intensity and context. Psychological Science, 6, 219-224.

Bagley, D.A., Kosson, D.S., Abramowitz, C.S. (2009). Vocal affect recognition and psychopathy: Converging findings across traditional and cluster analytic approaches to assessing the construct. Journal of Abnormal Psychology, 118(2), 388-398.

Banse, R., Scherer, K.R. (1996). Acoustic profiles in vocal emotion expression. Journal of Personality and Social Psychology, 70, 614-636.

Beatty, W. W., Goodkin, D. E., Weir, W. S., \& Staton, R. D. (1989). Affective judgments by patients with Parkinson's disease or chronic progressive multiple sclerosis. Bulletin of the Psychonomic Society, 27, 361-364.

Blair, R., Jones, L., Clark, F., Smith, M. (1997). The psychopathic individual: A lack of responsiveness to distress cues? Psychophysiology, 34, 192-198. 
Blair, R. (1999b). Responsiveness to distress cues in the child with psychopathic tendencies. Personality and Individual Differences, 27, 135-145.

Blair, R., Colledge, E., Mitchell, D.G. (2001a). Somatic markers and response reversal: Is there orbitofrontal cortex dysfunction in boys with psychopathic tendencies? Journal of Abnormal Child Psychology, 29, 491-498.

Blair, R., Mitchell, D., Richell, R., Kelly, S., Leonard, A., Newman, C., Scott, S.K. (2002). Turning a dear ear to fear: impaired recognition of vocal affect in psychopathic individuals. Journal of Abnormal Psychology, 111(4), 682-686.

Blair, J., Mitchell, D., Blair, K. (2005). The psychopath: Emotion and the brain. London: Blackwell Publishing Professional.

Blonder, L., Gur, R., \& Gur, R. (1989). The effects of right and left hemiparkinsonism on prosody. Brain and Language, 36, 193- 207.

Borod, J. (2000). The neuropsychology of emotion. New York: Oxford University Press.

Burkhardt, F., Audibert, N., Malatesta, L., Turk, O., Arslan, L., \& Auberge, V. (2006).

Emotional prosody - does culture make a difference? Proceedings of Speech Prosody 2006, Dresden, Germany

Caffi, C., \& Janney, R. (1994). Toward a pragmatics of emotive communication. Journal of Pragmatics, 22, 325-373.

Cannon, W. (1929). Bodily changes in pain, hunger, fear, and rage. New York: Appleton.

Cleckley, H. (1941). The mask of sanity (4th ed.). St. Louis: MO: Mosby.

Cleckley, H.M. (1976). The mask of sanity (5th ed.). St. Louis: MO: Mosby.

Cohen J., MacWhinney B., Flatt M., \& Provost J. (1993). PsyScope: A new graphic interactive environment for designing psychology experiments. Behavioral Research Methods, Instruments, and Computers, 25, 257-271. 
Cosmides, L. (1983). Invariances in the acoustic expression of emotion during speech. Journal of Experimental Psychology: Human Perception \& Performance, 9, 864-881.

Darwin, C. (1872/1965). The expression of the emotions in man and animals. London: John Murray.

Davitz, J. (1964). The communication of emotional meaning. New York: McGraw-Hill

Davitz, J., \& Davitz, L. (1959). The communication of feelings by content-free speech. The Journal of Communication, 9, 6-13.

Dougherty, F., Bartlett, E., \& Izard, C. (1974). Response of schizophrenics to expressions of the fundamental emotions. Journal of Clinical Psychology, 30, 243-246.

Dromey, C., Silveira, J., \& Sandor, P. (2005). Recognition of affective prosody by speakers of English as a first or foreign language. Speech Communication, 47, 351-359.

Edwards, J., Pattison, P.E., Jackson, H.J. et al. (2001). Facials affect and affective prosody recognition in first episode schizophrenia. Schizophrenia Research, 48, 235-253.

Eisenberg, N., Fabes, R., Guthrie, I., Murphy, B., Maszk, P., Holmgren, R., \& Suh, K. (1996). The relations of regulation and emotionality to problem behaviour in elementary school children. Development and Psychopathology, 8, 141-162.

Ekman, P. (1973). Darwin and facial expression. New York: Academic Press.

Ekman, P. (1992). An argument for basic emotions. Cognition \& Emotion, 6, 169-200.

Ekman,P. (1994). Strong evidence for universals in facial expressions: A reply to Russell's mistaken critique. Psychological Bulletin, 115, 268-287.

Eysenck, H. (1964). Crime and personality. London: Routledge \& Kegan Paul. 
Fisher, L., \& Blair, R. (1998). Cognitive impairment and its relationship to psychopathic tendencies in children with emotional and behavioural difficulties. Journal of Abnormal Child Psychology, 26, 511-519.

Flor, H., Birbaumer, N., Hermann, C., Ziegler, S., \& Patrick, C. (2002). Aversive Pavlovian conditioning in psychopaths: Peripheral and central correlates. Psychophysiology, 39, 505-518.

Fonagy, I., \& Magdics, K. (1963). Emotional patterns in intonation and music. Zeitschrift fur Phonetik, 16, 293-326.

Frick, R. (1985). Communicating emotion: The role of prosodic features. Psychological Bulletin, 97, 412-429.

Graves, R., Landis, T., \& Goodglass, H. (1981). Laterality and sex differences for visual recognition of emotional and non-emotional words. Neuropsychologia, 19, 95102.

Gray, J. (1987). The psychology of fear and stress (2nd ed.). Cambridge: Cambridge University Press.

Hare, R. (1996). Psychopathy: A clinical construct whose time has come. Criminal Justice and Behavior, 23, 25-54.

Hare, R.D., Quinn, M.J. (1971). Psychopathy and autonomic conditioning. Journal of Abnormal Psychology, 77, 223-235.

Hare, R.D., Williamson, S.E., \& Harpur, T.J. (1988b). Psychopathy and language. In T.E. Moffit, A.M. Sarnoff (Eds.), Biological Contributions to Crime Causation, NATO Advanced Science Series D: Behavior and Social Sciences (pp. 68-92). Dordrechtl: Martinus Nishoff.

Johnstone, T., \& Scherer, K. (2000). Vocal communication of emotion. In M. Lewis \& J. Haviland-Jones (Eds.), Handbook of emotions (pp. 220-235). New York: Guilford Press. 
Juslin, P., \& Laukka, P. (2001). Impact of intended emotion intensity on cue utilization and decoding accuracy in vocal expression of emotion. Emotion, 1, 381-412.

Kaiser, L. (1962). Communication of affects by single vowels. Synthese. 14, 300-319.

Kappas, A., \& Hess, U. (1995). Nonverbal aspects of oral communication. In U.M. Quasthoff (Ed.), Aspects of oral communication (pp. 169-180). Berlin: DeGruyter.

Kerr, S., \& Neale, J. (1993). Emotion perception in schizophrenia: specific deficit or further evidence of generalized poor performance? Journal of Abnormal Psychology, 102, 312-318.

Kiehl, K., Hare, R., McDonald, J., \& Brink, J. (1999a). Semantic and affective processing in psychopahts: An event-related potential (ERP) study. Psychopysiology, 36, $765-774$.

Kucharska-Pietura, K., Phillips, M., Gernand, W. et al. (2003). Perception of emotions from faces and voices following unilateral brain damage. Neuropsychologica, $41,1082-1090$.

Levenson, M., Kiehl, K., \& Fitzpatrick, C. (1995). Assessing psychopathic attributes 128 in a noninstitutionalized population. Journal of Personality and Social Psychology, 68, 151-151.

Levenston, G., Patrick, C., Bradley, M., \& Lang, P.J. (2000). The psychopath as observer: Emotion and attention in picture processing. Journal of Abnormal Psychology, 109, 373-386.

Lilienfeld, S.O., \& Andrews, B.P. (1996). Development and preliminary validation of a self-report measure of psychopathic personality traits in noncriminal populations. Journal of Personality Assessment, 66, 488- 524. 
Lorenz, A., \& Newman, J. (2002). Deficient response modulation and emotion processing in low-anxious caucasian psychopathic offenders: results from a lexical decision task. Emotion, 2, 91-104.

Lykken, D. (1957). A study of anxiety in the sociopathic personality. Journal of Abnormal and Social Psychology, 55, 6-10.

Lyyken, D.T. (1995). The antisocial personalities. Hillsdale, NJ: Lawrence Eribaum. Marty, A. (1908). Untersuchungen zur allgemeinen Grundlegung der Grammatik und Sprachphilosophie [Investigations on the general foundations of grammar and the philosophy of language]. Halle/Saale, Germany: Niemeyer.

Miller, M., Hanford, R., Fassbender, C., Duke, M., \& Schweitzer, J. (2010). Affect recognition in adults with ADHD. Journal of Attention Disorders. PMID: 20555036. (only e-print version available 13/9/10)

Murray, I., \& Arnott, J. (1993). Toward the simulation of emotion in synthetic speech: A review of the literature on human vocal emotion. Journal of the Acoustical Society of America, 93, 1097-1108.

Nathanson, C., Paulhus, D., \& Williams, K. (2006). Personality and misconduct correlates of body modification and other cultural deviance markers. Journal of Research in Personality, 40, 779-802.

Newman, J., \& Kosson, D. (1986). Passive avoidance learning in psychopathic and nonpsychopathic offenders. Journal of Abnormal Psychology, 95, 252-256.

Newman, J., Patterson, C., \& Kosson, D. (1987). Response perseveration in psychopaths. Journal of Abnormal Psychology, 96, 145-148.

Newman, J., \& Schmitt, W. (1998). Passive avoidance in psychopathic offenders: A replication and extension. Journal of Abnormal Psychology, 107, 526-532. 
Newman, J., Schmitt, W., \& Voss, W. (1997). The impact of motivationally neutral cues on psychopathic individuals: assessing the generality of the response modulation hypothesis. Journal of Abnormal Psychology, 106, 563-575.

Newman, J., Widom, C., \& Nathan, S. (1985). Passive avoidance in syndromes of disinhibition: Psychopathy and extraversion. Journal of Personality and Social Psychology, 48, 1316-1327.

O’Brien, B., \& Frick, P. (1996). Reward dominance: associations with anxiety, conduct problems, and psychopathy in children. Journal of Abnormal Child Psychology, $24,223-240$.

Patrick, C. (1994). Emotion and psychopathy: Startling new insights. Psychophysiology, 40, 934-938.

Patrick, C., Cuthbert B., \& Lang, P. (1994). Emotion in the criminal psychopath: Startle reflex modulation. Journal of Abnormal Psychology, 102, 82-92.

Perry, D., \& Perry, L. (1974). Denial of suffering in the victim as a stimulus to violence in aggressive boys. Child Development, 45, 55-62.

Pell, M., Paulmann, Dara, C., Alasseri, A., Kotz, S.A. (Factors in the recognition of vocally expressed emotions: A comparison of four languages. Journal of Phonetics, 37(4), 417-435.

Pell, M. , \& Skorup, V. (2008). Implicit processing of emotional prosody in a foreign versus native language. Speech Communication, 50, 519-530.

Pfaff, P. (1958). An experimental study of communication of feeling without contextual material. Speech Monographs, 21, 155-156.

Pike, K. (1947). Grammatical prerequisites to phonemic analysis. Word, 3, 155-72.

Pittam, J., \& Scherer, K. (1993). Vocal expression and communication of emotion. In M. Lewis \& J. Haviland (Eds.), Handbook of emotions (pp. 185-198). New York: Guilford Press. 
Scherer, K. (1984). On the nature and function of emotion: A component process approach. In K. Scherer \& P. Ekman (Eds.), Approaches to emotion (pp. 293318). Cambridge, England: Cambridge University Press.

Scherer, K. (1986). Vocal affect expression: A review and a model for future research. Psychological Bulletin, 99, 143-165.

Scherer, K. (1999b). On the sequential nature of appraisal processes: Indirect evidence from a recognition task. Cognition and Emotion, 13, 763-793.

Scherer, K. (2001a). Appraisal considered as a process of multi-level sequential checking. In K. Scherer, A. Schorr, \& T. Johnstone (Eds.), Appraisal processes in emotion: Theory, methods, research (pp. 92-120). New York: Oxford University Press.

Scherer, K. (2001b). The nature and study of appraisal: A review of the issues. In K. Scherer, A. Schorr, \& T. Johnstone (Eds.), Appraisal processes in emotion: Theory, methods, research (pp. 369-391). New York: Oxford University Press.

Scherer, K. (2003). Vocal communication of emotion: A review of research paradigms. Speech Communication, 40, 227-256.

Scherer, K., Banse, R., \& Wallbott, H. (2001). Emotion inferences from vocal expression correlate across languages and cultures. Journal of Cross-Cultural Psychology, 32, 76-92. DOI: 10.1177/0022022101032001009.

Scherer, K., Banse, R., Wallbott, H., \& Goldbeck, T. (1991). Vocal cues in emotion encoding and decoding. Motivation \& Emotion, 15, 123-148.

Scherer, K., \& Giles, H. (1979). Social markers in speech. Cambridge: Cambridge University Press.

Schröder, M. (2003). Experimental study of affect bursts. Speech Communication, 40, $99-116$. 
Scott, S., Young, A., Calder, A., Hellawell, D., Aggleton, J., \& Johnson, M.(1997). Impaired auditory recognition of fear and anger following bilateral amygdala lesions. Nature, 385, 254-257.

Silver, H., Shlomo, N., Turner, T. et al. (2002). Perception of happy and sad facial expressions in chronic schizophrenia: evidence for two evaluative systems. Schizophrenia Research, 55, 171-177.

Standke, R. (1992). Methods of digital speech analysis in research on vocal communication. Frankfurt: Peter Lang.

Strauss, E. (1983). Perception of emotional words. Neuropsychologia, 21, 99-103.

Thornquist, M., \& Zuckerman, M. (1995). Psychopathy, passive avoidance learning and basic dimensions of personality. Personality and Individual Differences, 19, 525-534.

Trasler, G. (1973). Criminal behaviour. In H. Eysenck (Ed.), Handbook of Abnormal Psychology. London: Pitman.

van Bezooijen, R. (1984). Characteristics and recognizability of vocal expressions of emotion. Dordrecht, the Netherlands: ICG Printing.

Wambacq, I., \& Jerger, J. (2004). Processing of affective prosody and lexical-semantics in spoken utterances as differentiated by event-related potentials. Cognitive Brain Research, 20, 427-437.

Williams, K., \& Paulhus, D.L. (2004). Factor structure of the Self-Report Psychopathy scale (SRP-II) in non-forensic samples. Personality and Individual Differences, $33,1520-1530$

Williams, C., \& Stevens, K. (1972). Emotions and speech: Some acoustical correlates. Journal of the Acoustical Society of America, 52, 1238-1250.

Williamson, S., Harpur, T., Hare, R. (1991). Abnormal processing of affective words by psychopaths. Psychophysiology, 28, 260-273. 
Wurm, L., Vakoch, D., Strasser, M., Calin-Jageman, R., Ross, S. (2001). Speech perception and vocal expression of emotion. Cognition and Emotion, 15, 831852. 


\section{Appendix A}

\section{Sentence-Length Stimuli Used in the Present Study}

\section{English}

All my wishes came true that day.

Looks like my luck is improving.

My boss is out of town for a whole week; no one to breathe down my neck.

After breakfast, | strolled down the beach.

At the party, all my favorite people were there.

I was pulled over by the police officer, but he decided not to give me a ticket.

The sunshine is warming my face.

I beamed at my newborn son.

This is the best sandwich l've ever had.

There were coffee and donuts by the bed when I woke up.

How relaxing that feels.

He told my supervisor I did a wonderful job.

Everything seems to be going my way today.

Now that my work is done, I can finally put up my feet.

I could not have asked for anything more.

I just lay there and watched the tall grass waving under the blue sky.

The group loved my ideas.

\section{French}

Tous mes rêves se sont réalisés aujourd'hui.

J'avais l'impression que ma chance augmentait.

Mon patron est en voyage pour une semaine; quand le chat n'est pas là les souris dansent.

Aprés le petit déjeuner, je me suis promené Happiness sur la plage.

A la fête, tous mes gens préferés étais là. Happiness

Je me suis fair arrêté par un policier, mais il Happiness ne m'a pas donné une contravention.

Le soleil me chauffe le visage.

J'ai été fasciné par mon nouveau-né.

C'est le meilleure sandwich que j'ai jamais manger.

Ils y avait du café et des beignes à côté du lit quand je me suis réveiller.

Comme c'est relaxant.

II a dit à mon chef que j'ai fais un très bon travaille.

Tout va comme je l'aurais voulu aujourd'hui.

Maintenant que j'ai fini mon travaille, je peux finalement me reposer.

Je n'aurais pas pu demander mieux.

Je suis resté allongé à regarder l'herbe haute se balancer sous le ciel bleu.

L'équipe a adoré mes idées.
Happiness

Happiness

\section{Emotion}

Happiness

Happiness

Happiness

Happiness

Happiness

Happiness

Happiness

Happiness

Happiness

Happiness

Happiness

Happiness 
Everyone I care about is in this room.

The house seemed empty without her.

My heart felt heavy as they announced the verdict.

It was a gloomy and cold day in mid-winter and I sat alone.

This is the third anniversary of my wife's death.

I'm just watching the hopeless faces of the hungry children on the t.v.

I closed the door of my house for the last time.

Everyone forgot my birthday so I spent the night alone.

My son left this morning to got to Africa for a year.

I had no money to buy Christmas gifts.

I found out that my daughter has cancer.

Everyone I love is far away.

Just before he died, he wagged his tail as if he was saying goodbye.

I don't think I'll be able to get it right.

I guess I expected more.

Everything I had, I lost in that fire.

Without this job my life has no meaning.

Tears welled in my eyes as I watched him board the plane.

I rolled slowly past the homeless man in my car and wished I had
Toutes les personnes que j'aime sont dans cette pièce.

La maison avait l'air vide sans elle.

Sadness

J'avais le coeur lourd quand on a annoncè le verdict.

C'étais une journée sombre et froide au milieu de l'hiver et j'étais asis(e) tout(e) seul(e).

C'étais le troisième anniversaire du décès de ma femme.

J'ai vu les visages désespérés des enfants affamés à la télé.

J'ai refermé la porte de ma maison pour la dernière fois.

Tout le monde à oublier mon anniversaire, donc j'ai passé la soirée seul.

Mon fils est parti ce matin pour passer une annèe en Afrique.

Je n'avais pas d'argent pour acheter des cadeaux de Noël.

$\mathrm{J}$ 'ai appris que ma fille a le cancer.

Sadness

Sadness

Sadness

Sadness

Sadness

Sadness

Sadness

Sadness

Sadness

Tout ceux que j'aime sont très loin.

Sadness

Juste avant de mourir, il remuait sa queue comme pour dire au revoir.

Je ne pense pas qu j'arriverais à le faire juste.

Sadness

Je m'attendais à plus.

Sadness

J'ai perdu tous ce que j'avais dans cet incendie.

Sadness

Sans cet emploi me vie ne vaut rien.

Sadness

J'avais les larmes aux yeux en le regardant monter à bord de l'avion.

Je roulais lentement près du clochard en souhaitant de pouvoir lui donner de
Sadness

Sadness 
some money to give him.

I'll never have a chance to find out.

I clenched my fists just thinking of what he had said to me.

The blood rushed to my head when I saw them together.

After I waited two weeks for it to arrive, it was all scratched up.

And you call yourself a professional.

This reckless driver splashed me while I was walking down the sidewalk.

He told me I had to work late again at the last minute and I had to cancel my date.

After I let my friend stay at my apartment for the whole summer, I noticed that it was a complete mess and he hadn't paid any of the bills.

Every time we had a meeting set up, she made me wait for at least an hour.

The officer was disrespecting me and treating me like an idiot.

Get out of the left lane!

I just wanted to give him a taste of his own medicine.

My face burned when I heard that he had lied to me.

He just smashed my new car.

Will he ever stop whistling?

Use your signal when you're switching lanes!

He knew I was there and he just made me wait.

If I never see you again, it will be too soon. l'argent.

Je crois que je ne saurais jamais.

Sadness

J'ai serré les poings en pensant à ce qu'il m'avait dit.

Anger

Quand je les ai vu ensemble, le sang m'est monté à la tête.

Après avoir attendu deux semaines pour son arrivée, il était tout cassé.

Anger

Anger

Ce conducteur irresponsable m'a éclaboussé pendant que je marchais sur le trottoir.

II m'a dit à la dernière minute que je devais travailler tard et j'ai du annuler mon rendezvous.

Après que j'ai permis à mon ami de rester dans mon appartement pendant tout l'été, j'ai remarqué qu'il était en désordre et qu'il n'avait pas payé aucune des factures.

Chaque fois que nous avions une réunion, elle me faisait attendre une heure.

Anger

L'officier était impoli et m'a traité comme

Anger un idiot.

Sors de la voie gauche!

Anger

J'ai juste voulu lui faire goûter à sa propre médecine.

Anger

Le visage me brûlait après avoir entendu qu Anger 'il m'a menti.

Il vient de démolir ma nouvelle voiture. Anger

V'a t'il arrête de siffler? Anger

Utilise ton clignotant quand tu changes de Anger voie!

Il savait qu j'étais-là et il m'a fait attendre. Anger

Je ne te verrais jamais plus.

Anger 
You can't tell me what to do.

I trembled and shook when she told me that I had been cheated.

What you deserve is to rot in hell for this.

I heard someone's footsteps behindme.

I hope they don't find me here.

The dog snarled and lunged at me.

The brakes aren't working and I'm slipping into the other lane.

The plane rattled and shook.

I thought about what would happen if nobody came to look for me.

I crouched in the corner, shivering.

The alley was dark and foreboding.

It was getting harder to breathe, and I knew time was running out.

A pair of yellow eyes stared at me from the darknes.

The drunk driver was coming straight at us.

The flames were drawing near.

I jolted out of bed when I heard the scream.

My hands trembled and I could feel myself breaking into a cold sweat.

The boat was filling with water faster than we could pump it out.

He could not see the wound, but he felt the warm blood running down his leg.

He did not dare look back as he ran.
Tu ne peux pas me dire ce que je dois faire. Anger

J'ai tremblé quan elle m'a dit que j'ai été Anger trompé.

Tu mérites de pourrir en enfer.

Anger

J'ai entendu les pieds de pas de quelqu'un Fear derrière moi.

J'espère qu'ils ne me trouvent pas ici. Fear

Le chien a crogné et nous attaque. Fear

Les friens ne fonctionnent pas et je suis Fear entrain de rentrer dans l'autre voie.

L'avion a vibré et tremblé Fear

J'ai pensé à ce que pourrais arriver si Fear personne ne venaitk me trouver.

Je me suis accroupis dans le coin en Fear tremblant.

L'allée était sombre et imprévisible. Fear

J'avais de la peine à respirer et je savais Fear que le temps presse.

Des yeux jaunes me fixaient dans le noir. Fear

Le conducteur ivre venait tout droit contre Fear nous.

Les flames s'approchaient. Fear

J'ai sauté du lit quand j'ai entendu le cris. Fear

Mes mains tremblaient et je sentais une Fear sueur froide.

Le bâteau se remplissait d'eai plus vite que Fear nous ne pouvions le vider.

II ne pouvait pas voir la blessure, maid il

Fear sentait le sang chaud couler le long de sa jambe.

II n'osait pas regarder en arrière en courant. Fear 
I hit the brakes but knew there was not enough time to avoid the tree.

I made a list and went off to the store.

I'm turning on the kitchen light and making some toast.

While stopped at the light, I noticed the pedestrian.

I went to find my shoes in the closet.

I left home at eight o'clock in the morning.

I bought my car three years ago.

I did a load of laundry while I waited for the water to boil.

Do you know the time?

My coffee table is brown.

I signed my name on the bottom of the form.

I packed my clothes for the trip.

It's time to fill the bird feeder.

The squirrels chased one another up the tree.

She selected blue furnishings for her home.

Hello again.

As I walked down the street, I looked at the houses.

We put the green ones in this basket.

This is your brother's old toaster.
J'ai freiné sec, sachant que je n'avais pas le temps d'éviter l'arbre.

J'ai fais ma liste et je suis allé au magazine. Neutral

Je suis entrain d'allumer la lumière dans la cuisine et faire du toast.

Pendant que j'étais arrêté au feu rouge, j'ai Neutral remarque le pétition.

Je suis allé chercher mes chaussures dans Neutral le placard.

J'ai quitté la maison à huit heures du matin. Neutral

J'ai acheté ma voiture il y a trois ans.

Neutral

Ja'i fait ma lessive en attendant que l'eau bouille.

Neutral

As-tu l'heure?

Neutral

Ma table basse est brune.

Neutral

J'ai signé mon nom au bas de la page.

Neutral

J'ai emballé mes vêtements pour le voyage, Neutral

Il est temps de nourrir les oiseaux,

Neutral

Les écureils se chassaient l'un après l'autre Neutral dans l'arbre.

Elle a choisi des meubles bleus pour sa Neutral maison.

Salut.

Neutral

En marchant dans la rue j'ai regardé aux Neutral maisons.

Nous avons mis les verts dans le panier. Neutral

C'est l'ancien toaster de ton frère.

Neutral 


\section{Appendix B}

\section{SRP III - R12}

Please rate the degree to which you agree with the following statements about you. You can be honest because your name will be detached from the answers as soon as they are submitted.

\begin{tabular}{|c|c|c|c|c|}
\hline 1 & 2 & 3 & 4 & 5 \\
\hline $\begin{array}{l}\text { Disagree } \\
\text { Strongly }\end{array}$ & Disagree & Neutral & Agree & $\begin{array}{c}\text { Disagree } \\
\text { Strongly }\end{array}$ \\
\hline
\end{tabular}

1. I'm a rebellious person.

2. I'm more tough-minded than other people.

3. I think I could "beat" a lie detector.

4. I have taken illegal drugs (e.g., marijuana, ecstasy).

5. I have never been involved in delinquent gang activity.

6. I have never stolen a truck, car or motorcycle.

7. Most people are wimps.

8. I purposely flatter people to get them on my side.

9. I've often done something dangerous just for the thrill of it.

10. I have tricked someone into giving me money.

11. It tortures me to see an injured animal.

12. I have assaulted a law enforcement official or social worker.

13. I have pretended to be someone else in order to get something. 
14. I always plan out my weekly activities.

15. I like to see fist-fights.

16. I'm not tricky or sly.

17. I'd be good at a dangerous job because I make fast decisions.

18. I have never tried to force someone to have sex.

19. My friends would say that I am a warm person.

20. I would get a kick out of 'scamming' someone.

21. I have never attacked someone with the idea of injuring them.

22. I never miss appointments.

23. I avoid horror movies.

24. I trust other people to be honest.

25. I hate high speed driving.

26. I feel so sorry when I see a homeless person.

27. It's fun to see how far you can push people before they get upset.

28. I enjoy doing wild things.

29. I have broken into a building or vehicle in order to steal something or vandalize.

30. I don't bother to keep in touch with my family any more.

31. I find it difficult to manipulate people.

32. I rarely follow the rules.

33. I never cry at movies.

34. I have never been arrested. 
35. You should take advantage of other people before they do it to you.

36. I don't enjoy gambling for real money.

37. People sometimes say that I'm cold-hearted.

38. People can usually tell if I am lying.

39. I like to have sex with people I barely know.

40. I love violent sports and movies.

41. Sometimes you have to pretend you like people to get something out of them.

42. I am an impulsive person.

43. I have taken hard drugs (e.g., heroin, cocaine).

44. I'm a soft-hearted person.

45. I can talk people into anything.

46. I never shoplifted from a store.

47. I don't enjoy taking risks.

48. People are too sensitive when I tell them the truth about themselves.

49. I was convicted of a serious crime.

50. Most people tell lies everyday.

51. I keep getting in trouble for the same things over and over.

52. Every now and then I carry a weapon (knife or gun) for protection.

53. People cry way too much at funerals.

54. You can get what you want by telling people what they want to hear.

55. I easily get bored. 
56. I never feel guilty over hurting others.

57. I have threatened people into giving me money, clothes, or makeup.

58. A lot of people are "suckers" and can easily be fooled.

59. I admit that I often "mouth off" without thinking.

60. I sometimes dump friends that I don't need any more.

61. I would never step on others to get what I want.

62. I have close friends who served time in prison.

63. I purposely tried to hit someone with the vehicle I was driving.

64. I have violated my probation from prison. 


\section{Appendix C}

Language Experience Questionnaire

\section{Language Experience Questionnaire}

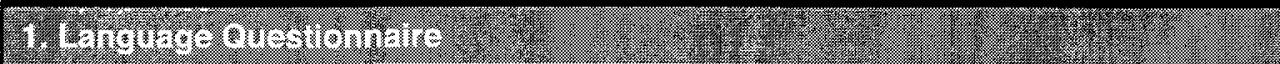

The following questionnaire is designed to evaluate your knowledge of the French language. Please remember that all data is coded for confidentiality, i.e. your name will NOT appear on the data files collected.

1. Number:

\section{2. $=1+4$}

The questions in Part 1 relate to your demographic information and brief medical history

1. Age:

2. Gender
1 Male
Tremale

3. Current degree major (e.g. BA in Psychology, BSc in Physics):

?.

4. Year in program (e.g. 1st, 3rd, 5th)

L

5. What is your first language? (i.e. the first language you began speaking as an infant) [C. - - - - -

6. What language do you use to communicate in for the majority of time? (If you use two or more equally, please specify.)

(n......

7. Have you ever had a head injury (e.g. concussion)
$\Gamma$ Yes
$\Gamma$ No

8. If you answered 'YES' to question 5, how severe was the head injury

$\begin{array}{cccccc} & 1 \text { (Mild) } & 2 & 3 \text { (Moderate) } & 4 & 5 \text { (Severe) } \\ \text { Severity } & r & r & r & r & r\end{array}$


Language Experience Questionnaire

9. Have you ever had a seizure?

$r$ No

$r$ Yes

If yes, how often do you have seizures? ( 1 e \# per week, per year)

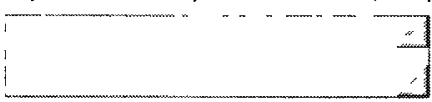

10. Have you ever had a hearing, reading or speech disorder?

$r$ No

r Yes

If yes, please specity

$+$

3. $\operatorname{sat}^{2}+2$

The questions in Part 2 relate to your personal experience with the French language. If a question does not apply to you, please answer NA (not applıcable)

\section{What is your first language?}

2. Do you speak any language other than English?
$r$ Yes
No

If yes, please specity

(1)

3. Do you speak French?

$\ulcorner$ Yes

$C$ No

4. If yes, how would you evaluate your knowledge of the French language?

$\begin{array}{lcccccc} & 1 \text { (poor) } & 2 & 3 \text { (Moderate) } & 4 & 5 \text { (Excellent) } & \text { N/A } \\ \text { Skill level } & r & r & r & r & r & r\end{array}$




\section{Language Experience Questionnaire}

5. How often do you currently speak French?
Almost never
Once a year
Several tımes a year
Once a month
Once a week
Once a day
Several times a day
r N/A

\section{At what age did you begin to learn French?}

7. How long have you been speaking French (i.e. years or months)?

8. Did you learn French in a formal school setting or other (please be specific)

9. How intensive was your French instruction?
Immersion
$\Gamma$ Several hours per day
1 hour per day
Several tımes a week
N/A

10. Do you watch French television, including the news?
$r$ Yes
r No

If yes, please estimate how many hours per day or week

[

11. Do you read French literature (i.e. newspaper, magazines, books)?

$$
\begin{aligned}
& \ulcorner\text { Yes } \\
& \ulcorner\text { no }
\end{aligned}
$$

If yes, please estimate how many hours per month or year 


\section{Language Experience Questionnaire}

12. Do you listen to French radio?

$$
\begin{aligned}
& r \text { Yes } \\
& r \text { No }
\end{aligned}
$$

If yes please estımate how many hours per day or week

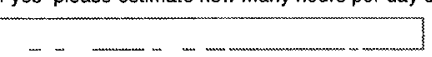

\section{Have you ever lived in a Francophone region or country?}

$\%$ Yes

No

If yes please specify$$
\text { , }
$$

14. Do other members of your family speak French?

C Yes

No

If yes please specify who

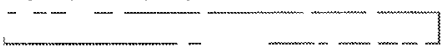

\section{F}

The questions in Part 3 relate to your proficiency in the French language Please read each statement carefully and respond with only one answer If you have never experienced some of the situations described below, try to evaluate how you thınk you would do

\section{I can follow dialogue in a French film without subtitles.}

I can do this perfectly

I can do this reasonably well

$r$ I can do this poorly

I cannot do this at all

\section{I can understand puns, sarcasm or irony in French}

r l can do this perfectly

r. I can do this reasonably well

r I can do this poorly

$r$ I cannot do this at all 


\section{Language Experience Questionnaire}

3. I understand most of the lyrics of a French song.

$r$ I can do this perfectly

r I can do this reasonably well

I can do this poorly

I cannot do this at all

\section{I can express my opinions in French.}

I can do this perfectly

I can do this reasonably well

r I can do this poorly

I cannot do this at all

5. I can understand a French novel.

I can do thıs perfectly

I can do this reasonably well

r. I can do this poorly

I cannot do this at all

\section{I can understand a French newspaper article}

I can do this perfectly

f 1 can do this reasonably well

I can do this poorly

r. I cannot do this at all

\section{I could work in a French-only speaking environment}

I can do thıs perfectly

I can do this reasonably well

I can do this poorly

I cannot do this at all 


\section{Language Experience Questionnaire}

8. If I watch a discussion between two people on a French television show, I can understand the arguments presented by each participant.

\footnotetext{
r I can do this perfectly

$r$ I can do this reasonably well

ᄃ 1 can do this poorly

s 1 cannot do this at all
} 


\section{Appendix D}

Explanation of Acoustic Measures

\section{Fundamental Frequency (F0)}

The fundamental frequency(F0) of the voice represents the rate of the vibration of the vocal folds during speech. The mean $(M)$, variability $(\mathrm{SD})$, minimum value (min) and maximum value were calculated using Praat software (Boersma \& Weenink, 1999).

\section{F0 Perturbation (Jitter)}

Jitter refers to small-scale perturbations in F0. It is often said to be realized in speech as a shaky or crying voice. The measurement was calculated again using Praat software (Boersma \& Weenink) and is expressed in percent deviation.

\section{Voice Intensity (VoInt)}

The voice intensity (VoInt) refers to the perceived loudness of the vocal expression. It was measured as the mean value in $\mathrm{dB}$ using Praat software (Boersma \& Weenink).

\section{Fundamental Frequency (F0) Contour}

In order to quantify the shape of the pitch contour, a rough index of the F0 contour was attained by calculating the ratio of rising:falling contours by adding all rising syllablebased contours (giving a value of 1 to each) and divided this sum by the sum of all falling syllable-based contours in the F0 contour of the same phrase. This yielded a single number for each portrayal. A rise or a fall was defined as a difference between the F0 value at the beginning of a contour and the F0 value at the end of a contour. A large relative amount of rising, as opposed to falling F0 contours yields a large value of F0 contour. 


\section{Appendix E}

Descriptive Statistics of Individual Measures for Each Emotion Category Emotion 1 (happy) talker 1

\begin{tabular}{|r|r|r|l|l|l|l|l|l|}
\hline & \multicolumn{1}{|l|}{$\begin{array}{l}\text { Duration } \\
(\mathrm{s})\end{array}$} & $\begin{array}{l}\text { F0 } \\
\text { Median }\end{array}$ & $\begin{array}{l}\text { F0 } \\
\text { SD }\end{array}$ & $\begin{array}{l}\text { F0 } \\
\text { Min }\end{array}$ & $\begin{array}{l}\text { F0 } \\
\text { Max }\end{array}$ & $\begin{array}{l}\text { Jitter } \\
\%\end{array}$ & $\begin{array}{l}\text { Intensity } \\
(\mathrm{dB})\end{array}$ & $\begin{array}{l}\text { F0 } \\
\text { delta }\end{array}$ \\
\hline Mean & 2.82 & 185.66 & 61.28 & 86.27 & 276.68 & 2.64 & 69.34 & 190.41 \\
\hline Median & 2.49 & 187.41 & 62.64 & 84.17 & 268.25 & 2.63 & 69.53 & 176.58 \\
\hline SD & 1.11 & 14.36 & 15.20 & 27.25 & 32.78 & 0.39 & 1.34 & 41.78 \\
\hline
\end{tabular}

\begin{tabular}{|c|c|c|c|c|c|c|c|}
\hline & $\begin{array}{l}\text { Rising } \\
\text { Contours }\end{array}$ & $\begin{array}{l}\text { Falling } \\
\text { Contours }\end{array}$ & $\begin{array}{l}\text { F0 } \\
\text { Contour } \\
\text { Index }\end{array}$ & $\begin{array}{l}\text { 1st Half } \\
\text { F0 }\end{array}$ & $\begin{array}{l}\text { 2nd Half } \\
\text { F0 }\end{array}$ & $\begin{array}{l}\text { Full } \\
\text { F0 }\end{array}$ & $\begin{array}{l}\text { F0 } \\
1^{\text {st }} / 2^{\text {nd }} \\
\text { half } \\
\text { delta }\end{array}$ \\
\hline Mean & 3.78 & 6.39 & 0.60 & 194.98 & 166.00 & 180.51 & 28.99 \\
\hline Median & 3.00 & 5.50 & 0.60 & 197.65 & 165.14 & 180.05 & 25.62 \\
\hline SD & 2.34 & 3.26 & 0.27 & 13.83 & 16.28 & 12.68 & 16.40 \\
\hline
\end{tabular}


Emotion 1 (happy) talker 2

Original analysis of descriptive statistics for Emotion 1/Talker 2: one of the sentences' F0 Max value was in error (likely due to mistracking F0 by the Praat algorithm for extracting F0. This value should be no more than $\sim 300-400 \mathrm{~Hz}$ ). To deal with this problem, a second analysis was performed with the data for this sentence (\#15) removed

\begin{tabular}{|r|r|r|l|l|l|l|l|r|}
\hline & \multicolumn{1}{|l|}{$\begin{array}{l}\text { Duration } \\
(\mathrm{s})\end{array}$} & $\begin{array}{l}\text { F0 } \\
\text { Median }\end{array}$ & $\begin{array}{l}\text { F0 } \\
\text { SD }\end{array}$ & $\begin{array}{l}\text { F0 } \\
\text { Min }\end{array}$ & F0 Max & $\begin{array}{l}\text { Jitter } \\
\%\end{array}$ & $\begin{array}{l}\text { Intensity } \\
(\mathrm{dB})\end{array}$ & F0 delta \\
\hline Mean & 2.72 & 276.15 & 59.61 & 154.13 & $\underline{\underline{2529.21}}$ & 1.63 & 69.78 & 2375.09 \\
\hline Median & 2.50 & 276.15 & 57.57 & 161.01 & $\underline{408.80}$ & 1.63 & 69.85 & 250.82 \\
\hline SD & 1.01 & 23.91 & 9.16 & 38.32 & $\underline{9015.71}$ & 0.29 & 0.88 & 9011.23 \\
\hline
\end{tabular}

Replacement table for Emotion 1 (happy) talker 2

\begin{tabular}{|r|r|r|l|l|l|l|l|l|}
\hline & \multicolumn{1}{|l|}{$\begin{array}{l}\text { Duration } \\
\text { (s) }\end{array}$} & $\begin{array}{l}\text { F0 } \\
\text { Median }\end{array}$ & $\begin{array}{l}\text { F0 } \\
\text { SD }\end{array}$ & $\begin{array}{l}\text { F0 } \\
\text { Min }\end{array}$ & $\begin{array}{l}\text { F0 } \\
\text { Max }\end{array}$ & $\begin{array}{l}\text { Jitter } \\
\%\end{array}$ & $\begin{array}{l}\text { Intensity } \\
(\mathrm{dB})\end{array}$ & $\begin{array}{l}\text { F0 } \\
\text { delta }\end{array}$ \\
\hline Mean & 2.82 & 274.74 & 60.06 & 153.03 & 404.23 & 1.65 & 69.77 & 251.19 \\
\hline Median & 2.54 & 275.56 & 58.21 & 160.32 & 408.61 & 1.63 & 69.78 & 238.75 \\
\hline SD & 0.94 & 23.87 & 9.22 & 39.21 & 53.23 & 0.28 & 0.90 & 77.42 \\
\hline
\end{tabular}

\begin{tabular}{|c|c|c|c|c|c|c|c|}
\hline & $\begin{array}{l}\text { Rising } \\
\text { Contours }\end{array}$ & $\begin{array}{l}\text { Falling } \\
\text { Contours }\end{array}$ & $\begin{array}{l}\text { F0 } \\
\text { Contour } \\
\text { Index }\end{array}$ & $\begin{array}{l}\text { 1st Half } \\
\text { F0 }\end{array}$ & $\begin{array}{l}\text { 2nd Half } \\
\text { F0 }\end{array}$ & $\begin{array}{l}\text { Full } \\
\text { F0 }\end{array}$ & $\begin{array}{l}\text { F0 } \\
1^{\text {st }} / 2^{\text {nd }} \\
\text { half } \\
\text { delta }\end{array}$ \\
\hline Mean & 4.33 & 5.28 & 0.84 & 305.79 & 242.15 & 273.97 & 63.64 \\
\hline Median & 4.00 & 5.00 & 0.82 & 303.55 & 242.03 & 276.00 & 68.59 \\
\hline SD & 2.33 & 1.87 & 0.41 & 16.49 & 21.44 & 14.49 & 24.96 \\
\hline
\end{tabular}


Emotion 1 (happy) talker 3

\begin{tabular}{|r|r|r|l|l|l|r|r|l|}
\hline & $\begin{array}{l}\text { Duration } \\
\text { (s) }\end{array}$ & $\begin{array}{l}\text { F0 } \\
\text { Median }\end{array}$ & $\begin{array}{l}\text { F0 } \\
\text { SD }\end{array}$ & $\begin{array}{l}\text { F0 } \\
\text { Min }\end{array}$ & $\begin{array}{l}\text { F0 } \\
\text { Max }\end{array}$ & $\begin{array}{l}\text { Jitter } \\
\%\end{array}$ & $\begin{array}{l}\text { Intensity } \\
(\mathrm{dB})\end{array}$ & $\begin{array}{l}\text { F0 } \\
\text { delta }\end{array}$ \\
\hline Mean & 2.26 & 119.70 & 65.44 & 57.07 & 177.59 & 3.79 & 67.52 & 120.53 \\
\hline Median & 2.05 & 119.92 & 64.49 & 49.18 & 166.50 & 3.73 & 67.29 & 119.00 \\
\hline SD & 0.86 & 5.65 & 17.87 & 21.52 & 30.56 & 0.80 & 1.57 & 43.53 \\
\hline
\end{tabular}

\begin{tabular}{|r|r|r|r|r|r|r|r|}
\hline & $\begin{array}{l}\text { Rising } \\
\text { Contours }\end{array}$ & $\begin{array}{l}\text { Falling } \\
\text { Contours }\end{array}$ & $\begin{array}{l}\text { F0 } \\
\text { Contour } \\
\text { Index }\end{array}$ & \multicolumn{1}{l|}{$\begin{array}{l}\text { 1st Half } \\
\text { F0 }\end{array}$} & $\begin{array}{l}\text { 2nd Half } \\
\text { F0 }\end{array}$ & $\begin{array}{l}\text { Full } \\
\text { F0 }\end{array}$ & $\begin{array}{l}\text { F0 } \\
1^{\text {st }} / 2^{\text {nd }} \\
\text { half } \\
\text { delta }\end{array}$ \\
\hline Mean & 3.33 & 4.11 & 0.82 & 128.61 & 110.72 & 119.70 & 17.90 \\
\hline Median & 3.50 & 4.00 & 0.82 & 127.83 & 109.09 & 118.02 & 15.61 \\
\hline SD & 1.46 & 1.37 & 0.24 & 7.63 & 8.54 & 6.37 & 9.82 \\
\hline
\end{tabular}

Emotion 1 (happy) talker 4

\begin{tabular}{|r|r|r|l|l|l|l|l|l|}
\hline & $\begin{array}{l}\text { Duration } \\
\text { (s) }\end{array}$ & $\begin{array}{l}\text { F0 } \\
\text { Median }\end{array}$ & $\begin{array}{l}\text { F0 } \\
\text { SD }\end{array}$ & $\begin{array}{l}\text { F0 } \\
\text { Min }\end{array}$ & $\begin{array}{l}\text { F0 } \\
\text { Max }\end{array}$ & $\begin{array}{l}\text { Jitter } \\
\%\end{array}$ & $\begin{array}{l}\text { Intensity } \\
\text { (dB) }\end{array}$ & $\begin{array}{l}\text { F0 } \\
\text { delta }\end{array}$ \\
\hline Mean & 3.37 & 88.33 & 65.21 & 56.69 & 172.27 & 3.13 & 71.36 & 115.58 \\
\hline Median & 2.98 & 89.05 & 69.36 & 60.54 & 166.25 & 2.94 & 70.61 & 111.79 \\
\hline SD & 1.20 & 5.07 & 36.92 & 14.29 & 43.19 & 0.49 & 2.48 & 46.46 \\
\hline
\end{tabular}

\begin{tabular}{|r|r|r|l|l|l|l|l|}
\hline & $\begin{array}{l}\text { Rising } \\
\text { Contours }\end{array}$ & $\begin{array}{l}\text { Falling } \\
\text { Contours }\end{array}$ & $\begin{array}{l}\text { F0 } \\
\text { lontour } \\
\text { Index }\end{array}$ & $\begin{array}{l}\text { 1st Half } \\
\text { F0 }\end{array}$ & $\begin{array}{l}\text { 2nd Half } \\
\text { F0 }\end{array}$ & $\begin{array}{l}\text { Full } \\
\text { F0 }\end{array}$ & $\begin{array}{l}\text { F0 } \\
1^{\text {st }} 2^{\text {nd }} \\
\text { half } \\
\text { delta }\end{array}$ \\
\hline Mean & 3.44 & 3.56 & 1.02 & 105.12 & 90.54 & 97.66 & 14.58 \\
\hline Median & 3.00 & 3.50 & 1.00 & 101.72 & 90.00 & 96.39 & 12.97 \\
\hline SD & 1.25 & 1.15 & 0.36 & 9.99 & 7.01 & 6.63 & 11.30 \\
\hline
\end{tabular}


Emotion 2 (Sad) talker 1

\begin{tabular}{|r|r|r|l|l|l|l|l|l|}
\hline & $\begin{array}{l}\text { Duration } \\
\text { (s) }\end{array}$ & $\begin{array}{l}\text { F0 } \\
\text { Median }\end{array}$ & $\begin{array}{l}\text { F0 } \\
\text { SD }\end{array}$ & $\begin{array}{l}\text { F0 } \\
\text { Min }\end{array}$ & $\begin{array}{l}\text { F0 } \\
\text { Max }\end{array}$ & $\begin{array}{l}\text { Jitter } \\
\%\end{array}$ & $\begin{array}{l}\text { Intensity } \\
(\mathrm{dB})\end{array}$ & $\begin{array}{l}\text { F0 } \\
\text { delta }\end{array}$ \\
\hline Mean & 2.95 & 133.35 & 85.96 & 63.88 & 172.74 & 3.53 & 59.66 & 108.86 \\
\hline Median & 2.89 & 132.60 & 89.37 & 53.55 & 165.90 & 3.42 & 59.64 & 113.65 \\
\hline SD & 0.97 & 4.51 & 16.30 & 26.93 & 22.38 & 0.55 & 1.32 & 34.65 \\
\hline
\end{tabular}

\begin{tabular}{|r|r|r|r|r|r|r|r|}
\hline & $\begin{array}{l}\text { Rising } \\
\text { Contours }\end{array}$ & $\begin{array}{l}\text { Falling } \\
\text { Contours }\end{array}$ & $\begin{array}{l}\text { F0 } \\
\text { Contour } \\
\text { Index }\end{array}$ & \multicolumn{1}{l|}{$\begin{array}{l}\text { 1st Half } \\
\text { F0 }\end{array}$} & $\begin{array}{l}\text { 2nd Half } \\
\text { F0 }\end{array}$ & $\begin{array}{l}\text { Full } \\
\text { F0 }\end{array}$ & $\begin{array}{l}\text { l0 } \\
1^{\text {st }} 2^{\text {nd }} \\
\text { half } \\
\text { delta }\end{array}$ \\
\hline Median & 2.00 & 2.53 & 0.80 & 144.22 & 127.70 & 135.93 & 16.52 \\
\hline SD & 1.00 & 1.02 & 0.34 & 6.09 & 10.19 & 6.14 & 11.49 \\
\hline
\end{tabular}

Emotion 2 (Sad) talker 2

\begin{tabular}{|r|r|r|l|l|l|l|l|l|}
\hline & $\begin{array}{l}\text { Duration } \\
\text { (s) }\end{array}$ & $\begin{array}{l}\text { F0 } \\
\text { Median }\end{array}$ & $\begin{array}{l}\text { F0 } \\
\text { SD }\end{array}$ & $\begin{array}{l}\text { F0 } \\
\text { Min }\end{array}$ & $\begin{array}{l}\text { F0 } \\
\text { Max }\end{array}$ & $\begin{array}{l}\text { Jitter } \\
\%\end{array}$ & $\begin{array}{l}\text { Intensity } \\
(\mathrm{dB})\end{array}$ & $\begin{array}{l}\text { l0 } \\
\text { delta }\end{array}$ \\
\hline Mean & 3.00 & 220.19 & 34.88 & 99.32 & 309.57 & 1.70 & 68.01 & 210.25 \\
\hline Median & 2.79 & 221.94 & 35.19 & 96.02 & 296.54 & 1.66 & 67.62 & 231.03 \\
\hline SD & 0.96 & 10.61 & 8.02 & 58.17 & 56.91 & 0.30 & 2.15 & 80.73 \\
\hline
\end{tabular}




\begin{tabular}{|c|c|c|c|c|c|c|c|}
\hline & $\begin{array}{l}\text { Rising } \\
\text { Contours }\end{array}$ & $\begin{array}{l}\text { Falling } \\
\text { Contours }\end{array}$ & $\begin{array}{l}\text { F0 } \\
\text { Contour } \\
\text { Index }\end{array}$ & $\begin{array}{l}1 \text { st Half } \\
\text { F0 }\end{array}$ & $\begin{array}{l}\text { 2nd Half } \\
\text { FO }\end{array}$ & $\begin{array}{l}\text { Full } \\
\text { F0 }\end{array}$ & $\begin{array}{l}\text { F0 } \\
1^{\text {st }} / 2^{\text {nd }} \\
\text { half } \\
\text { delta }\end{array}$ \\
\hline Mean & 4.79 & 5.26 & 0.96 & 241.98 & 200.90 & 221.34 & 41.08 \\
\hline Median & 5.00 & 5.00 & 0.87 & 241.56 & 202.59 & 223.02 & 39.15 \\
\hline SD & 1.48 & 1.52 & 0.32 & 15.53 & 6.98 & 9.79 & 14.42 \\
\hline
\end{tabular}

Emotion 2 (Sad) talker 3

\begin{tabular}{|r|r|r|l|l|l|l|l|l|}
\hline & \multicolumn{1}{|l|}{$\begin{array}{l}\text { Duration } \\
\text { (s) }\end{array}$} & $\begin{array}{l}\text { F0 } \\
\text { Median }\end{array}$ & $\begin{array}{l}\text { F0 } \\
\text { SD }\end{array}$ & $\begin{array}{l}\text { F0 } \\
\text { Min }\end{array}$ & $\begin{array}{l}\text { F0 } \\
\text { Max }\end{array}$ & $\begin{array}{l}\text { Jitter } \\
\%\end{array}$ & $\begin{array}{l}\text { Intensity } \\
(\mathrm{dB})\end{array}$ & $\begin{array}{l}\text { F0 } \\
\text { delta }\end{array}$ \\
\hline Mean & 2.45 & 106.47 & 47.99 & 52.57 & 137.63 & 3.45 & 64.17 & 85.07 \\
\hline SD & 2.41 & 105.51 & 43.04 & 44.28 & 137.50 & 3.44 & 63.49 & 90.38 \\
\hline
\end{tabular}

\begin{tabular}{|r|r|r|l|r|r|r|r|}
\hline & $\begin{array}{l}\text { Rising } \\
\text { Contours }\end{array}$ & $\begin{array}{l}\text { Falling } \\
\text { Contours }\end{array}$ & $\begin{array}{l}\text { F0 } \\
\text { Contour } \\
\text { Index }\end{array}$ & \multicolumn{1}{l|}{$\begin{array}{l}\text { F0 Half } \\
\text { F0 }\end{array}$} & $\begin{array}{l}\text { 2nd Half } \\
\text { F0 }\end{array}$ & $\begin{array}{l}\text { Full } \\
\text { F0 }\end{array}$ & $\begin{array}{l}\text { F0 } \\
1^{\text {st }} / 2^{\text {nd }} \\
\text { half } \\
\text { delta }\end{array}$ \\
\hline Mean & 2.16 & 2.16 & 0.95 & 112.98 & 101.96 & 107.47 & 11.02 \\
\hline Median & 2.00 & 2.00 & 1.00 & 111.96 & 100.86 & 106.37 & 11.12 \\
\hline SD & 0.60 & 0.77 & 0.36 & 5.10 & 4.03 & 3.80 & 5.33 \\
\hline
\end{tabular}

Emotion 2 (Sad) talker 4

\begin{tabular}{|r|r|r|r|r|r|r|r|r|}
\hline & \multicolumn{1}{|l|}{$\begin{array}{l}\text { Duration } \\
\text { (s) }\end{array}$} & $\begin{array}{l}\text { F0 } \\
\text { Median }\end{array}$ & $\begin{array}{l}\text { F0 } \\
\text { SD }\end{array}$ & $\begin{array}{l}\text { F0 } \\
\text { Min }\end{array}$ & $\begin{array}{l}\text { F0 } \\
\text { Max }\end{array}$ & $\begin{array}{l}\text { Jitter } \\
\%\end{array}$ & $\begin{array}{l}\text { Intensity } \\
\text { (dB) }\end{array}$ & $\begin{array}{l}\text { F0 } \\
\text { delta }\end{array}$ \\
\hline Mean & 3.90 & 70.81 & 76.34 & 41.23 & 102.51 & 3.32 & 61.72 & 61.27 \\
\hline Median & 3.81 & 70.98 & 75.51 & 35.99 & 102.60 & 3.24 & 61.76 & 61.00 \\
\hline SD & 1.11 & 2.11 & 29.41 & 12.55 & 13.38 & 0.71 & 1.74 & 17.87 \\
\hline
\end{tabular}




\begin{tabular}{|r|r|r|l|r|r|r|r|}
\hline & $\begin{array}{l}\text { Rising } \\
\text { Contours }\end{array}$ & $\begin{array}{l}\text { Falling } \\
\text { Contours }\end{array}$ & $\begin{array}{l}\text { F0 } \\
\text { Contour } \\
\text { Index }\end{array}$ & $\begin{array}{l}\text { F0 Half } \\
\text { F0 }\end{array}$ & $\begin{array}{l}\text { 2nd Half } \\
\text { F0 }\end{array}$ & $\begin{array}{l}\text { Full } \\
\text { F0 }\end{array}$ & $\begin{array}{l}\text { F0 } \\
1^{\text {st }} / 2^{\text {nd }} \\
\text { half } \\
\text { delta }\end{array}$ \\
\hline Mean & 2.00 & 2.26 & 1.01 & 76.13 & 69.31 & 72.72 & 6.83 \\
\hline Median & 2.00 & 2.00 & 1.00 & 75.04 & 67.92 & 72.47 & 6.91 \\
\hline SD & 0.94 & 1.37 & 0.39 & 4.99 & 4.38 & 3.16 & 6.96 \\
\hline
\end{tabular}

Emotion 3 (Angry) talker 1

\begin{tabular}{|r|r|r|l|l|l|l|r|r|}
\hline & \multicolumn{1}{|l|}{$\begin{array}{l}\text { Duration } \\
(\mathrm{s})\end{array}$} & $\begin{array}{l}\text { F0 } \\
\text { Median }\end{array}$ & $\begin{array}{l}\text { F0 } \\
\text { SD }\end{array}$ & $\begin{array}{l}\text { F0 } \\
\text { Min }\end{array}$ & $\begin{array}{l}\text { F0 } \\
\text { Max }\end{array}$ & $\begin{array}{l}\text { Jitter } \\
\%\end{array}$ & $\begin{array}{l}\text { Intensity } \\
(\mathrm{dB})\end{array}$ & $\begin{array}{l}\text { F0 } \\
\text { delta }\end{array}$ \\
\hline Mean & 3.03 & 240.38 & 55.71 & 137.91 & 326.12 & 2.24 & 76.49 & 188.21 \\
\hline Median & 2.66 & 243.91 & 53.82 & 130.50 & 327.30 & 2.23 & 76.67 & 196.91 \\
\hline SD & 1.59 & 20.67 & 11.35 & 29.55 & 31.49 & 0.45 & 2.97 & 34.45 \\
\hline
\end{tabular}

\begin{tabular}{|r|r|r|l|l|l|l|l|}
\hline & $\begin{array}{l}\text { Rising } \\
\text { Contours }\end{array}$ & $\begin{array}{l}\text { Falling } \\
\text { Contours }\end{array}$ & $\begin{array}{l}\text { F0 } \\
\text { Contour } \\
\text { Index }\end{array}$ \\
\hline Mean & 4.10 & 6.20 & 0.76 & 245.62 & 215.28 & 230.43 & $\begin{array}{l}\text { Fo Half } \\
\text { F0 }\end{array}$ \\
\hline Median & 3.00 & 6.00 & 0.65 & 245.82 & 220.93 & 231.34 & $\begin{array}{l}\text { Fo Half } \\
\text { F0 } \\
\text { half } \\
\text { helta }\end{array}$ \\
\hline SD & 2.08 & 3.09 & 0.45 & 27.16 & 19.10 & 18.66 & 28.48 \\
\hline
\end{tabular}


Emotion 3 (Angry) talker 2

\begin{tabular}{|r|r|r|l|l|l|l|r|l|}
\hline & \multicolumn{1}{|l|}{$\begin{array}{l}\text { Duration } \\
(\mathrm{s})\end{array}$} & $\begin{array}{l}\text { F0 } \\
\text { Median }\end{array}$ & $\begin{array}{l}\text { F0 } \\
\text { SD }\end{array}$ & $\begin{array}{l}\text { F0 } \\
\text { Min }\end{array}$ & $\begin{array}{l}\text { F0 } \\
\text { Max }\end{array}$ & $\begin{array}{l}\text { Jitter } \\
\%\end{array}$ & $\begin{array}{l}\text { Intensity } \\
(\mathrm{dB})\end{array}$ & $\begin{array}{l}\text { F0 } \\
\text { delta }\end{array}$ \\
\hline Mean & 3.04 & 227.54 & 40.81 & 118.13 & 326.10 & 2.02 & 70.96 & 207.96 \\
\hline Median & 2.69 & 217.22 & 38.66 & 144.88 & 318.49 & 1.97 & 71.10 & 211.94 \\
\hline SD & 1.43 & 30.04 & 10.80 & 55.15 & 60.78 & 0.37 & 1.41 & 64.72 \\
\hline
\end{tabular}

Error in Full F0 for sentence \#13 (values are out of range, likely due to error in F0 tracking algorithm)

\begin{tabular}{|c|c|c|c|c|c|c|c|}
\hline & $\begin{array}{l}\text { Rising } \\
\text { Contours }\end{array}$ & $\begin{array}{l}\text { Falling } \\
\text { Contours }\end{array}$ & $\begin{array}{l}\text { F0 } \\
\text { Contour } \\
\text { Index }\end{array}$ & $\begin{array}{l}\text { 1st Half } \\
\text { F0 }\end{array}$ & $\begin{array}{l}\text { 2nd Half } \\
\text { F0 }\end{array}$ & Full F0 & $\begin{array}{l}\text { F0 } \\
1^{\text {st }} / 2^{\text {nd }} \\
\text { half } \\
\text { delta }\end{array}$ \\
\hline Mean & 3.85 & 5.85 & 0.69 & 243.92 & 205.97 & 1285.07 & 37.95 \\
\hline Median & 3.00 & 5.50 & 0.61 & 239.04 & 201.37 & 224.89 & 33.57 \\
\hline SD & 1.79 & 2.35 & 0.30 & 35.64 & 24.47 & 4738.41 & 24.09 \\
\hline
\end{tabular}

Fixed version:

\begin{tabular}{|r|r|r|l|r|r|r|r|}
\hline & $\begin{array}{l}\text { Rising } \\
\text { Contours }\end{array}$ & $\begin{array}{l}\text { Falling } \\
\text { Contours }\end{array}$ & $\begin{array}{l}\text { F0 } \\
\text { Contour } \\
\text { Index }\end{array}$ & $\begin{array}{l}\text { 1st Half } \\
\text { F0 }\end{array}$ & $\begin{array}{l}\text { 2nd Half } \\
\text { F0 }\end{array}$ & $\begin{array}{l}\text { Full } \\
\text { F0 }\end{array}$ & $\begin{array}{l}\text { F0 } \\
1^{\text {st }} / 2^{\text {nd }} \\
\text { half } \\
\text { delta }\end{array}$ \\
\hline Mean & 3.95 & 6.00 & 0.69 & 244.66 & 206.36 & 225.54 & 38.30 \\
\hline Median & 3.00 & 6.00 & 0.60 & 242.52 & 201.88 & 222.48 & 34.26 \\
\hline SD & 1.78 & 2.31 & 0.31 & 36.46 & 25.07 & 28.84 & 24.69 \\
\hline
\end{tabular}


Emotion 3 (Angry) talker 3

\begin{tabular}{|r|r|r|l|l|l|l|l|l|}
\hline & \multicolumn{1}{|l|}{$\begin{array}{l}\text { Duration } \\
\text { (s) }\end{array}$} & $\begin{array}{l}\text { F0 } \\
\text { Median }\end{array}$ & $\begin{array}{l}\text { F0 } \\
\text { SD }\end{array}$ & $\begin{array}{l}\text { F0 } \\
\text { Min }\end{array}$ & $\begin{array}{l}\text { F0 } \\
\text { Max }\end{array}$ & $\begin{array}{l}\text { Jitter } \\
\%\end{array}$ & $\begin{array}{l}\text { Intensity } \\
(\mathrm{dB})\end{array}$ & $\begin{array}{l}\text { F0 } \\
\text { delta }\end{array}$ \\
\hline Mean & 2.64 & 114.12 & 60.46 & 58.22 & 151.25 & 3.65 & 66.30 & 93.03 \\
\hline Median & 2.45 & 114.67 & 62.20 & 48.99 & 148.30 & 3.74 & 66.24 & 91.29 \\
\hline SD & 1.20 & 4.88 & 32.29 & 27.77 & 19.43 & 0.71 & 1.65 & 36.96 \\
\hline
\end{tabular}

\begin{tabular}{|r|r|r|l|l|r|r|r|}
\hline & $\begin{array}{l}\text { Rising } \\
\text { Contours }\end{array}$ & $\begin{array}{l}\text { Falling } \\
\text { Contours }\end{array}$ & $\begin{array}{l}\text { F0 } \\
\text { Contour } \\
\text { Index }\end{array}$ & \multicolumn{1}{l}{$\begin{array}{l}\text { F0 Half } \\
\text { F0 }\end{array}$} & $\begin{array}{l}\text { 2nd Half } \\
\text { F0 Full F0 }\end{array}$ & $\begin{array}{l}\text { F0 } \\
1^{\text {st }} / 2^{\text {nd }} \\
\text { half } \\
\text { delta }\end{array}$ \\
\hline Mean & 3.05 & 3.6 & 0.856 & 122.363 & 113.833 & 118.091 & 8.53 \\
\hline Median & 3.00 & 3.00 & 0.90 & 123.80 & 111.13 & 115.64 & 10.90 \\
\hline SD & 1.23 & 1.19 & 0.23 & 6.93 & 11.34 & 7.10 & 12.31 \\
\hline
\end{tabular}

Emotion 3 (Angry) talker 4

\begin{tabular}{|r|r|r|l|l|l|l|l|l|}
\hline & \multicolumn{1}{|l|}{$\begin{array}{l}\text { Duration } \\
(\mathrm{s})\end{array}$} & $\begin{array}{l}\text { F0 } \\
\text { Median }\end{array}$ & $\begin{array}{l}\text { F0 } \\
\text { SD }\end{array}$ & $\begin{array}{l}\text { F0 } \\
\text { Min }\end{array}$ & $\begin{array}{l}\text { F0 } \\
\text { Max }\end{array}$ & $\begin{array}{l}\text { Jitter } \\
\%\end{array}$ & $\begin{array}{l}\text { Intensity } \\
(\mathrm{dB})\end{array}$ & $\begin{array}{l}\text { F0 } \\
\text { delta }\end{array}$ \\
\hline Mean & 3.53 & 106.76 & 70.64 & 71.90 & 152.73 & 3.04 & 72.97 & 80.83 \\
\hline Median & 3.22 & 105.26 & 71.02 & 76.25 & 154.70 & 3.00 & 73.42 & 75.60 \\
\hline SD & 1.65 & 15.49 & 21.65 & 22.06 & 16.37 & 0.75 & 2.51 & 19.94 \\
\hline
\end{tabular}




\begin{tabular}{|r|r|r|l|l|l|l|l|}
\hline & $\begin{array}{l}\text { Rising } \\
\text { Contours }\end{array}$ & $\begin{array}{l}\text { Falling } \\
\text { Contours }\end{array}$ & $\begin{array}{l}\text { F0 } \\
\text { Contour } \\
\text { Index }\end{array}$ \\
Mean & 3.05 & 3.35 & 0.95 & 114.07 & 102.17 & 108.14 & 11.91 \\
\hline Median & 3.00 & 3.50 & 1.00 & 117.04 & 102.40 & 108.10 & $\begin{array}{l}\text { F0 Half } \\
\text { F0 }\end{array}$ \\
\hline SD & 1.15 & 1.09 & 0.34 & 14.03 & 12.39 & 11.99 & $\begin{array}{l}\text { F0 } \\
1^{\text {st }} / 2^{\text {nd }} \\
\text { half } \\
\text { delta }\end{array}$ \\
\hline
\end{tabular}

Emotion 4 (Fear) talker 1

\begin{tabular}{|r|r|r|l|l|l|l|l|l|}
\hline & \multicolumn{1}{|l|}{$\begin{array}{l}\text { Duration } \\
\text { (s) }\end{array}$} & $\begin{array}{l}\text { F0 } \\
\text { Median }\end{array}$ & $\begin{array}{l}\text { F0 } \\
\text { SD }\end{array}$ & $\begin{array}{l}\text { F0 } \\
\text { Min }\end{array}$ & $\begin{array}{l}\text { F0 } \\
\text { Max }\end{array}$ & $\begin{array}{l}\text { Jitter } \\
\%\end{array}$ & $\begin{array}{l}\text { Intensity } \\
(\mathrm{dB})\end{array}$ & $\begin{array}{l}\text { F0 } \\
\text { delta }\end{array}$ \\
\hline Mean & 2.77 & 245.32 & 38.65 & 159.10 & 299.34 & 1.93 & 73.97 & 140.24 \\
\hline Median & 2.50 & 246.77 & 40.51 & 166.83 & 299.55 & 1.97 & 74.26 & 126.17 \\
\hline SD & 0.89 & 11.92 & 8.56 & 47.22 & 22.36 & 0.34 & 2.00 & 54.97 \\
\hline
\end{tabular}

\begin{tabular}{|r|r|r|r|r|r|r|r|}
\hline & $\begin{array}{l}\text { Rising } \\
\text { Contours }\end{array}$ & $\begin{array}{l}\text { Falling } \\
\text { Contours }\end{array}$ & $\begin{array}{l}\text { F0 } \\
\text { Contour } \\
\text { Index }\end{array}$ & \multicolumn{1}{l|}{$\begin{array}{l}\text { F0 Half } \\
\text { F0 }\end{array}$} & $\begin{array}{l}\text { F0 Half } \\
\text { F0 }\end{array}$ & $\begin{array}{l}\text { Full } \\
\text { F0 }\end{array}$ & $\begin{array}{l}\text { F0 } \\
1^{\text {st }} / 2^{\text {nd }} \\
\text { half } \\
\text { delta }\end{array}$ \\
\hline Mean & 3.89 & 2.56 & 1.84 & 248.71 & 229.25 & 238.98 & 19.46 \\
\hline Median & 3.00 & 2.00 & 1.50 & 249.40 & 230.68 & 237.68 & 21.66 \\
\hline SD & 1.91 & 1.38 & 1.27 & 11.63 & 14.10 & 11.63 & 11.28 \\
\hline
\end{tabular}

Emotion 4 (Fear) talker 2

\begin{tabular}{|r|r|r|l|l|l|l|r|r|}
\hline & \multicolumn{1}{|l|}{$\begin{array}{l}\text { Duration } \\
(\mathrm{s})\end{array}$} & $\begin{array}{l}\text { F0 } \\
\text { Median }\end{array}$ & $\begin{array}{l}\text { F0 } \\
\text { SD }\end{array}$ & $\begin{array}{l}\text { F0 } \\
\text { Min }\end{array}$ & $\begin{array}{l}\text { F0 } \\
\text { Max }\end{array}$ & $\begin{array}{l}\text { Jitter } \\
\%\end{array}$ & $\begin{array}{l}\text { Intensity } \\
(\mathrm{dB})\end{array}$ & $\begin{array}{l}\text { F0 } \\
\text { delta }\end{array}$ \\
\hline Mean & 2.64 & 218.82 & 34.14 & 131.85 & 313.65 & 2.07 & 69.12 & 181.80 \\
\hline Median & 2.30 & 218.46 & 34.70 & 154.01 & 298.02 & 2.09 & 69.18 & 156.14 \\
\hline SD & 0.80 & 12.44 & 6.76 & 44.89 & 61.40 & 0.32 & 0.99 & 67.35 \\
\hline
\end{tabular}




\begin{tabular}{|r|r|r|r|r|r|r|r|}
\hline & $\begin{array}{l}\text { Rising } \\
\text { Contours }\end{array}$ & $\begin{array}{l}\text { Falling } \\
\text { Contours }\end{array}$ & $\begin{array}{l}\text { F0 } \\
\text { lontour } \\
\text { Index }\end{array}$ & \multicolumn{1}{l|}{$\begin{array}{l}\text { 1st Half } \\
\text { F0 }\end{array}$} & $\begin{array}{l}\text { 2nd Half } \\
\text { F0 }\end{array}$ & $\begin{array}{l}\text { Full } \\
\text { F0 }\end{array}$ & $\begin{array}{l}\text { F0 } \\
1^{\text {st }} / 2^{\text {nd }} \\
\text { half } \\
\text { delta }\end{array}$ \\
\hline Mean & 5.22 & 6.67 & 0.80 & 236.11 & 201.21 & 218.77 & 34.90 \\
\hline Median & 5.00 & 6.00 & 0.77 & 233.40 & 198.06 & 216.15 & 32.04 \\
\hline SD & 1.44 & 1.91 & 0.19 & 15.54 & 12.72 & 12.63 & 12.93 \\
\hline
\end{tabular}

Emotion 4 (Fear) talker 3

\begin{tabular}{|r|r|r|l|l|l|l|l|l|}
\hline & $\begin{array}{l}\text { Duration } \\
\text { (s) }\end{array}$ & $\begin{array}{l}\text { F0 } \\
\text { Median }\end{array}$ & $\begin{array}{l}\text { F0 } \\
\text { SD }\end{array}$ & $\begin{array}{l}\text { F0 } \\
\text { Min }\end{array}$ & $\begin{array}{l}\text { F0 } \\
\text { Max }\end{array}$ & $\begin{array}{l}\text { Jitter } \\
\%\end{array}$ & $\begin{array}{l}\text { Intensity } \\
(\mathrm{dB})\end{array}$ & $\begin{array}{l}\text { F0 } \\
\text { delta }\end{array}$ \\
\hline Mean & 2.24 & 111.56 & 61.06 & 82.45 & 157.23 & 3.65 & 63.95 & 74.77 \\
\hline Median & 2.05 & 110.81 & 65.18 & 89.22 & 142.25 & 3.58 & 64.32 & 66.03 \\
\hline SD & 0.59 & 4.00 & 34.54 & 17.04 & 37.35 & 0.81 & 1.28 & 43.17 \\
\hline
\end{tabular}

\begin{tabular}{|r|r|r|l|r|l|l|l|}
\hline & $\begin{array}{l}\text { Rising } \\
\text { Contours }\end{array}$ & $\begin{array}{l}\text { Falling } \\
\text { Contours }\end{array}$ & $\begin{array}{l}\text { F0 } \\
\text { Contour } \\
\text { Index }\end{array}$ & \multicolumn{1}{l|}{$\begin{array}{l}\text { 1st Half } \\
\text { F0 }\end{array}$} & $\begin{array}{l}\text { 2nd Half } \\
\text { F0 }\end{array}$ & $\begin{array}{l}\text { Full } \\
\text { F0 }\end{array}$ & $\begin{array}{l}\text { F0 } \\
1^{\text {st }} 2^{\text {nd }} \\
\text { half } \\
\text { delta }\end{array}$ \\
\hline Mean & 1.67 & 1.89 & 0.97 & 115.61 & 105.82 & 110.71 & 9.79 \\
\hline Median & 1.50 & 2.00 & 1.00 & 116.11 & 104.49 & 110.74 & 8.97 \\
\hline SD & 1.44 & 1.91 & 0.19 & 15.54 & 12.72 & 12.63 & 12.93 \\
\hline
\end{tabular}


Emotion 4 (Fear) talker 4

\begin{tabular}{|r|r|r|l|l|l|l|l|l|}
\hline & $\begin{array}{l}\text { Duration } \\
\text { (s) }\end{array}$ & $\begin{array}{l}\text { F0 } \\
\text { Median }\end{array}$ & $\begin{array}{l}\text { F0 } \\
\text { SD }\end{array}$ & $\begin{array}{l}\text { F0 } \\
\text { Min }\end{array}$ & $\begin{array}{l}\text { F0 } \\
\text { Max }\end{array}$ & $\begin{array}{l}\text { Jitter } \\
\%\end{array}$ & $\begin{array}{l}\text { Intensity } \\
(\mathrm{dB})\end{array}$ & $\begin{array}{l}\text { F0 } \\
\text { delta }\end{array}$ \\
\hline Mean & 3.38 & 94.03 & 68.52 & 68.58 & 129.37 & 2.96 & 66.69 & 60.79 \\
\hline Median & 3.08 & 93.91 & 64.73 & 69.23 & 125.60 & 2.94 & 66.66 & 61.91 \\
\hline SD & 0.93 & 9.33 & 20.04 & 11.30 & 21.44 & 0.64 & 3.17 & 21.13 \\
\hline
\end{tabular}

\begin{tabular}{|r|r|r|r|r|r|r|r|}
\hline & $\begin{array}{l}\text { Rising } \\
\text { Contours }\end{array}$ & $\begin{array}{l}\text { Falling } \\
\text { Contours }\end{array}$ & $\begin{array}{l}\text { F0 } \\
\text { Contour } \\
\text { Index }\end{array}$ & \multicolumn{1}{l|}{$\begin{array}{l}\text { 1st Half } \\
\text { F0 }\end{array}$} & $\begin{array}{l}\text { 2nd Half } \\
\text { F0 }\end{array}$ & $\begin{array}{l}\text { Full } \\
\text { F0 }\end{array}$ & $\begin{array}{l}\text { F0 } \\
1^{\text {st }} 2^{\text {nd }} \\
\text { half } \\
\text { delta }\end{array}$ \\
\hline Mean & 3.17 & 2.94 & 1.17 & 99.93 & 92.09 & 96.02 & 7.83 \\
\hline Median & 3.00 & 3.00 & 1.00 & 100.84 & 91.92 & 96.78 & 10.83 \\
\hline SD & 0.92 & 1.00 & 0.47 & 8.52 & 7.91 & 7.58 & 6.29 \\
\hline
\end{tabular}

Emotion 5 (Neutral) talker 1

\begin{tabular}{|r|r|r|l|l|l|l|l|l|}
\hline & $\begin{array}{l}\text { Duration } \\
\text { (s) }\end{array}$ & $\begin{array}{l}\text { F0 } \\
\text { Median }\end{array}$ & $\begin{array}{l}\text { F0 } \\
\text { SD }\end{array}$ & $\begin{array}{l}\text { F0 } \\
\text { Min }\end{array}$ & $\begin{array}{l}\text { F0 } \\
\text { Max }\end{array}$ & $\begin{array}{l}\text { Jitter } \\
\%\end{array}$ & $\begin{array}{l}\text { Intensity } \\
(\mathrm{dB})\end{array}$ & $\begin{array}{l}\text { F0 } \\
\text { delta }\end{array}$ \\
\hline Mean & 2.06 & 138.56 & 81.95 & 86.25 & 177.56 & 3.39 & 62.77 & 91.31 \\
\hline Median & 2.06 & 138.45 & 90.21 & 98.56 & 171.41 & 3.34 & 62.18 & 78.54 \\
\hline SD & 0.79 & 6.14 & 28.40 & 26.98 & 23.32 & 0.66 & 1.69 & 34.19 \\
\hline
\end{tabular}


Prosodic Cues to Emotion 114

\begin{tabular}{|r|r|r|l|l|l|l|l|}
\hline & $\begin{array}{l}\text { Rising } \\
\text { Contours }\end{array}$ & $\begin{array}{l}\text { Falling } \\
\text { Contours }\end{array}$ & $\begin{array}{l}\text { F0 } \\
\text { Contour } \\
\text { Index }\end{array}$ & \multicolumn{1}{l|}{$\begin{array}{l}\text { Fo Half } \\
\text { F0 }\end{array}$} & $\begin{array}{l}\text { 2nd Half } \\
\text { F0 }\end{array}$ & $\begin{array}{l}\text { Full } \\
\text { F0 }\end{array}$ & $\begin{array}{l}\text { F0 } \\
1^{\text {st}} / 2^{\text {nd }} \\
\text { half } \\
\text { delta }\end{array}$ \\
\hline Mean & 2.28 & 3.06 & 1.06 & 148.66 & 131.47 & 140.07 & 17.19 \\
\hline Median & 2.00 & 3.00 & 0.78 & 147.87 & 129.35 & 138.57 & 19.23 \\
\hline SD & 0.96 & 1.43 & 1.04 & 11.96 & 9.87 & 7.81 & 15.39 \\
\hline
\end{tabular}

Emotion 5 (Neutral) talker 2

\begin{tabular}{|r|r|r|l|l|l|l|r|r|}
\hline & \multicolumn{1}{|l|}{$\begin{array}{l}\text { Duration } \\
(\mathrm{s})\end{array}$} & $\begin{array}{l}\text { F0 } \\
\text { Median }\end{array}$ & $\begin{array}{l}\text { F0 } \\
\text { SD }\end{array}$ & $\begin{array}{l}\text { F0 } \\
\text { Min }\end{array}$ & $\begin{array}{l}\text { F0 } \\
\text { Max }\end{array}$ & $\begin{array}{l}\text { Jitter } \\
\%\end{array}$ & $\begin{array}{l}\text { Intensity } \\
(\text { dB })\end{array}$ & $\begin{array}{l}\text { F0 } \\
\text { delta }\end{array}$ \\
\hline Mean & 2.22 & 219.11 & 21.85 & 155.03 & 279.30 & 1.62 & 70.98 & 124.27 \\
\hline Median & 2.27 & 214.54 & 19.66 & 165.99 & 255.57 & 1.57 & 70.87 & 88.71 \\
\hline SD & 0.70 & 19.12 & 8.63 & 40.73 & 75.62 & 0.28 & 1.25 & 85.48 \\
\hline
\end{tabular}

\begin{tabular}{|r|r|r|l|r|r|r|r|}
\hline & $\begin{array}{l}\text { Rising } \\
\text { Contours }\end{array}$ & $\begin{array}{l}\text { Falling } \\
\text { Contours }\end{array}$ & $\begin{array}{l}\text { F0 } \\
\text { Contour } \\
\text { Index }\end{array}$ & $\begin{array}{l}\text { 1st Half } \\
\text { F0 }\end{array}$ & $\begin{array}{l}\text { 2nd Half } \\
\text { F0 }\end{array}$ & $\begin{array}{l}\text { Full } \\
\text { F0 }\end{array}$ & $\begin{array}{l}\text { F0 } \\
1^{\text {st } / 2} \\
\text { half } \\
\text { delta }\end{array}$ \\
\hline Mean & 3.72 & 4.28 & 0.87 & 223.66 & 200.15 & 211.90 & 23.51 \\
\hline Median & 4.00 & 4.00 & 0.93 & 224.30 & 199.91 & 212.67 & 23.50 \\
\hline SD & 1.49 & 1.49 & 0.17 & 8.47 & 5.83 & 6.12 & 7.87 \\
\hline
\end{tabular}

Emotion 5 (Neutral) talker 3

\begin{tabular}{|r|r|r|l|l|l|l|r|r|}
\hline & \multicolumn{1}{|l|}{$\begin{array}{l}\text { Duration } \\
\text { (s) }\end{array}$} & $\begin{array}{l}\text { F0 } \\
\text { Median }\end{array}$ & $\begin{array}{l}\text { F0 } \\
\text { SD }\end{array}$ & $\begin{array}{l}\text { F0 } \\
\text { Min }\end{array}$ & $\begin{array}{l}\text { F0 } \\
\text { Max }\end{array}$ & $\begin{array}{l}\text { Jitter } \\
\%\end{array}$ & $\begin{array}{l}\text { Intensity } \\
(\mathrm{dB})\end{array}$ & $\begin{array}{l}\text { F0 } \\
\text { delta }\end{array}$ \\
\hline Mean & 1.82 & 114.20 & 57.67 & 56.40 & 152.18 & 3.34 & 65.19 & 95.79 \\
\hline Median & 1.90 & 113.86 & 58.03 & 49.22 & 153.05 & 3.37 & 65.48 & 107.41 \\
\hline SD & 0.56 & 5.11 & 34.93 & 29.95 & 18.45 & 0.68 & 1.29 & 38.89 \\
\hline
\end{tabular}


Error in Full F0 for sentence \#1 1 (values are out of range, likely due to error in F0 tracking algorithm)

\begin{tabular}{|r|r|r|r|r|r|r|r|}
\hline & $\begin{array}{l}\text { Rising } \\
\text { Contours }\end{array}$ & $\begin{array}{l}\text { Falling } \\
\text { Contours }\end{array}$ & $\begin{array}{l}\text { F0 } \\
\text { Contour } \\
\text { Index }\end{array}$ & \multicolumn{1}{l|}{$\begin{array}{l}\text { F0 Half } \\
\text { F0 }\end{array}$} & $\begin{array}{l}\text { 2nd Half } \\
\text { F0 }\end{array}$ & Full F0 & $\begin{array}{l}\text { F0 } \\
1^{\text {st }} / 2^{\text {nd }} \\
\text { half } \\
\text { delta }\end{array}$ \\
\hline Mean & 2.67 & 2.56 & 1.21 & 120.10 & 109.01 & 728.47 & 11.10 \\
\hline Median & 3.00 & 3.00 & 1.00 & 119.76 & 110.44 & 114.53 & 10.82 \\
\hline SD & 0.84 & 1.20 & 0.47 & 5.83 & 6.73 & 2628.94 & 5.35 \\
\hline
\end{tabular}

Fixed version below

\begin{tabular}{|r|r|r|r|r|r|r|r|}
\hline & $\begin{array}{l}\text { Rising } \\
\text { Contours }\end{array}$ & $\begin{array}{l}\text { Falling } \\
\text { Contours }\end{array}$ & $\begin{array}{l}\text { F0 } \\
\text { Contour } \\
\text { Index }\end{array}$ & \multicolumn{1}{l|}{$\begin{array}{l}\text { F0 Half } \\
\text { F0 }\end{array}$} & $\begin{array}{l}\text { 2nd Half } \\
\text { F0 }\end{array}$ & $\begin{array}{l}\text { Full } \\
\text { F0 }\end{array}$ & $\begin{array}{l}\text { F0 } \\
1^{\text {st }} / 2^{\text {nd }} \\
\text { half } \\
\text { delta }\end{array}$ \\
\hline Mean & 2.65 & 2.47 & 1.24 & 120.42 & 108.92 & 108.85 & 11.50 \\
\hline Median & 3.00 & 3.00 & 1.00 & 120.01 & 110.37 & 113.45 & 11.46 \\
\hline SD & 0.86 & 1.18 & 0.47 & 5.85 & 6.92 & 25.68 & 5.22 \\
\hline
\end{tabular}

Emotion 5 (Neutral) talker 4

\begin{tabular}{|r|r|r|l|l|l|l|l|l|}
\hline & \multicolumn{1}{|l|}{$\begin{array}{l}\text { Duration } \\
\text { (s) }\end{array}$} & $\begin{array}{l}\text { F0 } \\
\text { Median }\end{array}$ & $\begin{array}{l}\text { F0 } \\
\text { SD }\end{array}$ & $\begin{array}{l}\text { F0 } \\
\text { Min }\end{array}$ & $\begin{array}{l}\text { F0 } \\
\text { Max }\end{array}$ & $\begin{array}{l}\text { Jitter } \\
\%\end{array}$ & $\begin{array}{l}\text { Intensity } \\
(\mathrm{dB})\end{array}$ & $\begin{array}{l}\text { F0 } \\
\text { delta }\end{array}$ \\
\hline Mean & 2.93 & 82.81 & 53.96 & 36.96 & 111.36 & 2.97 & 69.42 & 74.40 \\
\hline Median & 3.03 & 83.12 & 49.60 & 36.04 & 107.30 & 3.00 & 67.76 & 72.83 \\
\hline SD & 1.00 & 4.82 & 31.16 & 11.16 & 17.05 & 0.40 & 9.04 & 18.77 \\
\hline
\end{tabular}


Prosodic Cues to Emotion 116

\begin{tabular}{|r|r|r|l|r|r|r|r|}
\hline & $\begin{array}{l}\text { Rising } \\
\text { Contours }\end{array}$ & $\begin{array}{l}\text { Falling } \\
\text { Contours }\end{array}$ & $\begin{array}{l}\text { F0 } \\
\text { Contour } \\
\text { Index }\end{array}$ & $\begin{array}{l}\text { 1st Half } \\
\text { F0 }\end{array}$ & $\begin{array}{l}\text { 2nd Half } \\
\text { F0 }\end{array}$ & $\begin{array}{l}\text { Full } \\
\text { F0 }\end{array}$ & $\begin{array}{l}\text { F0 } \\
1^{\text {st }} / 2^{\text {nd }} \\
\text { half } \\
\text { delta }\end{array}$ \\
\hline Mean & 2.56 & 2.50 & 1.10 & 87.72 & 79.41 & 83.57 & 8.31 \\
\hline Median & 2.50 & 2.50 & 1.00 & 88.38 & 80.26 & 83.93 & 8.99 \\
\hline SD & 1.20 & 1.20 & 0.39 & 4.53 & 7.37 & 5.25 & 6.28 \\
\hline
\end{tabular}

